\title{
Das inflammatorische Infiltrat im Seminom - Ein Hinweis auf den klinischen Verlauf?
}

\author{
INAUGURAL-DISSERTATION \\ zur Erlangung des Doktorgrades \\ der Medizinischen Fakultät der \\ Georg-August-Universität zu Göttingen
}

vorgelegt von

Fabian Alexander Gayer

aus

Nürnberg

Göttingen 2020 
Dekan:

\section{Betreuungsausschuss}

Betreuer/in

Ko-Betreuer/in:

\section{Prüfungskommission}

Referent/in

Ko-Referent/in:

Drittreferent/in:

Datum der mündlichen Prüfung:
Prof. Dr. med. W. Brück

Prof. Dr. med. L. Trojan

PD Dr. med. F. Bremmer
Prof. Dr. med. L. Trojan

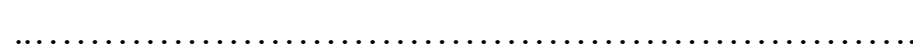


Hiermit erkläre ich, die Dissertation mit dem Titel "Das inflammatorische Infiltrat im Seminom - ein Hinweis auf den klinischen Verlauf?" eigenständig angefertigt und keine anderen als die von mir angegebenen Quellen und Hilfsmittel verwendet zu haben.

Göttingen, den 


\section{Inhaltsverzeichnis}

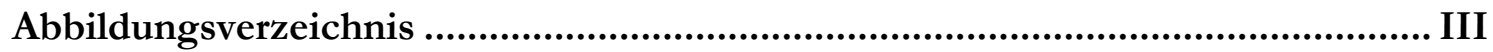

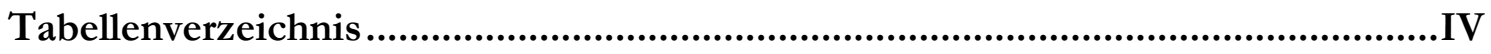

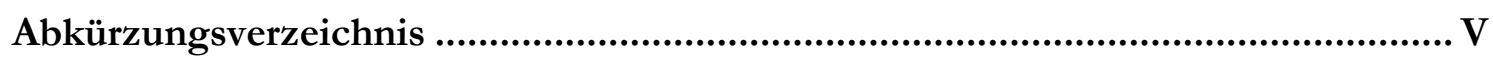

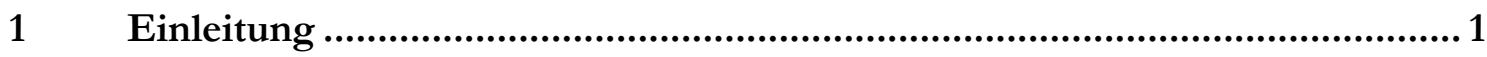

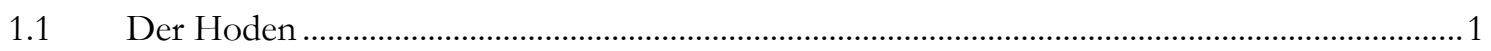

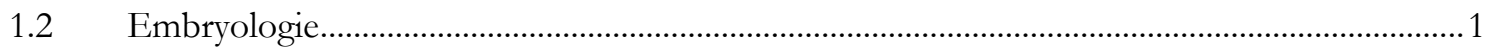

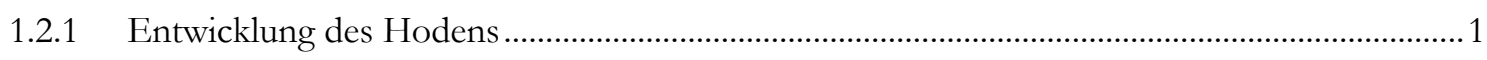

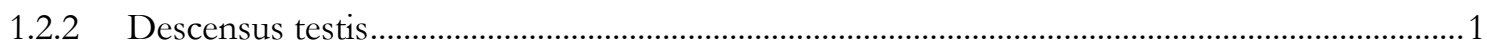

1.3 Anatomische und physiologische Grundlagen ...................................................................... 1

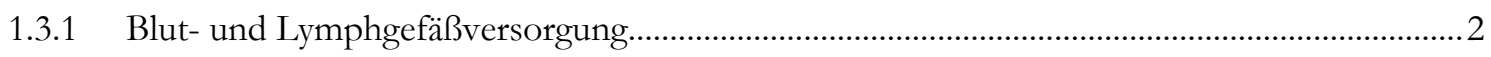

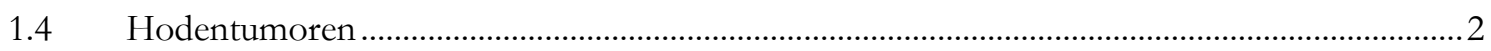

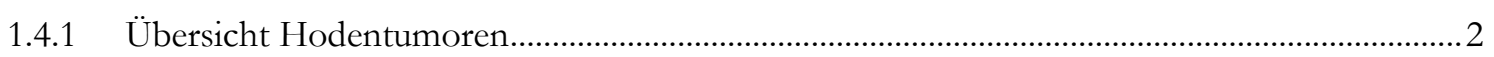

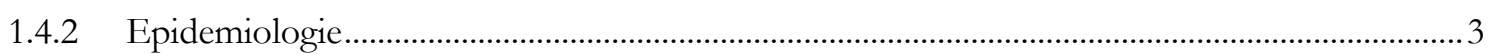

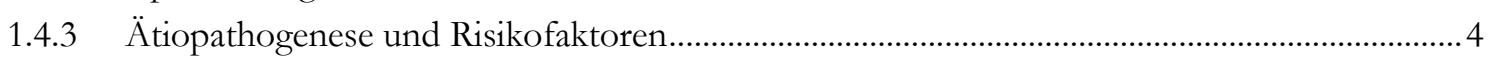

1.4.4 Testikuläre intraepitheliale Neoplasie (TIN/GCNIS/CIS) .........................................................

1.4.5 Metastasierung und ihre Risikofaktoren...............................................................................

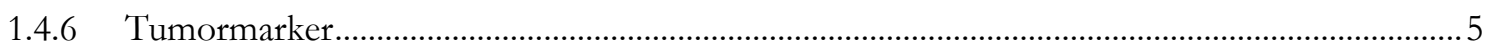

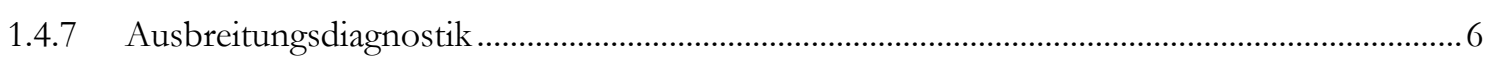

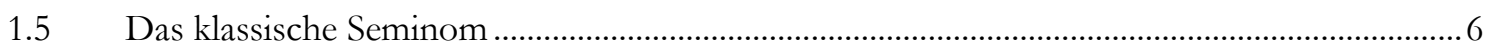

1.6 Klinische und histopathologische Stadieneinteilung .................................................................. 6

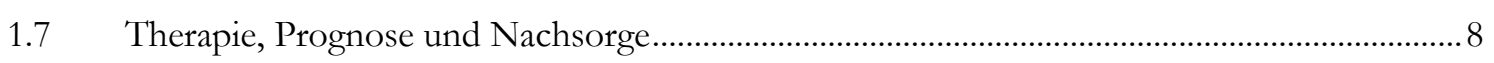

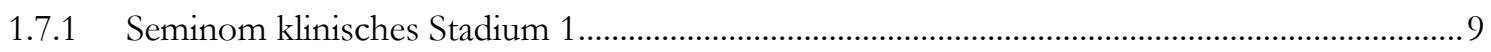

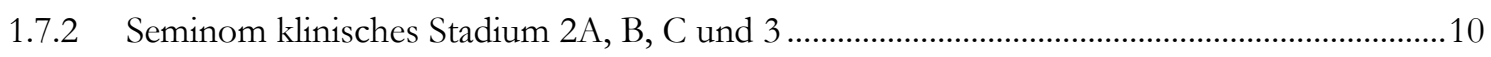

1.8 Das entzündliche Infiltrat des seminomatösen Hodentumors .................................................10

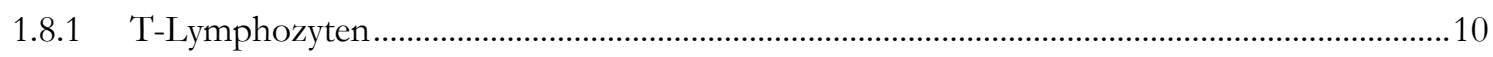

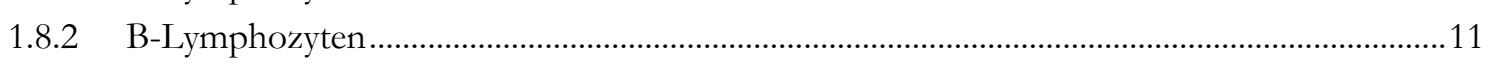

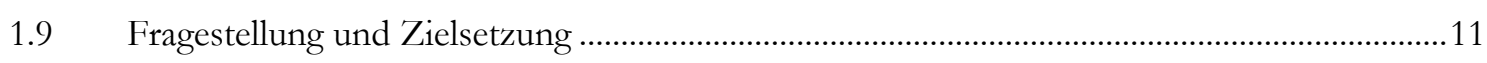

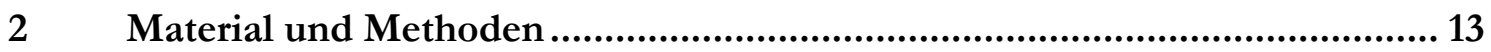

2.1 Datenerhebung des Patientenkollektivs / Studiendesign ..........................................................13

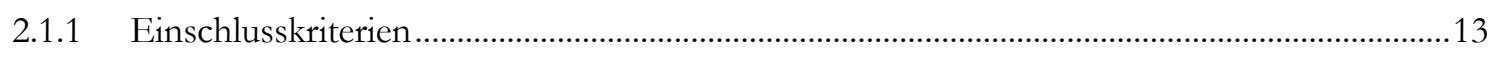

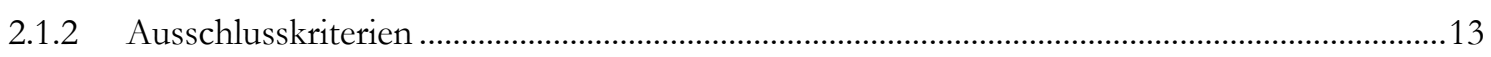

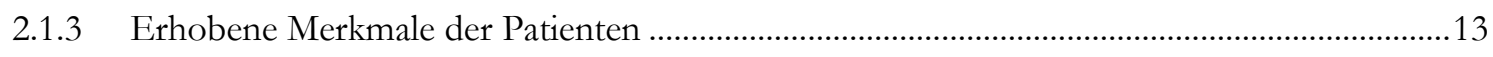

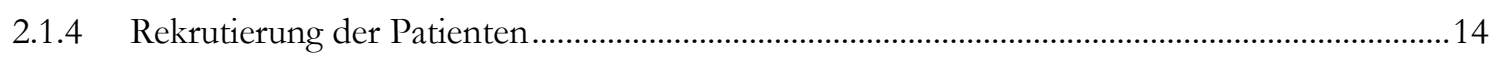

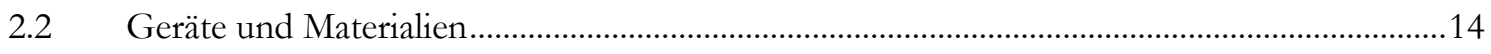

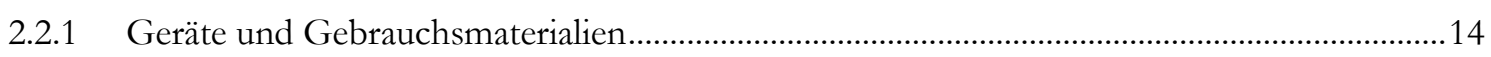

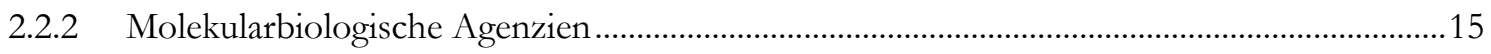


2.3 Herstellung und Aufarbeitung des histologischen Materials ................................................16

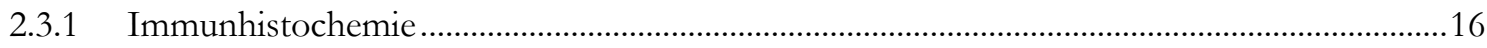

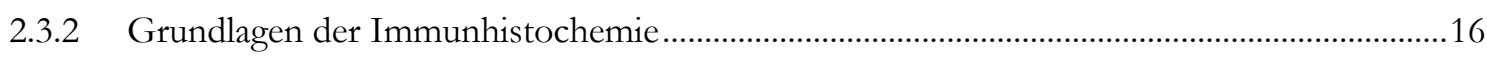

2.3.3 Aufarbeitung der Immunhistochemie der Seminompräparate .............................................16

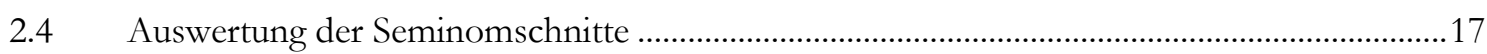

2.4.1 Quantitative Bestimmung des lymphozytären Entzündungsinfiltrats ..................................17

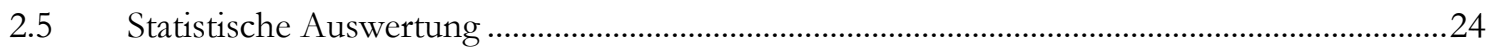

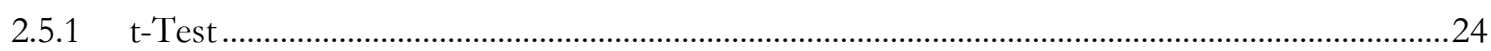

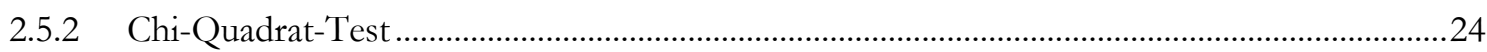

2.5.3 Wilcoxon-Mann-Whitney-Test/ Wilcoxon-Rangsummen-Test/ U-Test.............................24

2.5.4 Analytische Statistik / Prädiktionsmodelle .............................................................................24

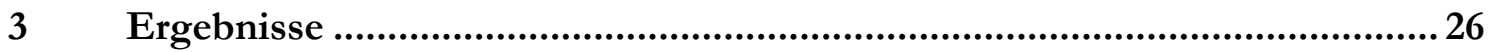

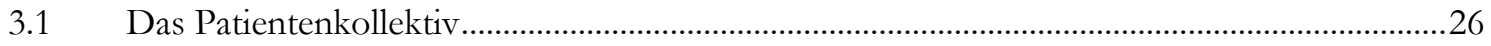

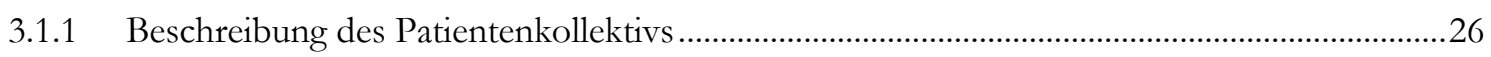

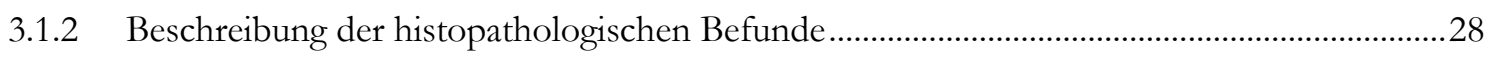

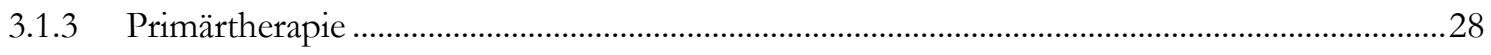

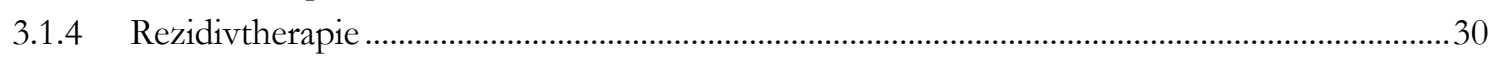

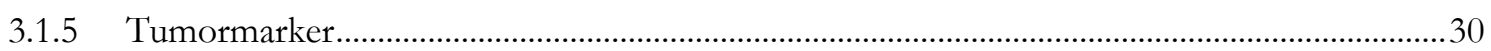

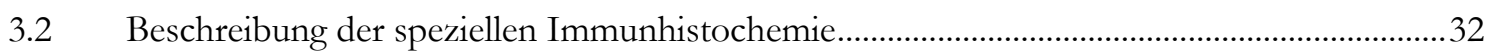

3.2.1 Mikroskopische Auswertung der speziellen Immunhistochemie ............................................3 32

3.2.2 ImageJ Auswertung der speziellen Immunhistochemie.........................................................33

3.2.3 Gegenüberstellung beider Methoden zur Analyse des inflammatorischen Infiltrats .............34

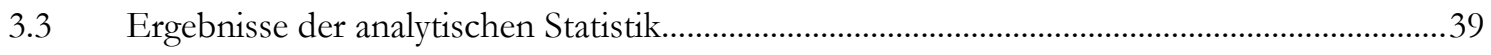

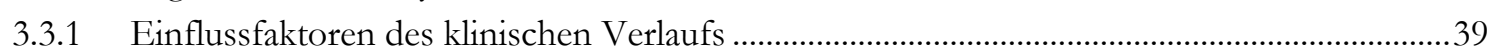

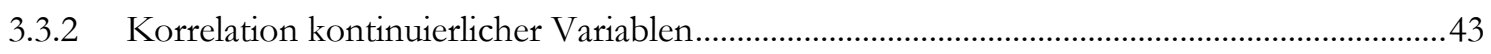

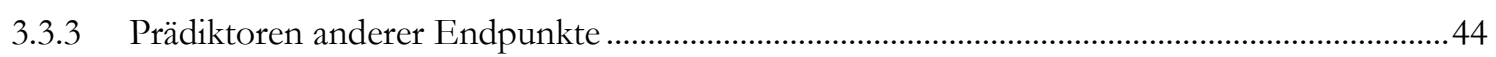

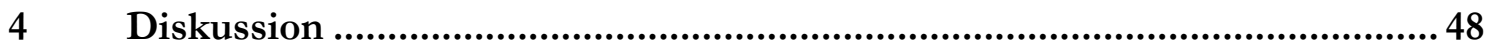

4.1 Das Patientenkollektiv und seine prognostischen Faktoren .................................................48

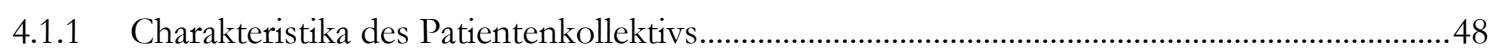

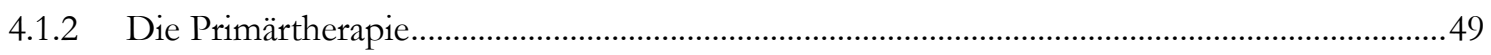

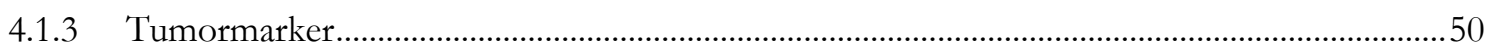

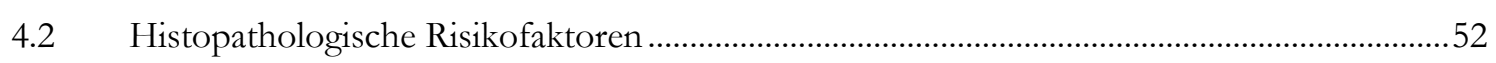

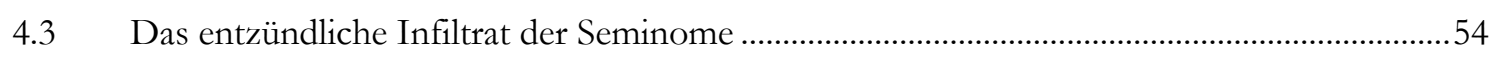

4.3.1 Heterogenität des entzündlichen Infiltrats im Seminom .........................................................54

4.4 Vergleich der Methoden zur Analyse der speziellen Immunhistochemie der Seminome .....57

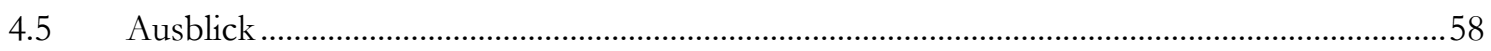

$5 \quad$ Zusammenfassung............................................................................. 61

$6 \quad$ Literaturverzeichnis .......................................................................63

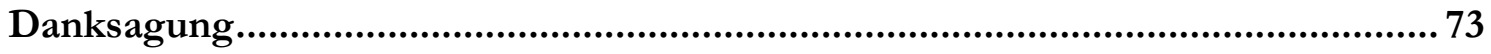

Lebenslauf ............................................................................................... 74 


\section{Abbildungsverzeichnis}

Abbildung 1: WHO-Klassifikation der Hodentumoren ..........................................................................

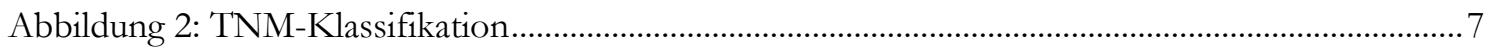

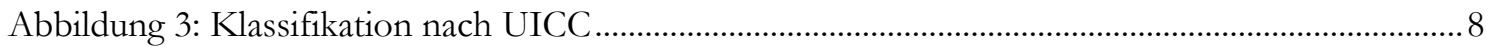

Abbildung 4: Therapiealgorithmus für Seminompatienten nach Orchiektomie ..................................... 9

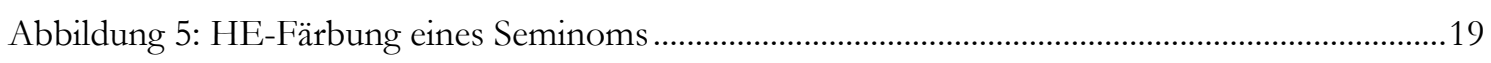

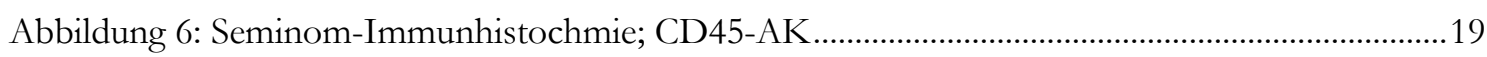

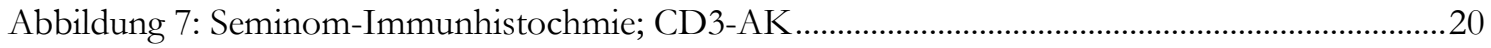

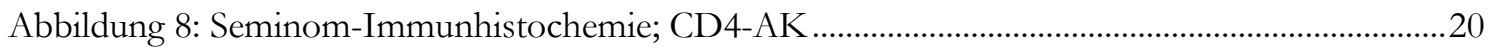

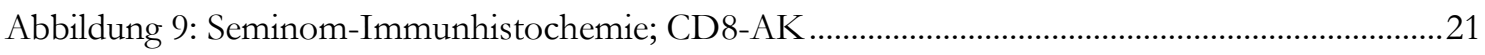

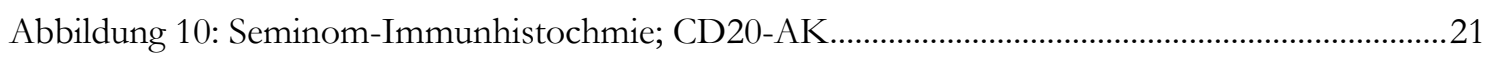

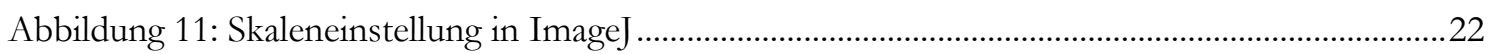

Abbildung 12: Funktion Threshold Color in ImageJ ...........................................................................22

Abbildung 13: Seminom-Immunhistochemie im Analyseprozess mit Image J......................................23

Abbildung 14: Seminom mit milder entzündlicher Infiltration .............................................................

Abbildung 15: Seminom mit reichlich entzündlicher Infiltration............................................................. 37

Abbildung 16: Seminom mit massiver entzündlicher Infiltration ........................................................37

Abbildung 17: Homogenes T-Zell-Infiltrat im Seminom.........................................................................

Abbildung 18: B-lymphozytäres Infiltrat mit Lymphfollikel....................................................................38

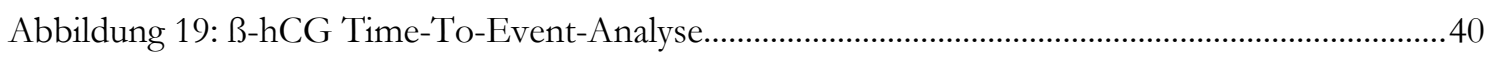

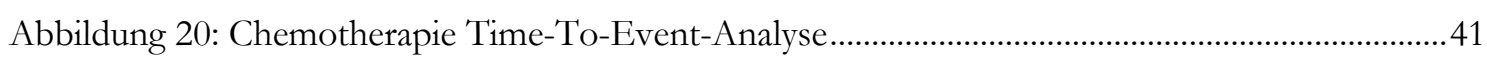

Abbildung 21: Monochemo- und Polychemotherapie Time-To-Event-Analyse......................................42

Abbildung 22: Verteilung und Korrelation kontinuierlicher Variablen.....................................................43

Abbildung 23: Einfluss von LDH auf die Lymphinvasion .................................................................... 45

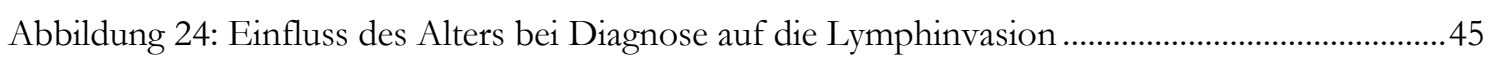

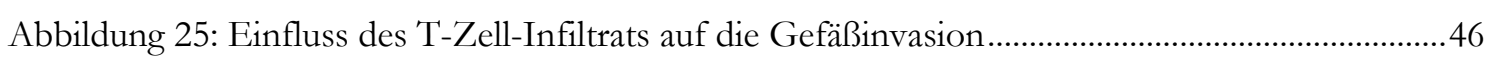

Abbildung 26: Einfluss der Tumorgröße auf die Gefäßinvasion ............................................................46 


\section{Tabellenverzeichnis}

Tabelle 1: Geräte und Gebrauchsmaterialien...................................................................................14

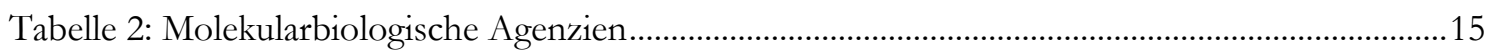

Tabelle 3: Übersicht der immunhistochemischen Marker und des Antigens .....................................17

Tabelle 4: Kategorisierung des entzündlichen Infiltrats des Tumors ...............................................18

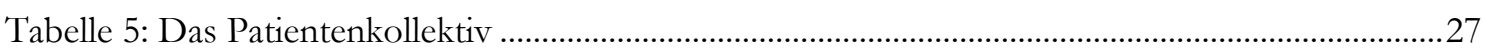

Tabelle 6: Histopathologische Charakteristika der Seminome..........................................................28

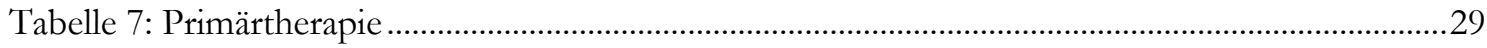

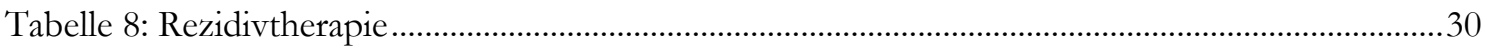

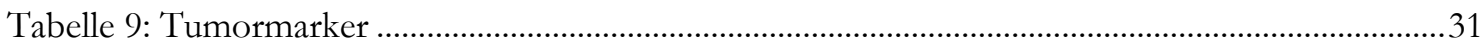

Tabelle 10: Mikroskopische Auswertung des entzündlichen Infiltrats .................................................32

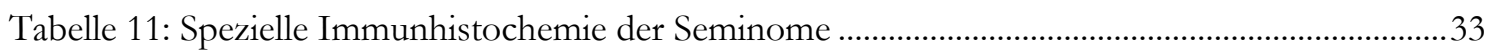

Tabelle 12: Das entzündliche Infiltrat - Übersicht der Auswertungsmethoden..................................34

Tabelle 13: Das entzündliche Infiltrat - Gegenüberstellung beider Auswertungsmethoden .............35

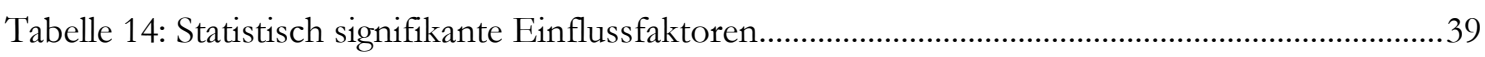

Tabelle 15: Statistisch signifikante Prädiktoren neuer Ziel-Variablen...................................................44 


\section{Abkürzungsverzeichnis}

\begin{tabular}{|c|c|}
\hline $5 \mathrm{JRW}$ & 5-Jahres-Rezidivwahrscheinlichkeit \\
\hline AK & Antikörper \\
\hline AS & Active Surveillance \\
\hline CLL & Chronisch lymphatische Leukämie \\
\hline $\mathrm{CSI} / \mathrm{II} / \mathrm{III}$ & Klinisches Stadium 1/2/3 \\
\hline CT & Computertomographie \\
\hline CYFRA 21-1 & Cytokeratinfragment 21-1 \\
\hline FOV & Field of View \\
\hline GCNIS & Germ Cell Neoplasia in Situ \\
\hline $\mathrm{HE}$ & Hämatoxylin-Eosin \\
\hline HWZ & Halbwertszeit \\
\hline KI & Konfidenzintervall \\
\hline OR & Odds Ratio \\
\hline KK & Korrelationskoeffizient \\
\hline AMCT & Adjuvante Monochemotherapie \\
\hline $\mathrm{AR}$ & Adjuvante Radiatio \\
\hline MW & Mittelwert \\
\hline HR & Hazard Ratio \\
\hline LAT & Linker of activated T Cells \\
\hline LCP2 & Lymphocyte cytosolic Protein 2 \\
\hline $\mathrm{LH}$ & Luteinisierendes Hormon \\
\hline $\mathrm{KZT}$ & Keimzelltumor/en \\
\hline LoE & Level of Evidence \\
\hline MRT & Magnetresonanztomopgraphie \\
\hline MRT & Magnetresonanztomographie \\
\hline $\mathrm{nKZ}$ & Natürliche Killerzellen \\
\hline NKZT & Nicht-Keimzelltumor/en \\
\hline NW & Nebenwirkungen \\
\hline ОСТ3/4 & Octamere-binding transcription Factor $3 / 4$ \\
\hline OS & Overall Survival \\
\hline PEB & Bleomycin, Etopisid, Cisplatin \\
\hline PEI & Cisplatin, Etopisid, Ifosfamid \\
\hline PLAP & Plazentare alkalische Phosphatase \\
\hline RLA & Retroperitoneale Lymphadenektomie \\
\hline TCR & T-Zell-Rezeptor \\
\hline TIN & Testikukuläre intraepitheliale Neoplasie \\
\hline UMG & Universitätsmedizin Göttingen \\
\hline ZAP70 & Zeta-Ketten-assoziiertes Protein, Gewicht $70 \mathrm{kDa}$ \\
\hline
\end{tabular}




\section{Einleitung}

\subsection{Der Hoden}

\subsection{Embryologie}

\subsubsection{Entwicklung des Hodens}

Die initiale Entwicklung des Hodens erfolgt beim Fetus zunächst unspezifisch (indifferente Gonade). Etwa ab der 7. Woche entsteht aus der gonadalen Anlage das Ovar oder der Hoden. Diese beeinflussen und steuern im weiteren Verlauf über differente Hormonproduktion die geschlechtliche Entwicklung. Geschlechtszellen wandern ein und es bilden sich Prospermatogonien. Ab der 8. Woche differenzieren sich aus den interstitiellen Zellen die LeydigZellen, die stark proliferieren und Testosteron produzieren und so das Wachstum des Hodens fördern (Virtanen und Toppari 2014).

\subsubsection{Descensus testis}

Ursprünglich liegt der Hoden in seiner Anlage intraperitoneal. Durch das fortschreitende Körperwachstum wandert er nach kaudal. Der Hoden erreicht den inneren Leistenring, das Gubernaculum testis vergrößert sich und ermöglicht so durch Dehnung des Leistenkanals den weiteren Progress des Descensus durch den Leistenkanal. Beim Abstieg des Hodens werden sowohl die ursprünglich kranialer entspringenden Blut- und Lymphgefäße, wie auch die den Hoden umgebenden Hodenhüllen der vorderen Bauchwand mit nach kaudal geführt (Hadziselimović und Kruslin 1979).

\subsection{Anatomische und physiologische Grundlagen}

Der Hoden (Testis) ist ein paarig angelegtes Organ. Neben der Spermatogenese ist der Hoden für die Produktion von ca. $95 \%$ des Hormons Testosteron verantwortlich. Der Hoden wird durch verschiedene Hüllen umgeben und durch aus der Tunica albuginea einstrahlende Fasern in einzelne Lobuli unterteilt. Er misst im ausgewachsenen Zustand ca. 4,5 x 2,5 cm mit einem Volumen von 25-30 ml. Jedes dieser Läppchen wird durch mindestens einen Tubulus seminiferus contortus durchzogen und enthält neben dem Keimepithel auch Sertolioder Stützzellen. Die Tubuli konvergieren zum Mediastinum testis und vereinen sich zum Rete testis. 
Im Stützgewebe zwischen den Tubuli befinden sich die Leydig'schen Zwischenzellen. Sie produzieren nach entsprechender Stimulation durch das luteinisierende Hormon (LH) aus der Adenohypophyse Testosteron.

Die im Hoden produzierten Spermien gelangen über 10 bis 20 Ductuli efferentes zum Kopf des Nebenhodens. Hier reifen die Spermien und treten bei der Ejakulation durch den Samenleiter aus. Im Samenstrang verlaufen der Samenleiter, die Arteria testikularis, die Arteria ductus deferentis, die Arteria cremasterica, der Plexus pampiniformis, Lympfbahnen und der Ramus genitalis des Nervus ilioinguinalis.

\subsubsection{Blut- und Lymphgefäßversorgung}

Arteriell wird der Hoden durch die Arteria testikularis aus der Aorta abdominalis versorgt. Sie hat ihren Ursprung kaudal der Nierenarterie. Danach verläuft sie im Funiculus spermaticus durch den Leistenkanal, begleitet die Tubuli seminiferi contorti, bis sie mit der Arteria ductus deferentis (aus der Arteria umbilicalis) eine Anastomose bildet. Die Arteria cremasterica entspringt der Arteria epigastrica inferior, bildet auf der Fascia spermatica interna ein arterielles Netz, gibt Äste zur Versorgung der skrotalen Wand ab und anastomosiert mit den beiden oben genannten Gefäßen (Mostafa et al. 2008).

Venös wird der Hoden durch den Plexus pampiniformis versorgt. Dieser bildet sich aus der Vena testikularis, die rechts in die Vena cava inferior und links in die Vena renalis sinistra mündet.

Der Lymphabfluss des Hodens erfolgt über Lymphgefäße des Samenstrangs in die paraaortalen Lymphknoten. Dies spielt vor allem für die lymphogene Metastasierung der Hodentumoren als primäre Lymphknotenstation eine entscheidende Rolle. Die Lymphgefäße der Hodenhülle und Skrotalhaut drainieren in Nodi lymphatici inguinales (Yeh et al. 1986).

\subsection{Hodentumoren}

\subsection{1 Übersicht Hodentumoren}

Die Hodentumoren lassen sich entsprechend ihres Phänotyps kategorisieren. So bilden sich die beiden großen Gruppen der Keimzelltumoren $(<90 \%)$ und Nicht-Keimzelltumoren $(<10 \%$ ) (Bahrami et al. 2007). Die Gruppe der Keimzelltumoren (KZT) teilt sich in die Seminome (50-55 \%) und die Nicht-Seminome (45-50\%) (McGlynn und Cook 2009). Zu der Gruppe der Nicht-Seminome gehören die reinen Embryonalzellkarzinome (11\%), Teratome (2\%), Chorionkarzinome $(<0,5 \%)$ und die Dottersack- und Stromatumoren $(2-4$ $\%$ ). Die Gruppe der Nicht-Seminome wird durch Mischtumoren komplettiert. Sie zeigen histologische Charakteristika verschiedener KZT. In der Mehrzahl der Fälle zeigen diese Mischtumoren Komponenten eines Embryonalzellkarzinoms (Bahrami et al. 2007). 
Abbildung 1 zeigt die aktuelle WHO-Klassifikation der Hodentumoren (Williamson et al. 2017). Sie unterscheidet zwischen Tumoren, die aus einer germ cell neoplasia in situ (GCNIS) hervorgehen und solchen, die nicht auf dem Boden einer GCNIS entstehen. Selten werden sog. „Ausgebrannte Hodentumoren“ diagnostiziert. Dabei handelt es sich um KZT, die sich bereits weitgehend zurückgebildet haben, oder sogar verschwunden sind. Sie fallen in der Regel durch metastatisch bedingte Symptome auf (Mosillo et al. 2017).

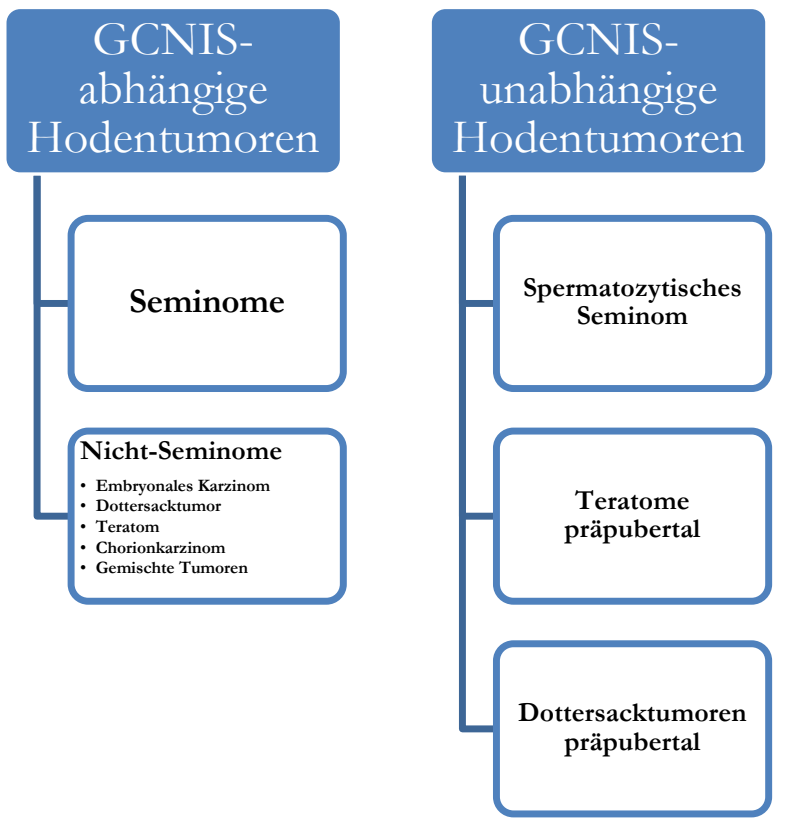

Abbildung 1: WHO-Klassifikation der Hodentumoren (Williamson et al. 2017)

Neben den hodeneigenen Tumoren gibt es diverse anderen Neoplasien, die im Hoden lokalisiert sein können. Zu Ihnen gehören unter anderem Lymphome, Leiomyosarkome, Liposarkome und Fibrome. Besonders bei Patienten ab einem Alter von 70 Jahren werden häufig Lymphome und sekundäre Karzinome beobachtet (Moch et al. 2016).

\subsubsection{Epidemiologie}

Der Hodentumor macht ca. 1-2 \% aller Tumoren bei Männern aus. Vor allem bei jungen Männern (Alter zwischen 15 und 34 Jahren) gehört er mit einer relativen Häufigkeit von fast $50 \%$ zu den häufigsten Malignomen. Das klassische Seminom ist mit $45 \%$ der häufigste KZT (Warde et al. 2002). In der Regel sind weiße Männer aus westlichen Industrieländern betroffen, wobei die Inzidenz gerade in Mittel- und Nordeuropa am höchsten ist. Deutlich seltener erkranken farbige und asiatische Männer (Ferlay et al. 2015). Mehr als 90\% aller Hodentumoren sind KZT. Sie treten weltweit mit einer Inzidenz zwischen 0,5 und 9,9/100000 auf. In Deutschland liegt die Inzidenz ca. bei 6,5/100000 Einwohner. Dabei treten Seminome und die Gruppe der Nicht-Seminome jeweils etwa gleich häufig auf. NichtSeminom-Patienten erkranken etwas früher (20. bis 30. Lebensjahr.). Seminome werden 
dagegen häufiger zwischen dem 30. und 40. Lebensjahr diagnostiziert. Insgesamt nimmt die Inzidenz zu. Innerhalb der letzten drei Jahrzehnte hat diese sich weltweit verdoppelt (Manecksha und Fitzpatrick 2009; Mikuz 2014; Trabert et al. 2015).

\subsection{3 Ätiopathogenese und Risikofaktoren}

KZT entstehen durch die fehlerhafte Reifung der primordialen Keimzelle (pluripotente Vorstufe der reifen Geschlechtszelle) zu Präspermatogonien und gehen vom germinativen Epithel aus. Die veränderten Keimzellen stellen die In-situ-Keimzellneoplasie (GCNIS bzw. TIN) dar und ruhen bis zum Eintritt in die Pubertät. Erst dann entwickeln sie sich durch den Zugewinn oder Verlust chromosomaler Regionen ggf. zu einem Seminom bzw. Nicht-Seminom (van Echten et al. 2002).

Patienten mit einem unilateralen Hodentumor haben ein 700-fach erhöhtes Risiko einen Tumor auf der kontralateralen Seite zu entwickeln. Auch eine testikuläre intraepitheliale Neoplasie unilateral erhöht das Risiko. Brüder und Söhne von betroffenen Patienten zeigen einen Risikozuwachs um den Faktor 8-10 bzw. 4 (Hemminki und Chen 2006). Eine berufliche Exposition gegenüber organischen Lösungsmitteln, Benzolen und verschiedenen Metallen scheint mit einer erhöhten Inzidenz einherzugehen. Diskutiert werden als Ursache auch wiederholte Hodentraumata (Manecksha und Fitzpatrick 2009).

Neben der testikulären intraepithelialen Neoplasie (TIN) zählen zu den gesicherten Risikofaktoren für die Entstehung von Hodentumoren die durchgemachte Mumpsorchitis, ein Kryptorchismus, die testikuläre Mikrolithiasis (Sternhimmelphänomen), ein Hypogonadimus bzw. eine Hodenatrophie und Infertilität. Der Kryptorchismus differenziert zwischen dem sog. Bauchhoden („echter“ Kryptorchismus), dem Leistenhoden, dem ektopen Hoden und dem Pendelhoden. Entscheidend sind dabei die erhöhte auf den Hoden einwirkende Körpertemperatur, die veränderte Blutversorgung und die daraus resultierende gestörte Gewebeausreifung (Fukawa und Kanayama 2018)

\subsubsection{Testikuläre intraepitheliale Neoplasie (TIN/GCNIS/CIS)}

Eine TIN stellt die Präkusorläsion aller KZT mit Ausnahme des spermatozytären Seminoms dar. $5 \%$ aller Patienten mit testikulären KZT zeigen kontralateral eine TIN. Bei extratestikulären KZT wird die TIN sogar in 30-40 \% der Fälle nachgewiesen (Fosså et al. 2003). Eine testikuläre intraepitheliale Neoplasie entwickelt sich innerhalb von 5 Jahren in $50 \%$ und innerhalb von 7 Jahren in $70 \%$ der Fälle zu einem malignen KZT. Es wird vermutet, dass im weiteren Verlauf aus jeder TIN ein invasiver KZT entsteht (SkakkebæK et al. 1987).

Eine TIN wird anhand des histopathologischen Befunds diagnostiziert. Neben der Morphologie trägt die Immunhistochemie zur Diagnosesicherung bei. Hierbei werden die Marker D2-40 und Plazentare Alkalische Phosphatase (PLAP) zur primären Diagnostik bestimmt. 
Wenn nötig wird ergänzend der Stammzellmarker Octamere-bindung Transcription Factor 3/4 (OCT3/4) bestimmt. Er wird spezifisch beim Vorliegen einer TIN oder eines invasiven KZT exprimiert (Boccellino et al. 2017).

Wird eine testikuläre intraepitheliale Neoplasie diagnosiziert, gibt es therapeutisch verschiedene Möglichkeiten. Neben dem operativen Therapieansatz mit Ablation des betroffenen Hodens kann man sich für Active Surveillance (AS), Chemotherapie oder lokale Radiotherapie entscheiden. Letztere stellt aktuell die aktive Therapie der Wahl bei Hodentumorpatienten mit kontralateraler TIN dar.

\subsubsection{Metastasierung und ihre Risikofaktoren}

Seminome metastasieren primär lymphogen, zeigen in $3 \%$ der Fälle aber auch eine hämatogene Metastasierung (Borski 1973). Die lymphogene Metastasierung beginnt mit hoher Wahrscheinlichkeit zunächst bei am Nierenstiel befindlichen Lymphknoten oder in retroperitonealen Lymphknoten (paraaortal, paracaval und iliacal). Dabei neigen rechtsseitige Tumoren eher zur lymphogenen Ausbreitung in das kontralaterale Retroperitoneum, während Tumoren des linken Hodens häufig ipsilateral lymphogen metastasieren. Im weiteren Verlauf breitet sich die Lymphknotenmetastasen des Retroperitoneums entlang der Lymphbahnen nach kranial aus. In der Regel werden dann mediastinale, retrokrurale und supradiaphragmale Lymphnotenmetastasen diagnostiziert. In Ausnahmefällen ist der Lymphabfluss des Patienten verändert bzw. zerstört und die lymphogene Metastasierung folgt nicht dem oben beschriebenen Schema. So können Operationen und Traumata in der Vorgeschichte dazu führen, dass KZT vorwiegend pelvine und inguinale Lymphknotenmetastasen zeigen.

Risikofaktoren für eine lymphogene Metastasierung sind eine Lymphgefäßinvasion des Primärtumors und bei Seminomen zusätzlich eine Tumorgröße $>4 \mathrm{~cm}$ bzw. eine Invasion des Rete testis (Warde et al. 1995; Kamba et al. 2010).

Die hämatogene Metastasierung tritt wesentlich später auf und ist vorwiegend in Lunge, Leber, Knochen und Gehirn lokalisiert. Ein Risikofaktor für die hämatogene Metastasierung ist eine Blutgefäßinvasion des Primärtumors (Khan und Protheroe 2007).

\subsubsection{Tumormarker}

Etwa $60 \%$ der Hodentumoren produzieren Tumormarker. Spezifische Marker für Tumoren des Hodens sind das Alpha-Fetoprotein (AFP), die B-Untereinheit des humanen Choriongonadotropins (B-hCG) und Cytokeratinfragment 21-1 (CYFRA 21-1). Ebenfalls von Relevanz ist die Laktatdehydrogenase (LDH). Sie ist zwar sehr unspezifisch und bei einer Vielzahl von Erkrankungen erhöht, hat aber vor allem bei metastasierten Tumoren bzgl. Therapiemonitoring und Prognoseklassifikation ihren Stellenwert. 
Seminome produzieren B-hCG und LDH. B-hCG ist durch eine HWZ von 24-36 Stunden charakterisiert. Nicht-Seminome produzieren unter anderem AFP. Reine Seminome produzieren diesen Tumormarker nicht. AFP hat eine HWZ von 2-8 Tagen (Guan et al. 2013). Die Kenntnis der Halbwertszeiten der Tumormarker ist wesentlich für die Beurteilung der Markerverläufe um die Klassifikation des Tumorstadiums (S-Klassifikation) vornehmen zu können (Bosl et al. 1981). Zusätzlich hilft der Verlauf der Tumormarker dabei, den Therapieerfolg der Chemotherapie abschätzen zu können (Krege et al. 2008).

\subsubsection{Ausbreitungsdiagnostik}

Postoperativ nach Orchiektomie werden Staging-Untersuchungen veranlasst. Bei dem Verdacht auf einen primär metastasierten Tumor kann die Bildgebung häufig der Orchiektomie vorangestellt werden. Die kontrastmittelgestützte Computertomographie hat klinisch den größten Stellenwert. Das liegt vor allem an der deutlich besseren Verfügbarkeit und den geringeren Kosten im Vergleich zur Magnetresonanztomographie (MRT). Beide zeigen hinsichtlich ihrer Detektion von Lymphknotenmetastasen eine Sensitivität von ca. 80 \% (Dalal et al. 2006). Die Positronenemissionstomographie (PET) ist wenig relevant, wobei die Fluorodesoxyglucose (FDG)-PET-CT mit einer Spezifität von 92,2 \% bei Seminom-Patienten zur Erkennung von Tumorresiduen nach erfolgter Chemotherapie genutzt wird (Müller et al. 2011). Bei dem klinischen Verdacht auf Fernmetastasen sollten weitere gezielte Untersuchungen (Sonographie, Sklettszintigraphie oder Schnittbildgebung des Schädels) durchgeführt werden (Michel 2016).

\subsection{Das klassische Seminom}

Das klassische Seminom wird zu 70-80 \% im klinischen Stadium 1 (CSI) diagnostiziert. Ca. $80 \%$ dieser Patienten sind mit einer inguinalen Ablatio testis geheilt. Das bedeutet aber auch, dass ca. 20 \% der Patienten dieses Kollektivs im Verlauf ein Rezidiv erleiden. In aller Regel metastasiert das Seminom in retroperitoneale Lymphknoten. Patienten, bei denen der Tumor mit $>40$ Jahren diagnostiziert wird, zeigen zu $>20 \%$ zum Diagnosezeitpunkt bereits Metastasen (van As et al. 2008).

\subsection{Klinische und histopathologische Stadieneinteilung}

Zur Einteilung eines seminomatösen Hodentumors gibt es verschiedene Klassifikationen. Neben der auch für andere Tumorerkrankungen geltenden TNM-Klassifikation (siehe Abbildung 2) sind besonders die Lugano-Klassifikation, die Klassifikation nach UICC (siehe 
Abbildung 3) und die IGCCCG-Klassifikation von Relevanz (Rajpert-De Meyts et al. 2000) (Schmoll et al. 2010).

Stage 0 (p'Tis): Testikuläre intraepitheliale Neoplasie

Stage IA (pT1, N0, M0, S0): Tumor beschränkt auf Hoden und Nebenhoden

Stage IB (pT2-4): Stage IA mit vaskulärer/lymphatischer, Tunica oder skrotaler Invasion

Stage II (alle pT, N1-3, M0, S0-1): Lymphknotenmetastasen, normale oder moderat erhöhte Serummarker

Stage IIA (N1): retroperitoneale Lymphknotenmetastasen $<2 \mathrm{~cm}$

Stage IIB (N2, S1): retroperitoneale Lymphknotenmetastasen $\geq 2 \mathrm{~cm}$ aber $<5 \mathrm{~cm}$

Stage IIC (N3, S1): retroperitoneale Lymphknotenmetastasen $\geq 5 \mathrm{~cm}$

Stage III (alle pT, alle N, M1, S1-3): Fernmetastasen

Stage IIIA (M1a, S0-1): nicht-regionale Lymphknoten- oder pulmonale Metastasen

Stage IIIB (M1a, S2): Stage IIIA mit hohen Serum Markern

Stage IIIC (M1a-b, S3): Andere Fernmetastasen als IIIA, oder sehr hohe Serum Marker

Abbildung 2: TNM-Klassifikation (Rajpert-De Meyts et al. 2000) 


\begin{tabular}{|c|c|c|c|c|c|c|c|c|c|}
\hline \multirow{2}{*}{$\begin{array}{l}\text { Clinical } \\
\text { Stage }\end{array}$} & \multicolumn{5}{|c|}{ TNM (UICC/AJC) catgory } & \multicolumn{3}{|c|}{ Serum tumor markers (S) } & \multirow{2}{*}{$\begin{array}{l}\text { IGCCCG } \\
\text { prognostic } \\
\text { group }^{c}\end{array}$} \\
\hline & & $\bar{T}$ & $\mathbf{N}$ & $M$ & $\mathrm{~S}$ & $\mathrm{LDH}^{\mathrm{a}}$ & $\begin{array}{c}\text { BHCG } \\
(\mathrm{mlU} / \mathrm{ml})^{\mathrm{b}}\end{array}$ & $\begin{array}{c}\text { AFP } \\
\text { (ng/ml) }\end{array}$ & \\
\hline 0 & pTis & $\begin{array}{l}\text { intratubular germ cell } \\
\text { neoplasia }\end{array}$ & No & Mo & - & - & - & - & n.a. \\
\hline IA & pT1 & $\begin{array}{l}\text { limited to testis and } \\
\text { epididymis, without } \\
\text { vascular/ lymphatic } \\
\text { invasion; tumour may } \\
\text { invade into the tunica } \\
\text { albuginea but not the tunica } \\
\text { vaginalis }\end{array}$ & No & Mo & $S_{\text {any }}$ & any level & any level & normal & n.a. \\
\hline \multirow[t]{3}{*}{ IB } & рT2 & $\begin{array}{l}\text { limited to testis and } \\
\text { epididymis, with vascular/ } \\
\text { lymphatic invasion or } \\
\text { tumour extending through } \\
\text { the tunica albuginea with } \\
\text { involvement of the tunica } \\
\text { vaginalis }\end{array}$ & \multirow[t]{3}{*}{ No } & \multirow[t]{3}{*}{ Mo } & \multirow[t]{3}{*}{$S_{\text {any }}$} & \multirow[t]{3}{*}{ any level } & \multirow[t]{3}{*}{ any level } & \multirow[t]{3}{*}{ normal } & \multirow[t]{3}{*}{ n.a. } \\
\hline & pT3 & invasion of spermatic cord & & & & & & & \\
\hline & pT4 & invasion of scrotum & & & & & & & \\
\hline IIA & $T_{\text {any }}$ & & $\mathrm{N} 1(\leq 2 \mathrm{~cm})$ & Mo & $S_{\text {any }}$ & any level & any level & normal & n.a. \\
\hline IIB & $T_{\text {any }}$ & & N2 $(>2-5 \mathrm{~cm})$ & Mo & $S_{\text {any }}$ & any level & any level & normal & n.a. \\
\hline IIC & $T_{\text {any }}$ & & N3 $(>5 \mathrm{~cm})$ & Mo & $S_{\text {any }}$ & any level & any level & normal & good \\
\hline IIIA/B/C & $T_{\text {any }}$ & & $N_{\text {any }}$ & $\begin{array}{l}\text { M1a } \\
\text { (non-regional nodal } \\
\text { and/or pulmonary } \\
\text { metastases) }\end{array}$ & $S_{\text {any }}$ & any level & any level & normal & good \\
\hline IIIC & $T_{\text {any }}$ & & $N_{\text {any }}$ & $\begin{array}{l}\text { MT (IIver, bone, CNS } \\
\text { or other visceral } \\
\text { metastases, e.g. } \\
\text { intestinum or skin; } \pm \\
\text { pulmonary metastases) }\end{array}$ & $\mathrm{S}_{\text {any }}$ & any level & any level & normal & intermediate \\
\hline IIIC & & mediastinal primary & $N_{\text {any }}$ & $M_{\text {any }}$ & $S_{\text {any }}$ & any level & any level & normal & intermediate \\
\hline
\end{tabular}

Abbildung 3: Klassifikation nach UICC (Schmoll et al. 2010)

\subsection{Therapie, Prognose und Nachsorge}

Das Therapieregim richtet sich nach dem klinischen Stadium. In aller Regel werden Seminom-Patienten primär orchiektomiert. Lediglich Patienten mit initial weit fortgeschrittene Tumorerkrankungen erhalten primär Chemotherapie und werden anschließend operativ versorgt (Beyer et al. 2013). Als adjuvante Therapieoptionen stehen Active Surveillance, Chemotherapie, Radiatio und die retroperitoneale Lymphadenektomie (RLA) zur Verfügung. Während man sich beim Seminom CS1 häufig für Active Surveillance entscheidet, wird bei fortgeschrittenen Tumorstadien eine aktive adjuvante Therapie empfohlen. Angesprochene adjuvante Therapien reduzieren das Risiko eines Rezidivs um ca. $5 \%$, gehen aber mit einer Vielzahl an Kurz- sowie Langzeitnebenwirkungen einher (Gorbonos 2015). Um möglichst vielen Patienten unnötige Kurz- und Langzeitnebenwirkungen ersparen zu können, wird nach neuen und verlässlicheren Prognosefaktoren für ein mögliches Rezidiv gesucht.

Insgesamt liegt die 5-JÜR für Patienten mit einem Seminom bei ca. 97 \% (Stang et al. 2013). 
In Abbildung 4 ist der adjuvante Therapiealgorithmus für Seminome nach Orchiektomie dargestellt.

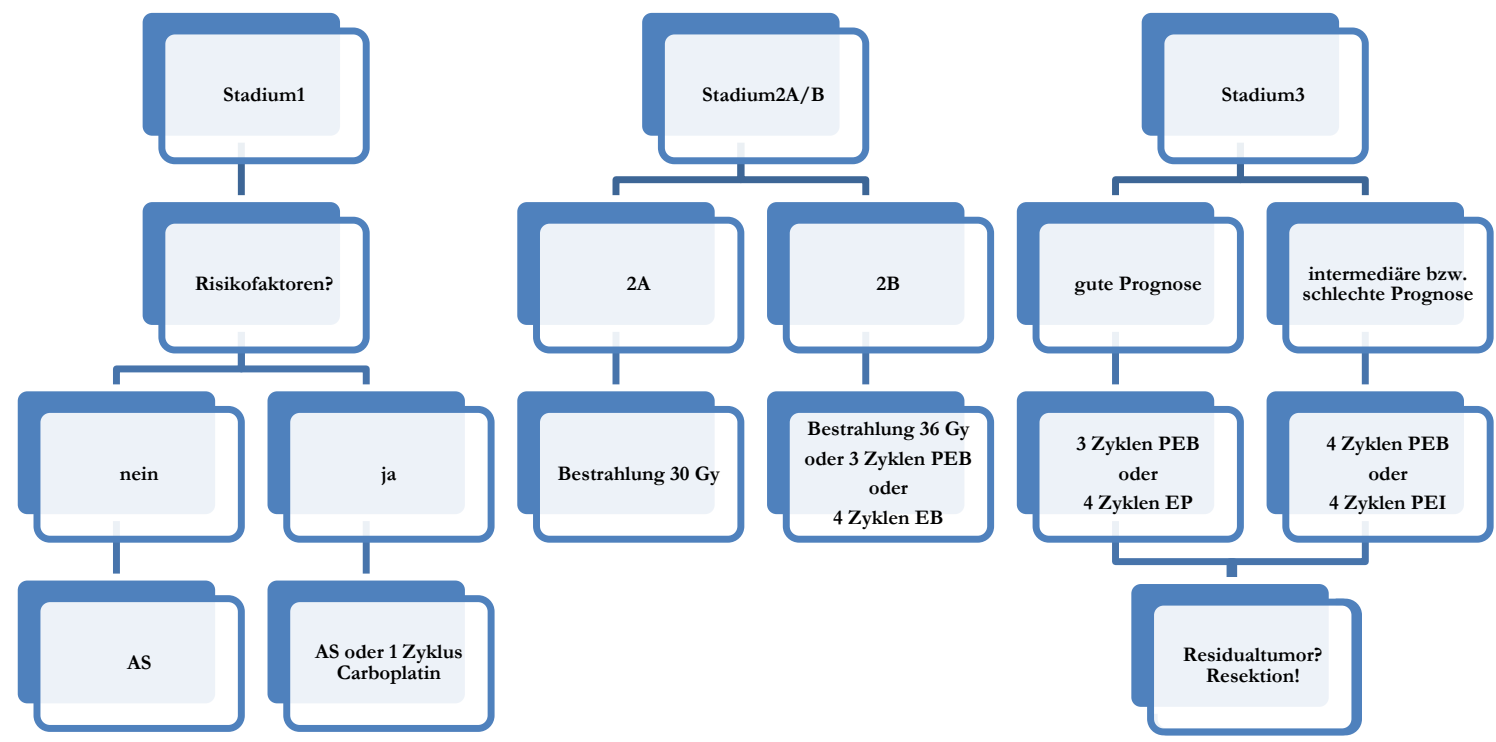

Abbildung 4: Therapiealgorithmus für Seminompatienten nach Orchiektomie

\subsubsection{Seminom klinisches Stadium 1}

Ca. 80-85 \% der Patienten im klinischen Stadium 1(CS1) würden mit einer adjuvanten Therapie eine Übertherapie erfahren, da nur 15-20 \% der Patienten nach Ablation des Hodens ein Rezidiv erleiden (van As et al. 2008). Eine adjuvante Chemotherapie reduziert das Risiko eines Rezidivs auf 5-6\%, was eine Rezidivrisikoreduktion von 60 bis $70 \%$ bedeutet. Um dem Gesamtkollektiv der CS1 Seminom-Patienten gerecht zu werden, muss man dieses entsprechend ihres Risikoprofils für ein Rezidiv betrachten. Patienten im CS1 ohne die in der Literatur anerkannten Risikofaktoren (Tumorgröße $>4 \mathrm{~cm}$ und Infiltration des Rete testis), zeigten in Studien lediglich eine 5-JRW von 11,9 \% (Warde et al. 1995). Patienten mit intermediärem Risikoprofil, sprich einem der beiden Risikofaktoren, zeigten eine 5-JRW von 15$16 \%$ und Seminom-Patienten mit beiden Risikofaktoren sogar von 30-35 \% (Ondrusova et al. 2015). Entscheidet man sich für eine adjuvante Therapie, stellt die Mono-Chemotherapie mit Carboplatin (AUC7) das Mittel der Wahl dar. In Ihrer Risikoreduktion für ein Rezidiv ist sie der Bestrahlung gleichwertig, zeigt aber weniger Nebenwirkungen. Vergleicht man das Gesamtüberleben von Patienten mit adjuvanter Radiatio und Active Surveillance, zeigt sich eine leicht verbesserte Statistik für bestrahlte Patienten mit einem Overall Survival (OS) nach 5und 10- Jahren von $97,9 \%$ und $94,8 \%$ bei $95,0 \%$ und $92,2 \%$ für AS Patienten. Beim OS nach 20 Jahren zeigt Active Surveillance mit 84,1 \% gegenüber 83,4 \% Vorteile (Jones et al. 2013). Für Active Surveillance im CS1 sprechen die Vermeidung von Übertherapie, die niedrige Rezidivrate, das Wegfallen von therapieassoziierten Nebenwirkungen (NW) und die exzellenten Kurationschancen bei einem Rezidiv (Warde et al. 2002). 


\subsubsection{Seminom klinisches Stadium 2A, B, C und 3}

Etwa $15 \%$ der diagnostizierten Seminome zeigen lokoregionale Metastasen (Classen et al. 2003). Unter Bestrahlung zeigen sie im klinischen Stadium 2A (CS2A) eine 5JRW von $<10$ $\%$. Für das klinische Stadium 2B (CS2B) scheinen adjuvante Chemotherapie mit Cisplatin und Bestrahlung gleichwertig zu sein (Albers et al. 2011). Im klinischen Stadium 3 (CS3) ist die Monochemotherapie mit Cisplatin der Bestrahlung und vor allem der Polychemotherapie mit 3 Zyklen PEB oder 4 Zyklen PE unterlegen (Krege et al. 2008). Die geringe Inzidenz dieser klinischen Stadien macht es für prospektive Studien schwierig, neue Erkenntnisse mit einem entsprechenden Level of Evidence (LoE) zu generieren.

\subsection{Das entzündliche Infiltrat des seminomatösen Hodentumors}

Das menschliche Immunsystem besteht neben dem angeborenen Immunsytem aus dem erworbenen Immunsystem. Dieses gliedert sich vorwiegend in die beiden großen Gruppen der T- und B-Lymphozyten. Sie sind entscheidend an der Erkennung und anschließenden Eliminierung von Fremdantigenen beteiligt. Darunter fallen auch Antigene, die durch Tumoren gebildet werden.

Seminome sind durch ein lebhaftes entzündliches Infiltrat gekennzeichnet. Dabei zeigen TZellen eine diffuse Verteilung, während B-Lymphozyten sich häufig in Follikel formieren und lokalisierter auftreten (Nakanoma et al. 1992). Es konnte gezeigt werden, dass funktionelle T-Zell-Antworten im Tumor wirksam sind und sogar an der lokalen immunologischen Kontrolle des Tumors beteiligt sein können (Hadrup et al. 2006). Dabei stellen zytotoxische T-Lymphozyten $\left(\mathrm{CD}^{+}\right)$eine große Gruppe der infiltrierenden Lymphozyten dar (Yakirevich et al. 2002). Bei Patienten mit Seminomen konnte im Blut eine T-Zell-gerichtete Immunantwort gegen Epitope derselben nachgewiesen werden (Pearce et al. 2017). Im fortgeschrittenen Tumorstadium zeigen Patienten ein reduziertes Auftreten von T-Zellen (Siska et al. 2017). Eine Forschungsgruppe der Kyoto Universität in Japan berichtet von einer Akkumulation von gamma/delta T-Zellen in Seminomen. Diesen T-Zellen konnte „Anti-TumorAktivität" verbunden mit der Bildung von granulomatösen Entzündungsprozessen nachgewiesen werden, die mit einer günstigen Prognose der Patienten einhergehen sollen (Zhao et al. 1995). Für andere Tumoren konnte bereits nachgewiesen werden, dass das entzündliche Infiltrat entscheidenden Anteil am Krankheitsverlauf der Patienten haben kann (Clark 1991; Zhang et al. 2003). Die genaue Bedeutung für die Prognose bzw. den klinischen Verlauf von Seminom-Patienten ist aktuell jedoch weiterhin ungeklärt (Hvarness et al. 2013).

\subsubsection{T-Lymphozyten}

T-Helferzellen $\left(\mathrm{CD}^{+}\right)$und zytotoxischen T-Zellen $\left(\mathrm{CD}^{+}\right)$bilden die Mehrheit der Lymphozyten. $\mathrm{CD}^{+}-$Zellen spielen vor allem bei der Erkennung von Antigenen mit 
anschließender Aktivierung anderer Immunozyten über die Sekretion von Zytokinen eine wesentliche Rolle (Luckheeram et al. 2012).

Zytotoxische T-Zellen $\left(\mathrm{CD}^{+}\right)$sind zentral für die Clearance von intrazellulären Pathogenen und Tumoren. Dabei entfalten sie ihre Wirkung über die Sekretion zytotoxischer Proteine wie z.b. Granzym und Perforin und induzieren so in der Zielzelle die Apoptose (Larosa und Orange 2008).

\subsubsection{B-Lymphozyten}

Als Bestandteil des angeborenen Immunsystems im menschlichen Körper kommt den BLymphozyten vor allem über die Antikörper-vermittelte Immunantwort eine entscheidende Rolle in der humoralen Immunität zu. Neben der Antikörper-vermittelten Funktion sind sie in ihrer Interaktion mit den T-Lymphozyten an ihrer Initiierung und somit an der Reaktion auf Pathogene essentiell (LeBien und Tedder 2008).

\subsection{Fragestellung und Zielsetzung}

Sowohl im metastasierten Tumorstadium, als auch adjuvant bei lokalisierten Hodentumorerkrankungen werden Patienten mit Chemotherapie behandelt. Das Risiko von Kurz- und Langzeitnebenwirkungen wird dabei der kurativen Intention der Therapie untergeordnet. In vielen Fällen erfahren Patienten im CSI jedoch im Sinne der Rezidivrisikoreduktion eine Übertherapie und werden dementsprechend den angesprochenen Nebenwirkungen ausgesetzt.

Das Ziel muss sein, durch detaillierte Risikostratifizierung des einzelnen Patienten bzgl. Prognose und Krankheitsverlauf bei Diagnosestellung die Patienten zu identifizieren, die ein signifikant erhöhtes Rezidivrisiko aufweisen und nur sie entsprechend adjuvant zu therapieren. Verschiedene Studien sind in den letzten Jahren daran gescheitert, neben den bereits bekannten Prädiktoren für ein Rezidiv (Tumorgröße $>4 \mathrm{~cm}$, Rete Testis-Infiltration) neue Faktoren zu identifizieren, die prognostische Signifikanz zeigen.

Möglicherweise liegt ein Schlüssel in molekularpathologischen Methoden und dem Wissen über die Bedeutung des entzündlichen Infiltrats bei Seminomen.

Für andere Tumoren konnte bereits nachgewiesen werden, dass das entzündliche Infiltrat entscheidenden Anteil am Krankheitsverlauf der Patienten haben kann (Clark 1991; Zhang et al. 2003).

Diese Arbeit widmet sich der Fragestellung nach der Bedeutung des entzündlichen Infiltrats und seiner Subtypen im seminomatösen Hodentumor. Durch die Aufarbeitung und Analyse der immunhistochemischen Tumorpräparate mit Betrachtung der beiden großen Gruppen der Lymphozyten (T- und B-Lymphozyten) und ihrer Quantität und Infiltration im Seminom sollen Rückschlüsse auf die histopathologischen Charakteristika des Tumors gezogen 
werden. In Kombination mit den klinischen Follow-up-Daten der betroffenen Patienten wird die Bedeutung des inflammatorischen Infiltrats für den Krankheitsverlauf untersucht. Neben der Frage nach der Bedeutung der lymphozytären Infiltration werden histopathologische und klinische Charakteristika der Patienten mit Blick auf ihren Einfluss auf den Krankheitsverlauf der Patienten analysiert. So sollen mögliche neue Prädiktoren für rezidivierende Krankheitsverläufe identifiziert werden.

Dabei soll besonders die Gruppe der T-Lymphozyten und ihrer Bedeutung im Hodentumor untersucht werden. Auch die Frage nach der Bedeutung der B-Lymphozyten mit ihrer potentiellen lokal regulatorischen Wirkung im Primarius und der viel diskutierten antikörpervermittelten systemischen Immunantwort soll erarbeitet werden. 


\section{$2 \quad$ Material und Methoden}

\subsection{Datenerhebung des Patientenkollektivs / Studiendesign}

Diese retrospektive klinische Studie umfasst ein Patientenkollektiv von 92 Patienten. Die Daten wurden mit Hilfe von Microsoft Excel (Excel 2018; Version 16.10) entsprechend des Ethikvotums der Universitätsmedizin Göttingen (Antragsnummer 18/2/16) aus dem Jahr 2016 erhoben und ausgewertet (siehe Anhang). Die Patienten haben schriftlich Ihre Erklärung zu dem Einverständnis zur Analyse der Follow-Up-Daten und der Biomarker des Tumorgewebes gegeben. Zusätzlich stimmten Sie dem Datenaustausch zwischen der UMG und den niedergelassenen Nachsorgern zur Aktualisierung des Krankheitsverlaufs zu. Die Erhebung der Follow-Up-Daten ist auf einen Zeitraum von 10 Jahren ausgelegt. Begonnen im Jahr 2008 wurden die Daten der Patienten bis einschließlich 2018 pseudonymisiert erfasst.

\subsubsection{Einschlusskriterien}

- Hodentumor vom histologischen Typ „klassisches Seminom“

- Vorliegende Einverständniserklärung bei Einwilligungsfähigkeit des Patienten

\subsubsection{Ausschlusskriterien}

- Histopathologische Hodenmischtumoren

- Keine Erteilung des Einverständnisses bei Einwilligungsfähigkeit des Patienten

\subsubsection{Erhobene Merkmale der Patienten}

Bei der Erhebung der Daten aus archivierten und/oder elektronisch gespeicherten Akten wurden zu jedem Patienten die wesentlichen histopathologischen Merkmale seines Tumors, persönliche Patientendaten, Daten zum klinischen Verlauf und die Tumormarker im Blut festgehalten. Folgende Daten wurden zu jedem Patienten erhoben:

- Patientendaten: Geburtsdatum, Alter, Alter bei Diagnose, Zeitpunkt des Todes

- Histopathologische Daten: TNM-Klassifikation, Rete-testis-Infiltration, Lymphgefäßinvasion, Blutgefäßinvasion, Größe des Tumors, Samenstranginfiltration, Biopsieergebnis des kontralateralen Hoden, immunhistochemische Charakteristika des Tumors

- Klinischer Verlauf: Primärtherapie (Orchiektomie, Active Surveillance, Radiatio, Chemotherapie, Retroperitoneale Lymphadenektomie), Rezidiv (ja/nein), Zeitraum bis zum Rezidiv nach Primärtherapie, Therapie des Rezidivs (Radiatio, Chemotherapie, Retroperitoneale Lymphadenektomie), Klinisches Tumorstadium, Lokalisation und Anzahl von Metastasen, Prognosegruppe, Nachsorgezeitraum nach Diagnosestellung 
- Laborchemische Parameter/Tumormarker (prätherapeutisch): Lactatdehydrogenase (LDH), B-hCG, Alpha-Fetoprotein (AFP)

Durch die Kooperation mit den ärztlichen Kollegen aus der Niederlassung wurde versucht, für jeden Patienten einen möglichst langen dokumentierten Nachsorgezeitraum zu generieren. Alle Patienten hatten hierzu schriftlich Ihr Einverständnis erteilt. Die auf diesem Weg erlangten Arztbriefe der niedergelassenen Nachsorger ermöglichten das Wissen über den Krankheitsverlauf der Patienten nach Entlassung aus der UMG.

\subsubsection{Rekrutierung der Patienten}

Die Rekrutierung der Patienten und der entsprechenden Einverständniserklärungen erfolgten entweder durch persönliche Gespräche oder durch Telefonate mit folgendem postalischem Versand der Unterlagen (siehe Anhang).

\subsection{Geräte und Materialien}

\subsubsection{Geräte und Gebrauchsmaterialien}

Tabelle 1: Geräte und Gebrauchsmaterialien

\begin{tabular}{|l|l|}
\hline \multicolumn{1}{|c|}{ Gerät/ Gebrauchsmaterial } & \multicolumn{1}{c|}{ Hersteller } \\
\hline Objektträger Superfrost Plus & Thermo Fischer Scientific, Waltham, USA \\
\hline Mikrotom SM $2000 \mathrm{R}$ & Leica Microsystems GmbH \\
\hline Kühlplatte $\left(-7^{\circ} \mathrm{C}\right)$ & PFM Medical Germany \\
\hline Streckbad $\left(45^{\circ} \mathrm{C}\right)$ & PFM Medical Germany \\
\hline Trockenschrank $\left(60^{\circ} \mathrm{C}\right)$ & Memmert GmbH Germany \\
\hline PT Link PT2000 Slide Stainer & Dako, Hamburg, Deutschland \\
\hline Link 48 Autostainer & Dako, Hamburg, Deutschland \\
\hline Reagenzfläschchen & Dako, Hamburg, Deutschland \\
\hline Tissue-Tek Film 4740 & Sakura Finetek Germany GmbH \\
\hline Objektträger & Süsse Labortechnik GmbH \& Co. KG \\
\hline Mikroskop: Scope A1 Axio & Zeiss AG, Oberkochen, Deutschland \\
\hline Kamera: Axiocam 105 color & Zeiss AG, Oberkochen, Deutschland \\
\hline
\end{tabular}




\subsubsection{Molekularbiologische Agenzien}

Tabelle 2: Molekularbiologische Agenzien

\begin{tabular}{|c|c|}
\hline Agens & Hersteller \\
\hline $\begin{array}{l}\text { EnVision FLEX Target Retrieval Solution } \\
\text { high } \mathrm{pH}\end{array}$ & Dako, Hamburg, Deutschland \\
\hline $\begin{array}{l}\text { EnVision FLEX Target Retrieval Solution } \\
\text { low } \mathrm{pH}\end{array}$ & Dako, Hamburg, Deutschland \\
\hline EnVision FLEX Wash Buffer & Dako, Hamburg, Deutschland \\
\hline $\begin{array}{l}\text { EnVision FLEX Peroxidase-Blocking Rea- } \\
\text { gent }\end{array}$ & Dako, Hamburg, Deutschland \\
\hline EnVision FLEX / HRP & Dako, Hamburg, Deutschland \\
\hline EnVision FLEX DAB + Chromogen & Dako, Hamburg, Deutschland \\
\hline EnVision FLEX Substrat Buffer & Dako, Hamburg, Deutschland \\
\hline EnVision FLEX + Mouse (Linker) & Dako, Hamburg, Deutschland \\
\hline EnVision FLEX + Rabbit (Linker) & Dako, Hamburg, Deutschland \\
\hline EnVision FLEX Hematoxylin & Dako, Hamburg, Deutschland \\
\hline EnVision FLEX Antibody Diluent & Dako, Hamburg, Deutschland \\
\hline Anti-ZAP70 Polyclonal Rabbit & Sigma-Aldrich, München, Deutschland \\
\hline Anti-pZAP70 (Y493) Monoclonal Mouse & R\&D Systems, Minneapolis, USA \\
\hline Anti-CD3 Polyclonal Rabbit & Dako, Hamburg, Deutschland \\
\hline Anti-CD4 Monoclonal Mouse, Clone 4B 12 & Dako, Hamburg, Deutschland \\
\hline $\begin{array}{l}\text { Anti-CD8 Monoclonal Mouse, Clone } \\
\text { C8/144B }\end{array}$ & Dako, Hamburg, Deutschland \\
\hline $\begin{array}{l}\text { Anti-CD20cy Monoclonal Mouse, Clone } \\
\text { L26 }\end{array}$ & Dako, Hamburg, Deutschland \\
\hline $\begin{array}{l}\text { CD45 Monoclonal Mouse, Clones 2B } 11+ \\
\text { PD7/26 }\end{array}$ & Dako, Hamburg, Deutschland \\
\hline EtOH $96 \%, 99 \%$, Xylol & Universitätsmedizin Göttingen \\
\hline
\end{tabular}




\subsection{Herstellung und Aufarbeitung des histologischen Materials}

Im Folgenden wird das standardisierte prädiagnostisch-postoperative Verfahren zur Aufarbeitung des Hodenfrischgewebes beschrieben. Davon zu unterscheiden ist das Anfertigen der für diese Arbeit außerhalb der Routinediagnostik relevanten Seminom-Paraffinblöcke aus Kapitel 2.3.

Die Orchiektomiepräparate werden postoperativ mit 4\%igem Formalin 24 Stunden fixiert und anschließend in Paraffin eingebettet. Die Paraffinblöcke werden mit Hilfe des Schlittenmikrotoms auf eine Dicke von $5 \mu \mathrm{m}$ geschnitten, auf Glasobjektträger aufgebracht und in einem Wasserbad (bei Raumtemperatur) bzw. auf einer Heizplatte gestreckt. Abschließend werden die Objektträger über Nacht bei $40{ }^{\circ} \mathrm{C}$ in einem Wärmeschrank getrocknet.

Die Befundung der mit Hämatoxylin-Eosin (HE) gefärbten Operationspräparate geschieht durch ärztliche Mitarbeiter des Instituts für Pathologie der UMG. Zur sicheren Diagnosestellung wurde das Hodenfrischmaterial immunhistochemisch mit für Seminome spezifischen Antikörpern gefärbt (siehe Tabelle 3). Über das Intranet (IxServ) der UMG oder archivierte Akten konnte auf einen Großteil der Befunde zurückgegriffen werden.

\subsubsection{Immunhistochemie}

Das Gewebe für die immunhistochemischen Untersuchungen stammt aus der Biobank des Pathologischen Instituts der Universitätsmedizin Göttingen (UMG). Alle Patienten haben schriftlich ihr Einverständnis zur Aufarbeitung und Begutachtung der Seminompräparate gegeben.

\subsubsection{Grundlagen der Immunhistochemie}

Die Immunhistochemie dient der Darstellung und Erkennung von molekularen Strukturen in histologischen Gewebeschnitten. Mit Hilfe von Antikörpern, die spezifisch eine molekulare Struktur - das sogenannte Antigen - erkennen und eine Bindung mit ihr eingehen, können Zellen charakterisiert werden, einer speziellen Subgruppe zugeordnet werden und es können funktionelle Eigenschaften beschrieben werden. Die Antikörper können primär mit Farbstoffen markiert werden oder über enzymatische Kopplung erst farblose Substrat-Chomogen-Lösungen in farbige Produkte spalten und so sichtbar machen.

\subsubsection{Aufarbeitung der Immunhistochemie der Seminompräparate}

Die Auswahl der immunhistochemisch aufgearbeiteten Seminomschnitte erfolgte durch PD Dr. med. Felix Bremmer (Oberarzt der Klinik für Pathologie der UMG). Insgesamt wurden 
pro Patienten fünf Schnitte wie oben beschrieben angefertigt und mit den in Tabelle 3 angegebenen Markern/Antikörpern immunhistochemisch gefärbt:

Tabelle 3: Übersicht der immunhistochemischen Marker und des Antigens

\begin{tabular}{|l|l|}
\hline Antikörper & Zelluläres Korrelat/ Antigen \\
\hline Anti-CD20-Antikörper & B-Lymphozyten \\
\hline Anti-CD3-Antikörper & T-Lymphozyten \\
\hline Anti-CD4-Antikörper & CD4-positive T-Helfer-Zellen \\
\hline Anti-CD8-Antikörper & CD8-positive zytotoxische T-Zellen \\
\hline Anti-CD45-Antikörper & Leukozyten \\
\hline
\end{tabular}

\subsection{Auswertung der Seminomschnitte}

\subsubsection{Quantitative Bestimmung des lymphozytären Entzündungsinfiltrats}

Die Auswertung der immunhistochemisch gefärbten Seminomschnitte bestand aus zwei wesentlichen Komponenten. Jede Färbung wurde zum einen mikroskopisch (beschrieben in 2.3.1.1), zum anderen mittels Aufnahmen und dem Bildbearbeitungs- und Auswertungsprogramm ImageJ (Version 1.52a) (beschrieben in 2.3.2.1) analysiert. Dabei wurde der folgende Algorithmus angewandt:

In einem ersten Schritt wurden sowohl die HE-Färbungen als auch die mit Anti-CD45-Antikörper gefärbten Schnitte zur Beurteilung des gesamten entzündlichen Infiltrats des Tumors untersucht. Zur Ermittlung des Anteils von T- und B-Lymphozyten am lymphozytären Infiltrat wurden die Anti-CD3- und Anti-CD20-Färbungen ausgewertet. Die CD4- und CD8-Färbungen ließen uns die $\mathrm{CD}^{+} / \mathrm{CD}^{+}$-Ratio des T-Zell-Infiltrats bestimmen und das T-Zell-Infiltrat weiter subklassifizieren. 


\subsubsection{Mikroskopische Analyse}

Um eine valide Aussage über die gesamte Infiltration der Immunozyten im Tumor tätigen zu können, wurden für jeden immunhistochemischen Schnitt in der mikroskopischen Auswertung zehn verschiedene Field of views (Fov) mittels 100-fach-Vergrößerung untersucht. Das entzündliche Infiltrat wird in jedem Fov in Relation zur Gesamtzellzahl beurteilt und prozentual angegeben. Mit Hilfe der so beurteilten zehn Fov wurde ein Mittelwert gebildet, welcher das Entzündungsinfiltrat im gesamten Tumor widerspiegelt. Um nicht nur eine nummerische Aussage über das Infiltrat im Tumor tätigen zu können, wurden fünf Kategorien erstellt, denen jeder Hodentumor zugeordnet wurde (siehe Tabelle 4). In den Abbildungen 6 bis 10 sind exemplarisch Aufnahmen der immunhistochemisch aufgearbeiteten Seminompräparate der verschiedenen Marker dargestellt. Abbildung 5 zeigt eine HE-Färbung eines Seminoms. Dabei ist jeweils einerseits (links in der Abbildung bzw. im Hintergrund) eine 250-fach Vergrößerung und andererseits (rechts in der Abbildung bzw. im Vordergrund) eine 100-fach Vergrößerung bzw. Übersicht des Tumors und der Verteilung des lymphozytären Infiltrats dargestellt.

Tabelle 4: Kategorisierung des entzündlichen Infiltrats des Tumors

\begin{tabular}{|l|l|}
\hline Kategorie des entzündlichen Infiltrats & Definition der Kategorie \\
\hline 1. Kein entzündliches Infiltrat & $0 \%$ lymphozytäres Infiltrat \\
\hline 2. Mildes entzündliches Infiltrat & $1 \%-19 \%$ lymphozytäres Infiltrat \\
\hline 3. Mäßiges entzündliches Infiltrat & $20 \%-39 \%$ lymphozytäres Infiltrat \\
\hline 4. Reichlich entzündliches Infiltrat & $40 \%-74 \%$ lymphozytäres Infiltrat \\
\hline 5. Massives entzündliches Infiltrat & $75 \%-100 \%$ lymphozytäres Infiltrat \\
\hline
\end{tabular}




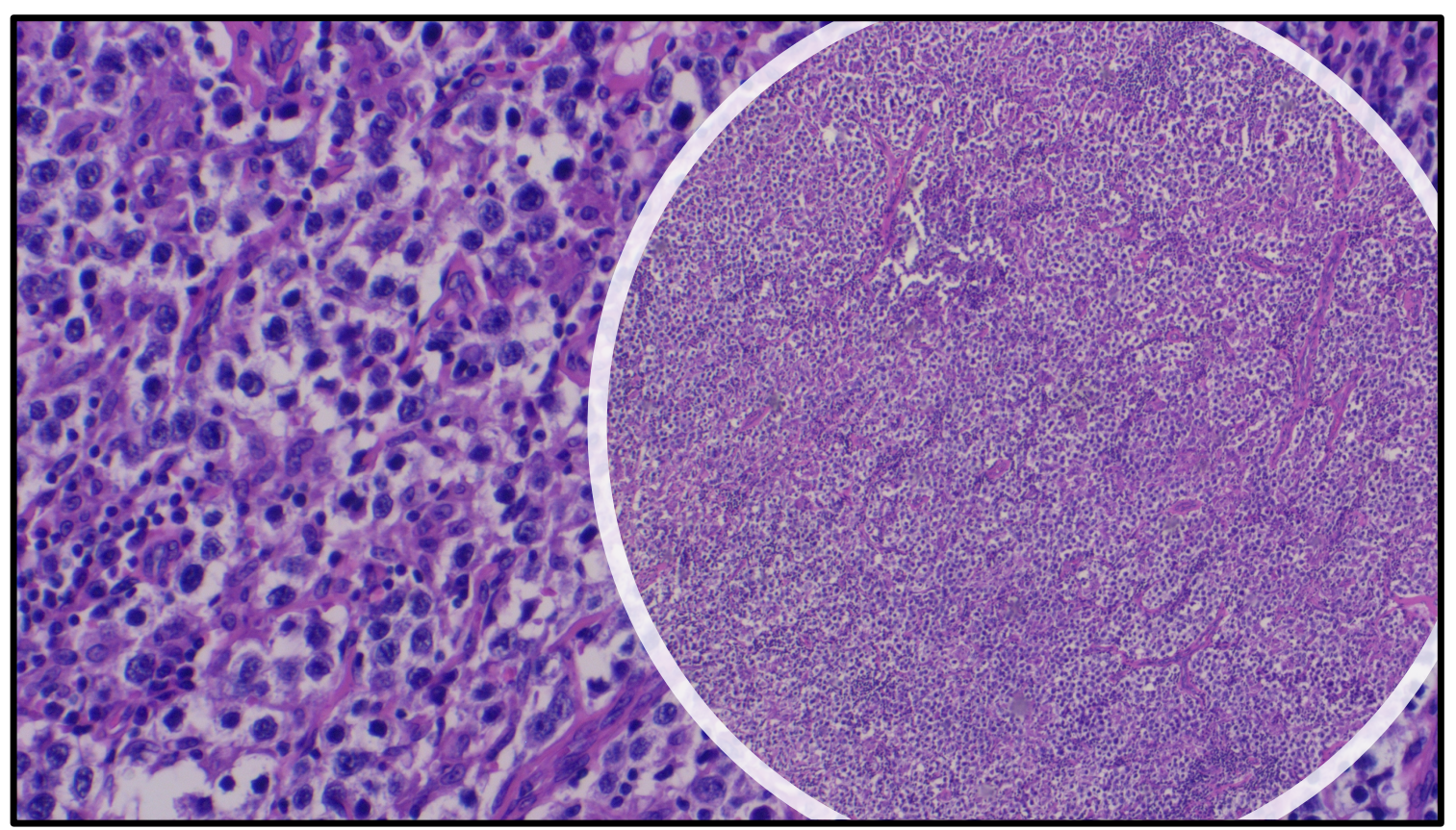

Abbildung 5: HE-Färbung eines Seminoms

Links/im Hintergrund: 250-fach Vergrößerung, rechts: 100-fach Vergrößerung. Zu sehen sind die seminomatösen Tumorzellen des Hodens. Neben bindegewebigen Strukturen sind als dunkle kleine Zellen Lymphozyten zu erkennen.

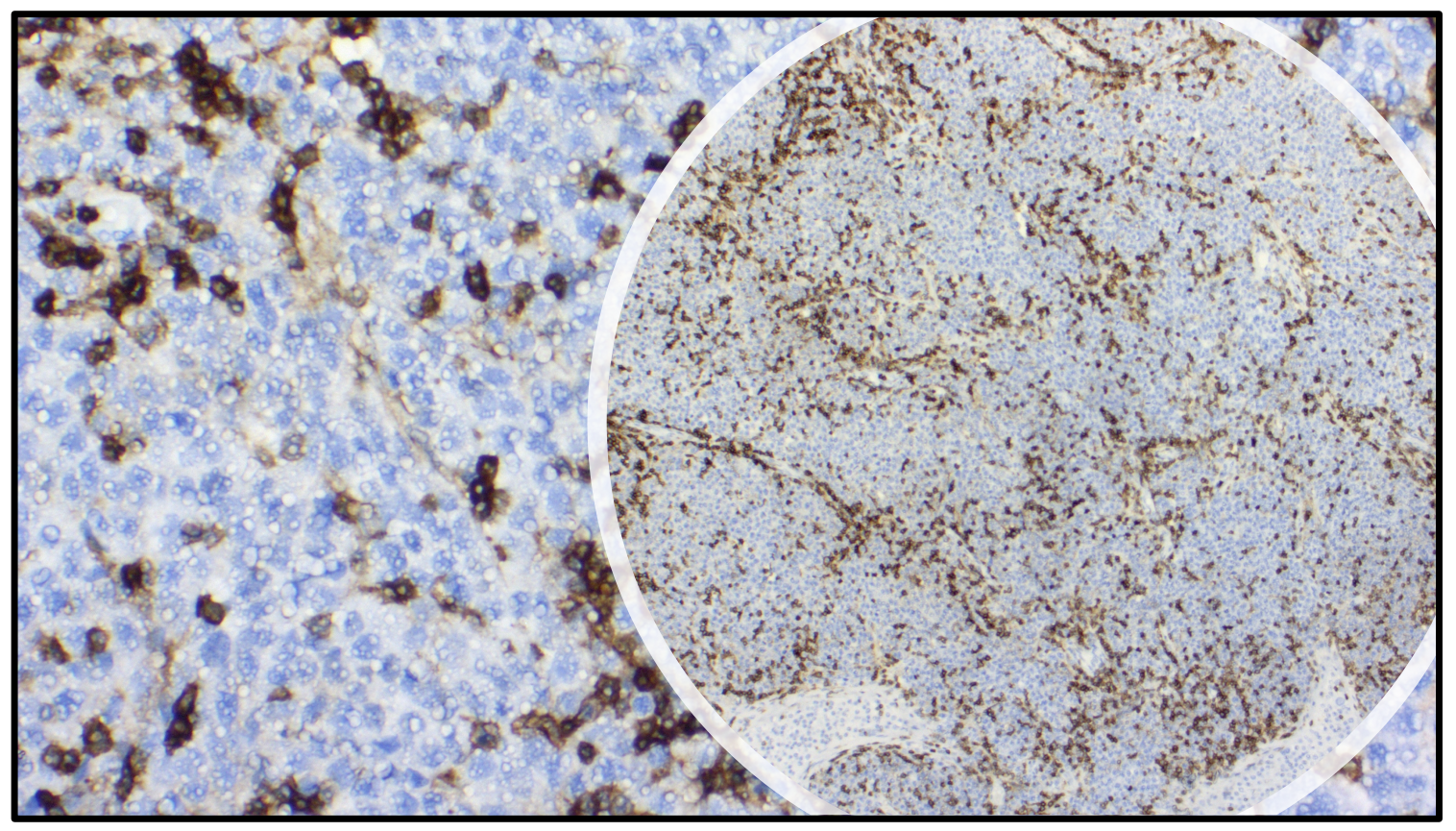

Abbildung 6: Seminom-Immunhistochmie; CD45-AK

Links/im Hintergrund: 250-fach Vergrößerung, rechts: 100-fach Vergrößerung. Die bräunlich-schwarz imponierenden Zellen stellen Lymphozyten dar (CD45+-Zellen). Bläulich erscheinen die seminomatösen Tumorzellen des Hodens mit den hellen interzellulären Räumen. Zusätzlich sind Bindegewebssepten zu erkennen. 


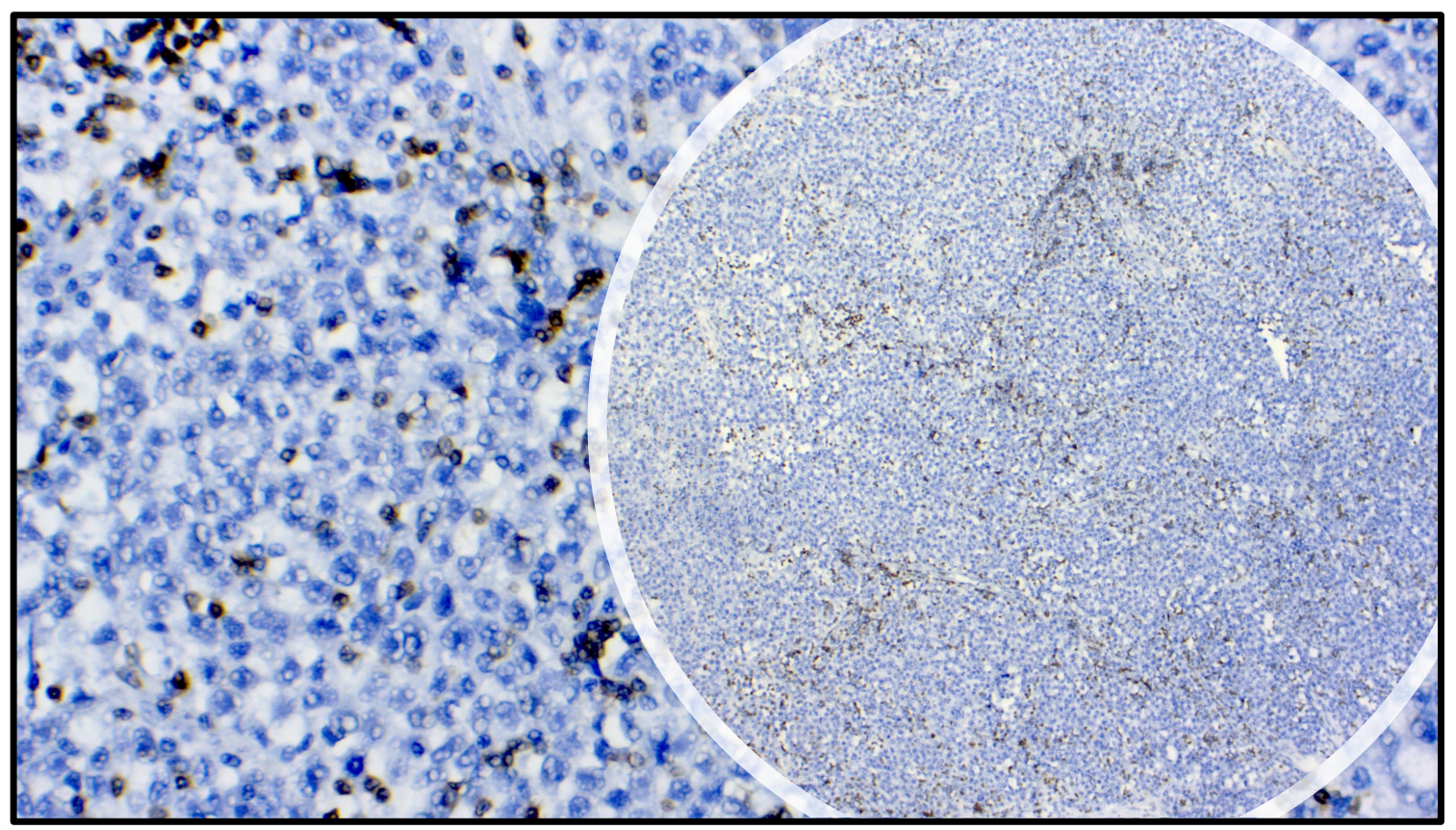

Abbildung 7: Seminom-Immunhistochmie; CD3-AK

Links/im Hintergrund: 250-fach Vergrößerung, rechts: 100-fach Vergrößerung. Die bräunlich-schwarz imponierenden Zellen stellen T-Lymphozyten dar (CD ${ }^{+}$-Zellen). Bläulich erscheinen die seminomatösen Tumorzellen des Hodens mit den hellen interzellulären Räumen. Zusätzlich sind Bindegewebssepten zu erkennen.

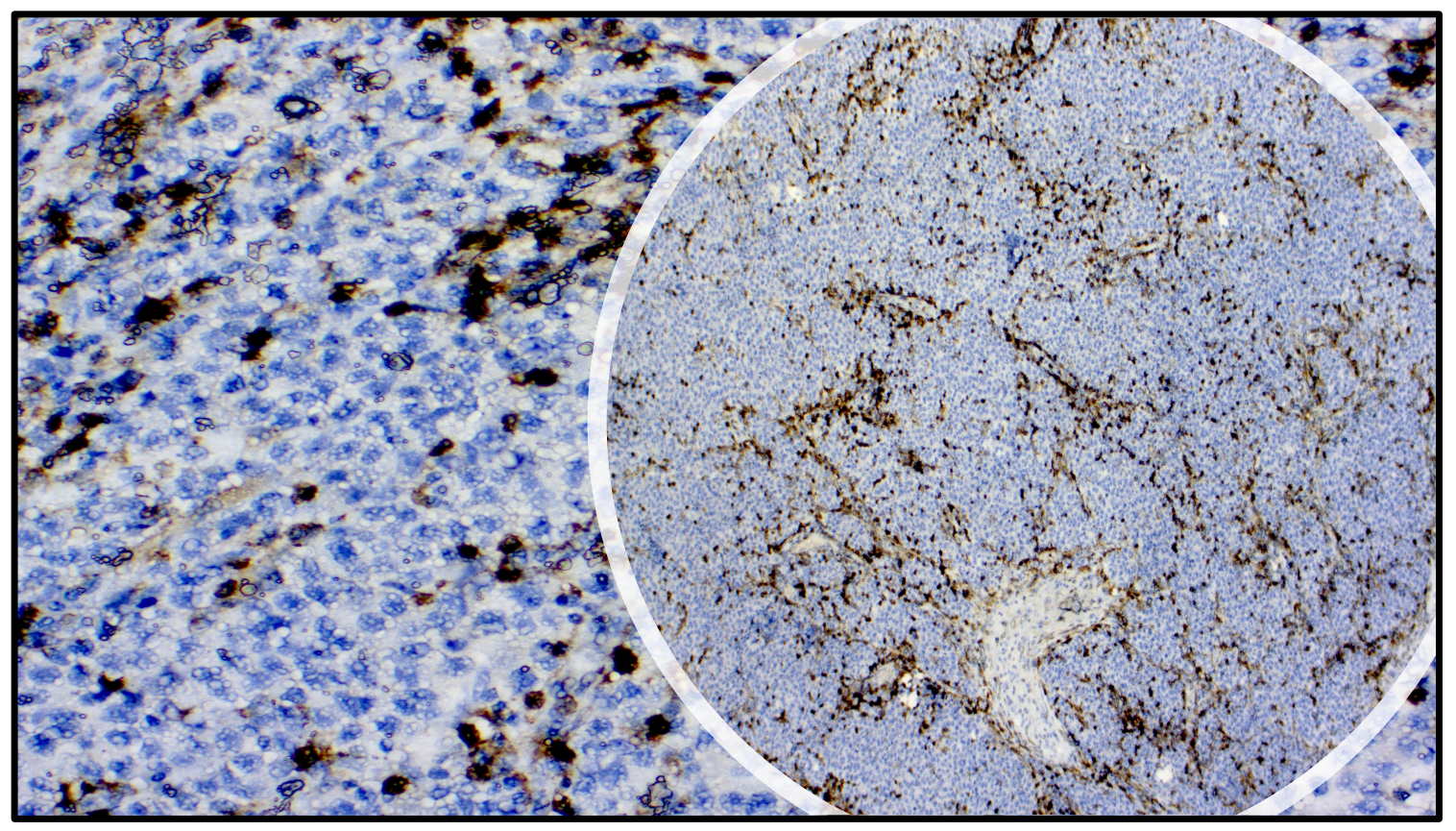

Abbildung 8: Seminom-Immunhistochemie; CD4-AK

Links/im Hintergrund: 250-fach Vergrößerung, rechts: 100-fach Vergrößerung. Die bräunlich-schwarz imponierenden Zellen stellen T-Lymphozyten (T-Helferzellen) dar (CD4 ${ }^{+}$-Zellen). Bläulich erscheinen die seminomatösen Tumorzellen des Hodens mit den hellen interzellulären Räumen. Zusätzlich sind Bindegewebssepten zu erkennen. 


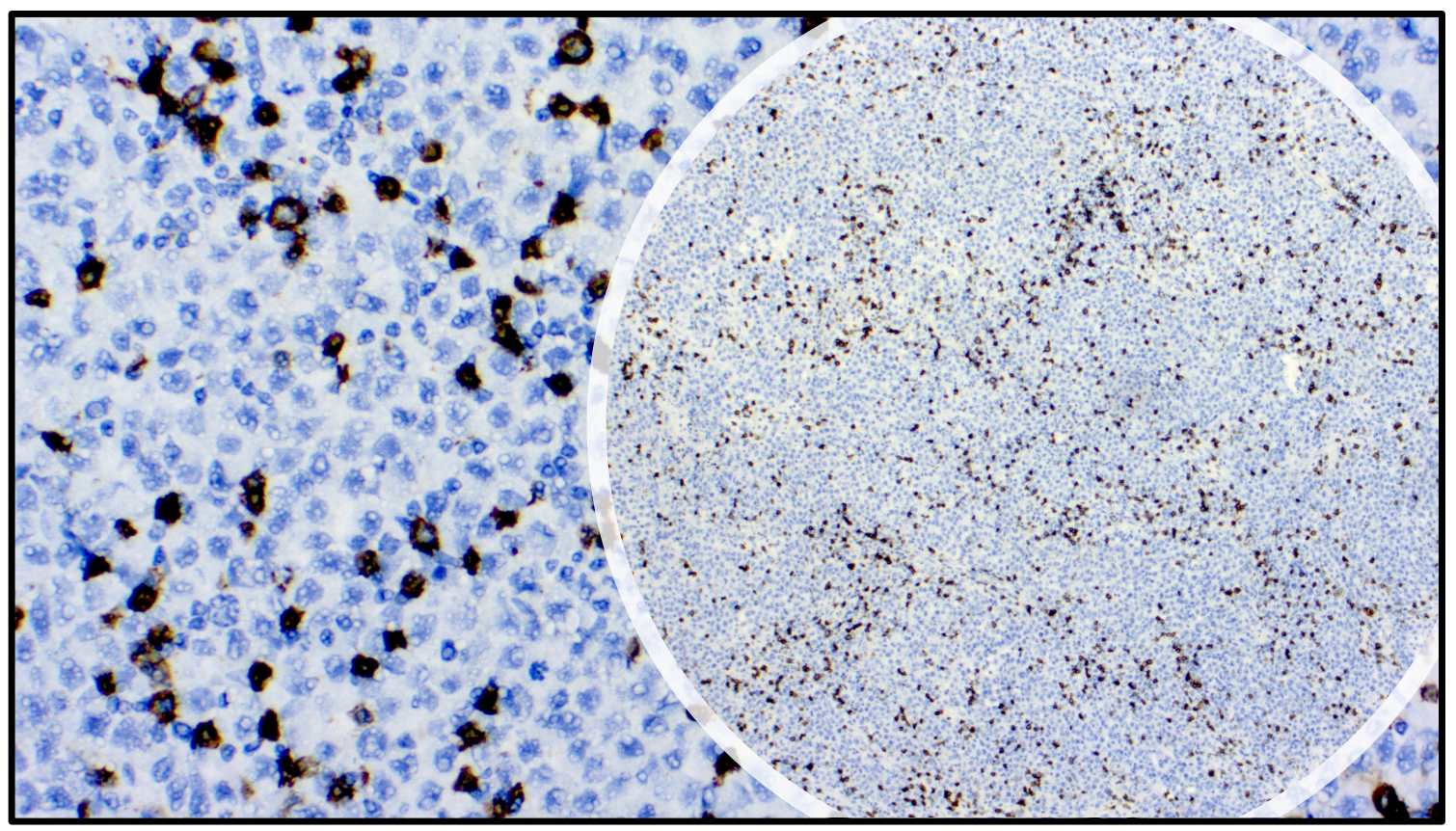

Abbildung 9: Seminom-Immunhistochemie; CD8-AK

Links/im Hintergrund: 250-fach Vergrößerung, rechts: 100-fach Vergrößerung. Die bräunlich-schwarz imponierenden Zellen stellen zytotoxische T-Zellen dar (CD8 ${ }^{+}$-Zellen). Bläulich erscheinen die seminomatösen Tumorzellen des Hodens mit den hellen interzellulären Räumen. Zusätzlich sind Bindegewebssepten zu erkennen.

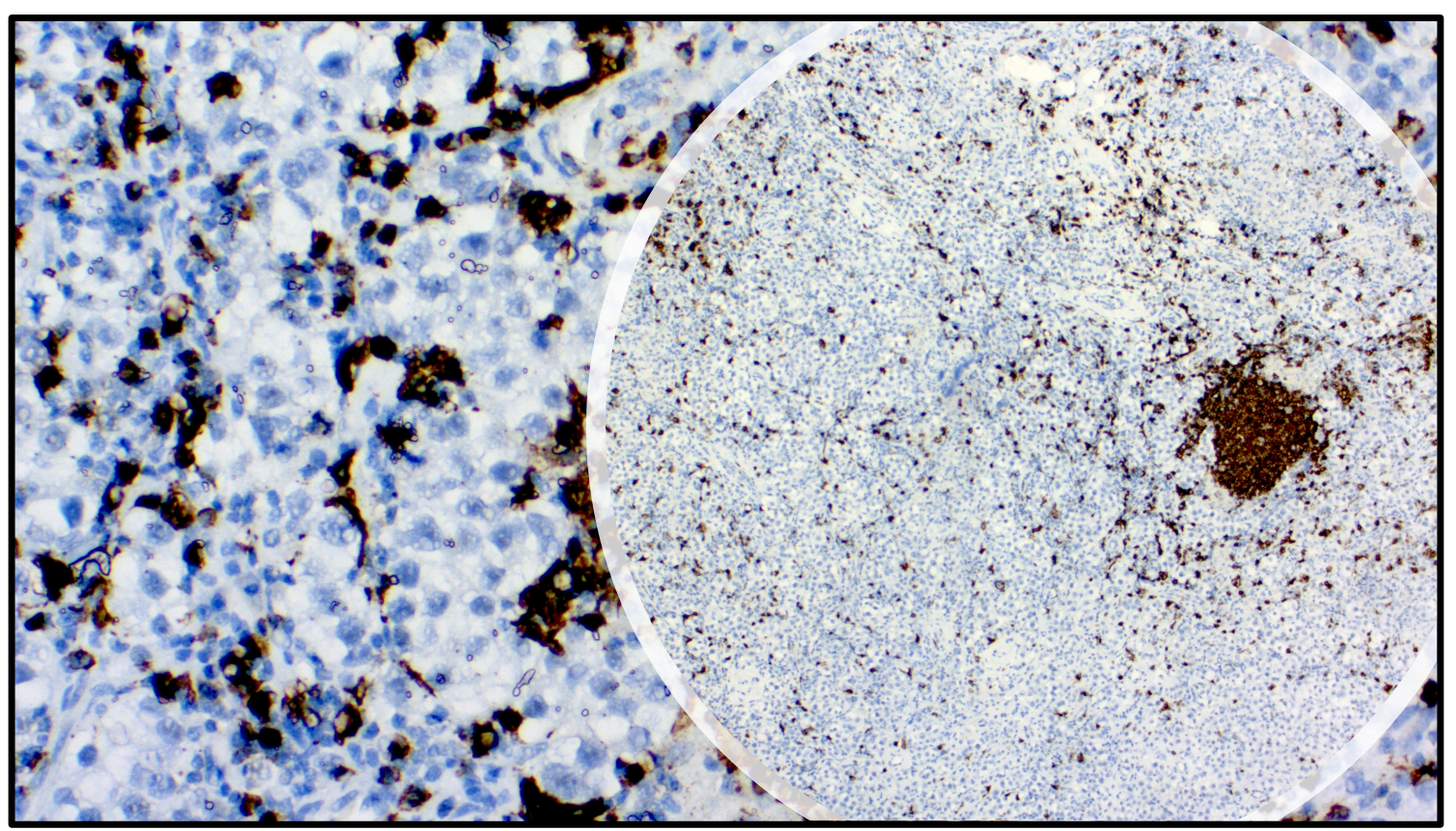

Abbildung 10: Seminom-Immunhistochmie; CD20-AK

Links/im Hintergrund: 250-fach Vergrößerung, rechts: 100-fach Vergrößerung. Die bräunlich-schwarz imponierenden Zellen stellen B-Lymphozyten dar (CD20+-Zellen). Rechts in der rundlichen Vergrößerung ist ein bräunlicher Lymphfollikel zu erkennen. Bläulich 
erscheinen die seminomatösen Tumorzellen des Hodens mit den hellen interzellulären Räumen. Zusätzlich sind Bindegewebssepten zu erkennen.

\subsubsection{Bearbeitung und Analyse mit ImageJ}

Von jedem immunhistochemischen Seminomschnitt wurden Aufnahmen eines repräsentativen Fov in 250-fach Vergrößerung angefertigt. Dafür wurde die Zeiss Mikroskopsoftware ZEN (Version 2012 lite) verwendet. Zur Auswertung der Bilder wurden die aus Abbildung 11 ersichtlichen Voreinstellungen festgelegt. Abbildung 12 stellt exemplarisch die Funktion Threshold Color des Bildbearbeitungs- und Auswertungsprogramms ImageJ (Version 1.52a, Java 1.8.0_172 (64-bit), USA) dar.

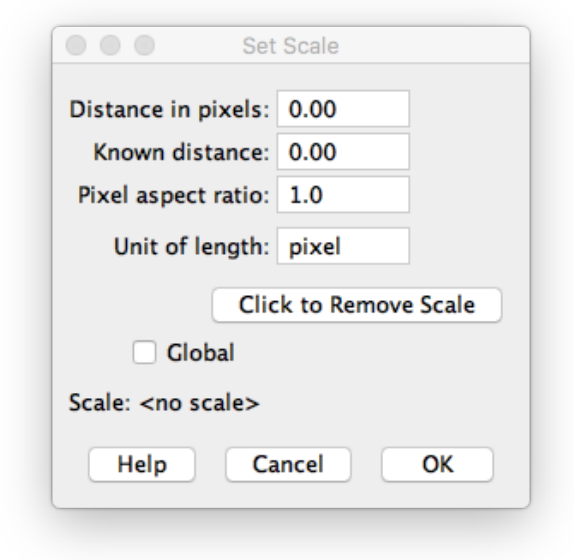

Abbildung 11: Skaleneinstellung

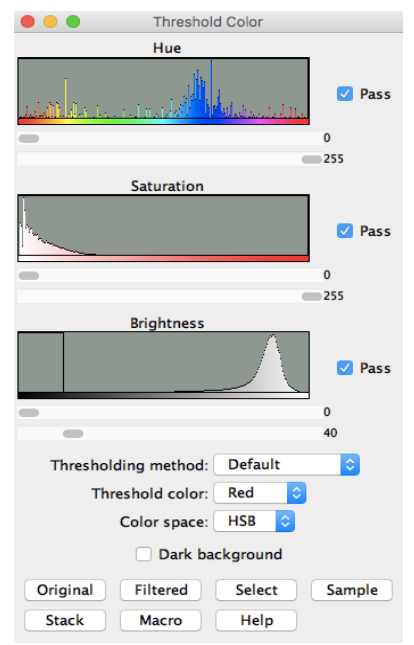

Abbildung 12: Funktion Threshold Color

Abbildung 11 zeigt die Skaleneinstellung in ImageJ vor der Analyse der Seminombilder. So ergibt sich für jede Aufnahme die identische Pixelanzahl. Abbildung 12 zeigt die Funktion Threshold Color in ImageJ. Dargestellt sind die verschiedenen Tool-Bars, die die Helligkeits-, Sättigungs- und Farbverteilung des aktuellen Bilds anzeigen. Durch justieren der Skalen lassen sich die immunhistochemisch gefärbten Bereiche (die Immunozyten) der Seminompräparate markieren.

So ergibt sich für jedes Bild eine Gesamtpixelzahl, die mit der Funktion Measure ausgegeben wurde. Um die Funktion Measure auf die immunhistochemisch gefärbten Entzündungszellen zu begrenzen, wurde die ImageJ Funktion Color Threshold verwendet. Color Threshold schließt durch benutzergesteuerte Regulation der Hui-, Saturation- und Brightness-Bar nur für den Benutzer relevante Bildbereiche mit in die folgende neue Evaluierung mit ein. Die so ermittelte Anzahl der Pixel steht stellverstretend für die Infiltration des untersuchten Subtyps der Entzündungszellen. Um den Anteil eines Subtyps am gesamten inflammatorischen Infiltrat beurteilen zu können, werden die ermittelten Pixel mit denen der CD45 -Färbung in Relation gesetzt. Im Folgenden (siehe Abbildung 13) ist der Prozess der Bildbearbeitung exemplarisch dargestellt: 


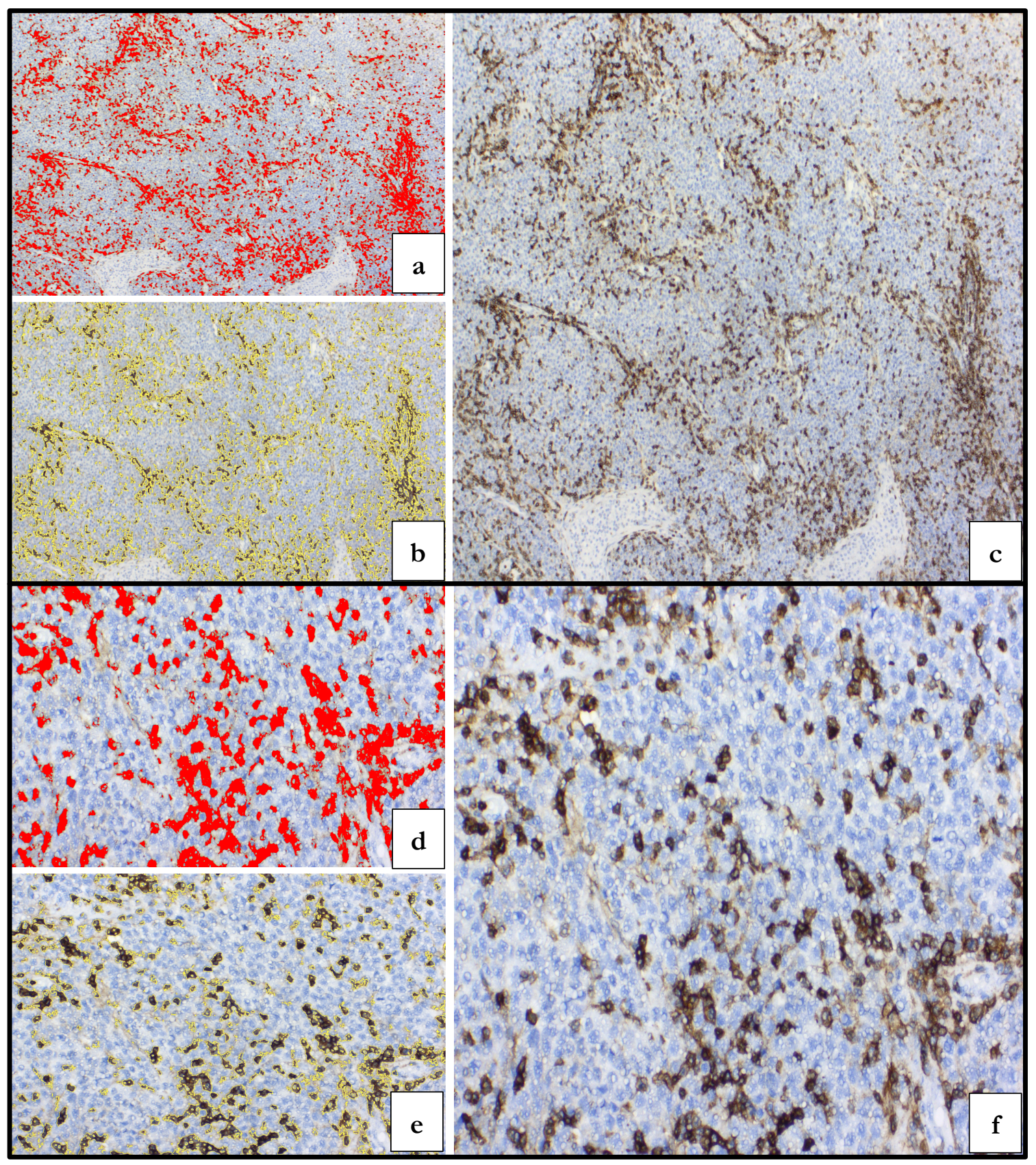

Abbildung 13: Seminom-Immunhistochemie im Analyseprozess mit ImageJ

Dargestellt sind die Aufnahmen eines Ausschnitts eines mit anti-CD45-AK immunhistochemisch aufgearbeiteten Seminoms in 100-fach Vergrößerung (a-c) und in 250-fach Vergrößerung $(\mathrm{d}-\mathrm{f})$ des identischen Präparats. Die Abbildungen $c$ und $f$ zeigen die Immunhistochemie eines Seminoms vor der Bearbeitung mit ImageJ. Die Abbildungen $a$ und $d$ zeigen die durch Justierung der Tool Bars mit rot markierten Lymphozyten. Die Aufnahmen $b$ und $e$ zeigen die zur Analyse gewählten Lymphozyten gelb umrahmt. 


\subsection{Statistische Auswertung}

Zur statistischen Auswertung der erhobenen Merkmale des Patientenkollektivs und der untersuchten immunhistochemischen Seminomschnitte mit der Programmiersprache R (Version 3.5.1) sind die in den folgenden Kapiteln beschriebenen Methoden zur Anwendung gekommen. Hierbei wird zwischen der deskriptiven und der analytischen Statistik unterschieden.

Das Signifikanzniveau wurde für alle Analysen auf $\alpha=5 \%(p<0,05)$ festgelegt.

\subsection{1 t-Test}

Der t-Test umschreibt eine Gruppe von Hypothesentests mit t-verteilter Testprüfgröße. Der Einstichproben-t-Test untersucht signifikante Unterschiede der Mittelwerte einer normalverteilten Grundgesamtheit und einer Stichprobe. Der Zweistichprobentest untersucht das Verhalten der Mittelwerte zweier unabhängiger Stichproben für zwei Grundgesamtheiten zueinander.

\subsubsection{Chi-Quadrat-Test}

Der Chi-Quadrat-Test untersucht, ob sich eine empirisch beobachtete Verteilung einer kategorialen Variablen von einer theoretisch erwarteten Häufigkeitsverteilung unterscheidet. Dazu wird der sog. Chi-Quadrat-Anpassungstest verwendet. Die Variable wird im Zuge dessen auf Signifikanz geprüft. In Abhängigkeit der Ergebnisse wird die untersuchte Nullhypothese verworfen oder bestätigt. Häufig werden Verteilungen von Variablen auf das Vorliegen einer Normalverteilung geprüft.

\subsubsection{Wilcoxon-Mann-Whitney-Test/ Wilcoxon-Rangsummen-Test/ U-Test}

Der Wilcoxon-Rangsummen-Test untersucht die Signifikanz der Übereinstimmung zweier gepaarter Verteilungen mit kontinuierlichen Variablen. Er dient als Alternative zum t-Test, wenn dessen Voraussetzungen (annähernde Normalverteilung) nicht erfüllt sind. Der U-Test untersucht zwei unverbundene Verteilungen auf signifikante Unterschiede.

\subsubsection{Analytische Statistik / Prädiktionsmodelle}

Die analytische Statistik (schließende bzw. deduktive Statistik) dient der Übertragung der in der deskriptiven Statistik beschriebenen und zusammengefassten Daten der Stichprobe auf 
die Grundgesamtheit. Sie untersucht dabei Zusammenhänge und prüft die Wahrscheinlichkeit für das zufällige Auftreten von Unterschieden bzw. Gemeinsamkeiten.

\subsubsection{Analyse binärer Variablen mittels logistischer Regression}

Die logistische Regression ist Teil der Regressionsanalysen, die der statistischen Auswertung der Beziehung einer abhängigen zu einer oder mehreren unabhängigen Variablen dient. Für diese Arbeit ist dabei vor allem die binomiale logistische Regression genutzt worden.

\subsubsection{Time-To-Event-Analyse mittels Cox Proportional Hazards}

Die Cox-Regression ist eine ereignisanalytische Methode zur Evaluierung des Einflusses unabhängiger Variablen auf die Zeit bis zum Eintreten eines Events bzw. der „Überlebenszeit“ (Time-To-Event-Analyse) oder Ihres Hazards. Die Hazardrate (Ausfallrate) untersucht dabei die Wahrscheinlichkeit eines Ereignisses zu einem definierten Zeitpunkt. Die Hazardratio vergleicht zwei Hazardraten. Für diese Arbeit kam die beschriebene statistische Methode zur Analyse der Eintrittwahrscheinlichkeit eines Rezidivs des erkrankten Patienten zur Anwendung. 


\section{Ergebnisse}

\subsection{Das Patientenkollektiv}

In den folgenden beiden Kapiteln wird das Patientenkollektiv beschrieben. Es handelt sich hierbei lediglich um den deskriptiven Teil der Follow-Up-Daten. Hierzu werden in Kapitel 3.1.1 die klinischen Daten und in Kapitel 3.1.2 die histopathologischen Charakteristika der Patienten und der Tumoren beschrieben.

\subsubsection{Beschreibung des Patientenkollektivs}

Die folgende Tabelle 5 stellt die wesentlichen Charakteristika des Patientenkollektivs anhand der erhobenen klinischen Follow-Up-Daten dar. Dabei sind die TNM-Klassifikation der Tumoren, das entsprechende klinische Stadium nach UICC und der Nachsorgezeitraum beschrieben. Anschließend an die tabellarische Darstellung werden die erwähnten Charakteristika näher beschrieben. Dabei wird beispielsweise auf die Lokalisation von Metastasen, das Zusammenfassen der klinischen Stadien, detaillierte Informationen zur Altersverteilung des Patientenkollektivs und das Auftreten von rezidivierenden Krankheitsverläufen eingegangen.

Die angegebenen Prozentzahlen beziehen sich jeweils auf die konstruierten Kollektive („Total“, „kein Rezidiv“ und „Rezidiv“) der entsprechenden Spalte. Das maximale Alter bei Diagnosestellung lag bei 74 Jahren, das Minimum im 19. Lebensjahr. $18 \%$ der Patienten bekamen ein Rezidiv. Die Dauer bis zu einem Rezidiv nach Diagnosestellung lag bei 16.38 $( \pm 11,09)$ Monaten. Das Alter zum Zeitpunkt eines Rezidivs lag bei 38,48 ( $\pm 11,02)$ Jahren. Bei den zwei Patienten mit T-Stadium 0 handelt es sich um ausgebrannte Seminome. Das klinische Stadium nach UICC ist hier zusammengefasst beschrieben (1 = Ia, Ib, Is; 2 = IIac; 3 = IIIa-c). Die fünf in der TNM-Klassifikation angegebenen Fernmetastasen sind in zwei Fällen Organmetastasen (hepatisch/pulmonal und ossär), einmal pulmonal und in mediastinalen Lymphknoten und zweimal supradiaphragmal bzw. supraclaviculär lokalisiert. 
Tabelle 5: Das Patientenkollektiv

\begin{tabular}{|c|c|c|c|c|}
\hline & $\begin{array}{c}\text { Total } \\
\mathrm{n}=92\end{array}$ & $\begin{array}{c}\text { kein Rezidiv } \\
\mathrm{n}=75\end{array}$ & $\begin{array}{c}\text { Rezidiv } \\
\mathrm{n}=17\end{array}$ & p-Wert \\
\hline $\begin{array}{l}\text { Alter bei Diagnose- } \\
\text { stellung }\end{array}$ & $42,01( \pm 12,01)$ & $43,13( \pm 12,03)$ & $37,06( \pm 10,92)$ & 0,067 \\
\hline \multicolumn{4}{|l|}{$\mathbf{T}$} & 0,69 \\
\hline 0 & $2(2,17 \%)$ & $2(2,67 \%)$ & $0(0,00 \%)$ & \\
\hline 1 & $70(76,09 \%)$ & $56(74,67 \%)$ & $14(82,35 \%)$ & \\
\hline 2 & $17(18,48 \%)$ & $15(20,00 \%)$ & $2(11,76 \%)$ & \\
\hline 3 & $3(3,26 \%)$ & $2(2,67 \%)$ & $1(5,88 \%)$ & \\
\hline \multicolumn{4}{|l|}{$\mathbf{N}$} & 0,30 \\
\hline 0 & $78(84,78 \%)$ & $63(84,00 \%)$ & $15(88,24 \%)$ & \\
\hline 1 & $1(1,09 \%)$ & $1(1,33 \%)$ & $0(0,00 \%)$ & \\
\hline 2 & $5(5,43 \%)$ & $3(4,00 \%)$ & $2(11,76 \%)$ & \\
\hline 3 & $8(8,70 \%)$ & $8(10,67 \%)$ & $0(0,00 \%)$ & \\
\hline \multicolumn{4}{|l|}{ M } & 0,58 \\
\hline 0 & $87(94,57 \%)$ & $70(93,33 \%)$ & $17(100,00 \%)$ & \\
\hline 1 & $5(5,43 \%)$ & $5(6,67 \%)$ & $0(0,00 \%)$ & \\
\hline \multicolumn{4}{|c|}{ klinisches Stadium nach UICC } & 1,00 \\
\hline 1 & $79(85,87 \%)$ & $63(84,00 \%)$ & $16(94,12 \%)$ & \\
\hline 2 & $9(9,78 \%)$ & $8(10,67 \%)$ & $1(5,88 \%)$ & \\
\hline 3 & $4(4,35 \%)$ & $4(5,33 \%)$ & $0(0,00 \%)$ & \\
\hline \multicolumn{4}{|l|}{ Nachsorgezeitraum } & 0,23 \\
\hline Mean (SD) & $28,74( \pm 27,56)$ & $27,93( \pm 28,78)$ & $32,24( \pm 21,99)$ & \\
\hline Fehlend & $2(2,17 \%)$ & $2(2,67 \%)$ & $0(0 \%)$ & \\
\hline \multicolumn{5}{|c|}{ Nachsorgezeitraum angegeben in Monaten } \\
\hline
\end{tabular}




\subsubsection{Beschreibung der histopathologischen Befunde}

Tabelle 6 fasst die histopathologischen Charakteristika der zur Diagnosestellung untersuchten Orchiektomie-Präparate zusammen. Hier aufgeführt sind die relevanten Eigenschaften der Tumoren: Tumorgröße, Lymphgefäßinvasion, Gefäßinvasion, Rete testis-Infiltration und Samenstranginfiltration.

Tabelle 6: Histopathologische Charakteristika der Seminome

\begin{tabular}{|c|c|c|c|c|}
\hline & $\begin{array}{c}\text { Total } \\
\mathrm{n}=92\end{array}$ & $\begin{array}{c}\text { kein Rezidiv } \\
\mathrm{n}=75\end{array}$ & $\begin{array}{c}\text { Rezidiv } \\
\mathbf{n}=17\end{array}$ & p-Wert \\
\hline Tumorgröße & $3,80( \pm 2,25)$ & $3,80( \pm 2,37)$ & $3,80( \pm 1,62)$ & 0,87 \\
\hline Fehlend & $1(1,09 \%)$ & $0(0 \%)$ & $1(5,88 \%)$ & \\
\hline \multicolumn{4}{|c|}{ Lymphgefäßinvasion } & 0,68 \\
\hline nein & $81(88,04 \%)$ & $65(86,67 \%)$ & $16(94,12 \%)$ & \\
\hline ja & $11(11,96 \%)$ & $10(13,33 \%)$ & $1(5,88 \%)$ & \\
\hline \multicolumn{4}{|l|}{ Gefäßinvasion } & 0,51 \\
\hline nein & $74(80,43 \%)$ & $59(78,67 \%)$ & $15(88,24 \%)$ & \\
\hline ja & $18(19,57 \%)$ & $16(21,33 \%)$ & $2(11,76 \%)$ & \\
\hline \multicolumn{4}{|c|}{ Rete testis-Infiltration } & 0,78 \\
\hline nein & $53(57,61 \%)$ & $44(58,67 \%)$ & $9(52,94 \%)$ & \\
\hline ja & $33(35,87 \%)$ & $26(34,67 \%)$ & $7(41,18 \%)$ & \\
\hline Fehlend & $6(6,52 \%)$ & $5(6,67 \%)$ & $1(5,88 \%)$ & \\
\hline \multicolumn{4}{|c|}{ Samenstranginfiltration } & 1,00 \\
\hline nein & $83(90,22 \%)$ & $68(90,67 \%)$ & $15(88,24 \%)$ & \\
\hline ja & $6(6,52 \%)$ & $5(6,67 \%)$ & $1(5,88 \%)$ & \\
\hline Fehlend & $3(3,26 \%)$ & $2(2,67 \%)$ & $1(5,88 \%)$ & \\
\hline
\end{tabular}

Die angegebenen Prozentzahlen beziehen sich jeweils auf die konstruierten Kollektive (,Total“, „kein Rezidiv“ und „Rezidiv“) der entsprechenden Spalte. Die unter „Fehlend“ klassifizierten Charakteristika zur Samenstranginfiltration und zur Rete testis-Infiltration entstehen durch fehlende Angaben in den pathologischen Hauptbefunden.

\subsubsection{Primärtherapie}

Die Primärtherapie umfasst alle getroffenen Maßnahmen (Operation, Chemotherapie, Bestrahlung und Active Surveillance), die vor der Diagnosestellung eines Rezidivs getätigt wurden. 
Wurde eine Patient beispielsweise orchiektomiert und adjuvant mit Chemotherapie behandelt, fallen beide therapeutischen Maßnahmen unter den Begriff der Primärtherapie und werden hier geführt. Die Charakteristika der Primärtherapie des vorliegenden Kollektivs beschreibt Tabelle 7. Davon zu unterscheiden ist die im folgenden Kapitel beschriebene Rezidivtherapie. Alle Patienten haben, neben den in Tabelle 7 dargestellten adjuvanten Therapieverfahren, eine primäre Orchiektomie erhalten.

Tabelle 7: Primärtherapie

\begin{tabular}{|c|c|c|c|c|}
\hline & $\begin{array}{c}\text { Total } \\
\mathrm{n}=92\end{array}$ & $\begin{array}{c}\text { kein Rezidiv } \\
\mathrm{n}=75\end{array}$ & $\begin{array}{c}\text { Rezidiv } \\
\mathrm{n}=17\end{array}$ & p-Wert \\
\hline \multicolumn{4}{|c|}{ Active Surveillance } & 0,17 \\
\hline nein & $29(31,52 \%)$ & $26(34,67 \%)$ & $3(17,65 \%)$ & \\
\hline ja & $60(65,22 \%)$ & $46(61,33 \%)$ & $14(82,35 \%)$ & \\
\hline Fehlend & $3(3,26 \%)$ & $3(4,00 \%)$ & $0(0,00 \%)$ & \\
\hline \multicolumn{4}{|c|}{ Chemotherapie } & 0,059 \\
\hline nein & $55(59,78 \%)$ & $41(54,67 \%)$ & $14(82,35 \%)$ & \\
\hline ja & $34(36,96 \%)$ & $31(41,33 \%)$ & $3(17,65 \%)$ & \\
\hline Fehlend & $3(3,26 \%)$ & $3(4,00 \%)$ & $0(0,00 \%)$ & \\
\hline \multicolumn{4}{|l|}{ Radiatio } & 0,34 \\
\hline nein & $88(95,65 \%)$ & $72(96,00 \%)$ & $16(94,12 \%)$ & \\
\hline ja & $2(2,17 \%)$ & $1(1,33 \%)$ & $1(5,88 \%)$ & \\
\hline Fehlend & $2(2,17 \%)$ & $2(2,67 \%)$ & $0(0,00 \%)$ & \\
\hline \multicolumn{4}{|c|}{ Retroperitoneale Lymphadenektomie } & 1,0 \\
\hline nein & $84(91,30 \%)$ & $68(90,67 \%)$ & $16(94,12 \%)$ & \\
\hline ja & $6(6,52 \%)$ & $5(6,67 \%)$ & $1(5,88 \%)$ & \\
\hline Fehlend & $2(2,17 \%)$ & $2(2,67 \%)$ & $0(0,00 \%)$ & \\
\hline
\end{tabular}

Die angegebenen Prozentzahlen beziehen sich jeweils auf die konstruierten Kollektive (,Total“, „kein Rezidiv“ und „Rezidiv“) der entsprechenden Spalte. Unter die Therapieoption Chemotherapie fallen sowohl die Polychemotherapie (3-4 Zyklen PEB oder PEI) und die adjuvante Monochemotherapie mit Cisplatin. Sechs Patienten haben sowohl eine retroperitoneale Lymphadenektomie wie eine Polychemotherapie mit drei bzw. vier Zyklen PEB erhalten. Einer dieser Patienten wurde zusätzlich bestrahlt. Ein Patient erhielt eine RadioChemo-Therapie. Im CS1 wurden 60 Patienten im Rahmen von AS beobachtet. Bei 14 (23,3 $\%$ dieser Patienten wurde ein Rezidiv diagnostiziert. 14 CS1-Patienten erhielten einen 
Zyklus Cisplatin. Im Verlauf zeigte sich bei zwei dieser 14 Patienten ein Rezidiv (14,29\%). Zwei weitere Patienten wurden adjuvant bestrahlt.

\subsubsection{Rezidivtherapie}

Die folgende Tabelle 8 beschreibt die Therapie eines Rezidivs. Ein klinischer Verlauf mit Rezidiv wird definiert als erneuter therapeutischer Handlungsbedarf nach abgeschlossener Primärtherapie. In der Regel stellten bildgebende Nachsorgeuntersuchungen (CT bzw. MRT) ein Rezidiv im Verlauf fest.

Tabelle 8: Rezidivtherapie

\begin{tabular}{|c|c|}
\hline & $\begin{array}{l}\text { Total } \\
\mathrm{n}=17\end{array}$ \\
\hline Chems & \\
\hline nein & $2(11,76 \%)$ \\
\hline ja & $15(88,24 \%)$ \\
\hline Radiat & \\
\hline nein & $14(82,34 \%)$ \\
\hline ja & $3(17,65 \%)$ \\
\hline Retrop & \\
\hline nein & $15(88,24 \%)$ \\
\hline ja & $2(11,76 \%)$ \\
\hline
\end{tabular}

15 von 17 Patienten mit einem gesicherten Rezidiv wurden mit Polychemotherapie (3 bzw. 4 Zyklen PEB) therapiert. Zwei Patienten wurden sowohl mittels Polychemotherapie wie auch einer anschließenden retroperitonealen Lymphadenektomie behandelt. Ein Patient erhielt eine kombinierte Radio-Chemo-Therapie.

\subsubsection{Tumormarker}

Tumormarker sind wesentlicher Bestandteil der Diagnostik und der Beurteilung des klinischen Verlaufs der Patienten. Tabelle 9 beschreibt die Konzentrationen der verschiedenen Tumormarker (AFP, LDH und B-hCG), die vor der Einleitung der Primärtherapie abgenommen wurden. 
Tabelle 9: Tumormarker

\begin{tabular}{|c|c|c|c|c|}
\hline & $\begin{array}{c}\text { Total } \\
\mathrm{n}=92 \\
\end{array}$ & $\begin{array}{c}\text { kein Rezidiv } \\
\mathrm{n}=75\end{array}$ & $\begin{array}{c}\text { Rezidiv } \\
\mathrm{n}=17\end{array}$ & p-Wert \\
\hline \multicolumn{4}{|l|}{ AFP } & 0,86 \\
\hline Mean (SD) & $3,50( \pm 6,05)$ & $3,76( \pm 6,66)$ & $2,41( \pm 1,94)$ & \\
\hline Fehlend & $4(4,35 \%)$ & $4(5,33 \%)$ & $0(0 \%)$ & \\
\hline \multicolumn{4}{|l|}{ AFP erhöht } & 0,58 \\
\hline nein & $84(91,30 \%)$ & $67(89,33 \%)$ & $17(100,00 \%)$ & \\
\hline ja & $5(5,43 \%)$ & $5(6,67 \%)$ & $0(0,00 \%)$ & \\
\hline Fehlend & $3(3,26 \%)$ & $3(4,00 \%)$ & $0(0,00 \%)$ & \\
\hline \multicolumn{4}{|l|}{ B-hCG } & 0,48 \\
\hline Mean (SD) & $55,20( \pm 275,86)$ & $67,86( \pm 307,07)$ & $3,69( \pm 4,63)$ & \\
\hline Fehlend & $16(17,39 \%)$ & $14(18,67 \%)$ & $2(11,76 \%)$ & \\
\hline \multicolumn{4}{|c|}{ B-hCG erhöht } & 0,063 \\
\hline nein & $50(54,35 \%)$ & $44(58,67 \%)$ & $6(35,29 \%)$ & \\
\hline ja & $39(42,39 \%)$ & $28(37,33 \%)$ & $11(64,71 \%)$ & \\
\hline Fehlend & $3(3,26 \%)$ & $3(4,00 \%)$ & $0(0,00 \%)$ & \\
\hline \multicolumn{4}{|l|}{ LDH } & 0,78 \\
\hline Mean (SD) & $327,01( \pm 247,79)$ & $335,40( \pm 265,46)$ & $294,94( \pm 166,08)$ & \\
\hline Fehlend & $10(10,87 \%)$ & $10(13,33 \%)$ & $0(0 \%)$ & \\
\hline \multicolumn{4}{|l|}{ LDH erhöht } & 1,00 \\
\hline nein & $45(48,91 \%)$ & $36(48,00 \%)$ & $9(52,94 \%)$ & \\
\hline ja & $44(47,83 \%)$ & $36(48,00 \%)$ & $8(47,06 \%)$ & \\
\hline Fehlend & $3(3,26 \%)$ & $3(4,00 \%)$ & $0(0,00 \%)$ & \\
\hline
\end{tabular}

Angegeben sind die präoperativ bestimmten Tumormarker der Patienten. Dabei sind einerseits die Mittelwerte der verschiedenen Kollektive (vollständiges Kollektiv, Kollektiv der Patienten ohne Rezidiv und Kollektiv der Patienten mit einem Rezidiv), andererseits die dichotomisierten Analysen der selben Kollektive dargestellt. Der Cut-Off-Wert zur Einteilung in erhöhte bzw. normale Tumormarkerkonzentrationen (Dichotomisierung) wurde entsprechend der aktuellen Leitlinien festgelegt und entspricht denen der Universitätsmedizin Göttingen. Er liegt für AFP bei 1-9 $\mu \mathrm{g} / \mathrm{I}$, für $\beta$-hCG bei <0,9 IU/I und für LDH bei <248 U/I. Angegeben sind die präoperativ bestimmten Tumormarker. 


\subsection{Beschreibung der speziellen Immunhistochemie}

In den folgenden Kapiteln 3.2.1 und 3.2.2 werden die Ergebnisse der neben der Routinediagnostik speziell im Rahmen dieser Arbeit angefertigten immunhistochemischen Seminompräparate beschrieben. Dabei wird zwischen der mikroskopischen Auswertung (Methode beschrieben in Kapitel 2.3.1.1) und der Auswertung mit ImageJ unterschieden (Methode beschrieben in Kapitel 2.3.1.2). Kapitel 3.2.3 stellt beide Methoden einander gegenüber. Insgesamt wurden Paraffinschnitte von 73 Patienten mittels immunhistochemischer Marker mikroskopisch untersucht. Aus verschiedenen Gründen standen die Tumoren der fehlenden 19 Patienten nicht zur immunhistochemischen Aufarbeitung zur Verfügung. So wurden bspw. vier Patienten nicht in der Klinik für Urologie der UMG orchiektomiert. Fünf Tumoren ließen sich im Rahmen von massiven entzündlichen Prozessen nicht mehr für diagnostische Zwecke adäquat aufarbeiten. Drei Patienten haben lediglich ihr Einverständnis zum Gebrauch der klinischen Daten gegeben und stimmten einer Aufarbeitung und Analyse ihrer Hodentumorfrischgewebe nicht zu. Von vier Patienten konnten keine Lokalisierung des Paraffinmaterials im Archiv erfolgen. Eine weitere Reduktion der Anzahl der im Ergebnisteil aufgeführten Schnitte beider Methoden erklärt sich durch von PD Dr. F. Bremmer als „nicht-auswertbar“ klassifizierte Schnitte in der mikroskopischen Auswertung. Unter diese Kategorie fallen acht angefertigte immunhistochemische Schnitte der Färbung mit Anti$\mathrm{CD} 45^{+}$.

\subsubsection{Mikroskopische Auswertung der speziellen Immunhistochemie}

Tabelle 10 beschreibt die Ergebnisse der mikroskopischen Auswertung (Methode beschrieben in Kapitel 2.3.1-2.3.1.1) der immunhistochemischen Schnitte.

Tabelle 10: Mikroskopische Auswertung des entzündlichen Infiltrats

\begin{tabular}{|l|c|r|r|}
\hline & $\begin{array}{c}\text { Total } \\
\mathbf{n}=\mathbf{9 2}\end{array}$ & $\begin{array}{c}\text { kein Rezidiv } \\
\mathbf{n}=\mathbf{7 5}\end{array}$ & $\begin{array}{c}\text { Rezidiv } \\
\mathbf{n}=\mathbf{1 7}\end{array}$ \\
\hline \multicolumn{3}{|l}{ Entzündliches Infiltrat (CD45) } \\
\hline Mean $(\mathrm{SD})$ & $23 \%( \pm 0,14)$ & $23 \%( \pm 0,14)$ & $22 \%( \pm 0,11)$ \\
\hline Fehlend & $19(20,65 \%)$ & $16(21,33 \%)$ & $3(17,65 \%)$ \\
\hline
\end{tabular}

Die tabellarisch dargestellten Prozentangaben stellen sowohl für das gesamte Kollektiv als auch für die konstruierten Kollektive „,kein Rezidiv“ und „Rezidiv“ den prozentualen Anteil der mikroskopisch ermittelten Mengen des entzündlichen Infiltrats am gesamten mikroskopisch untersuchten Präparat dar. Es liegen prozentual kaum Unterschiede zwischen den 
Kollektiven „Rezidiv“ und „kein Rezidiv“ bzgl. des Anteils des entzündlichen Infiltrats am Gesamttumor vor.

\subsubsection{ImageJ Auswertung der speziellen Immunhistochemie}

Die folgende Tabelle 11 zeigt die Ergebnisse der mittels ImageJ analysierten immunhistochemischen Seminomschnitte. Dargestellt sind die Ergebnisse der Analysen der immunhistochemischen Hodentumoren mittels ImageJ. Das gesamte Kollektiv wird in rezidivierende und nichtrezidivierende Krankheitsverläufe geteilt. Die in der Tabelle aufgeführten Zahlen stellen das Verhältnis eines immunhistochemisch gefärbten Zelltyps zu einem anderen dar. So lässt sich der Anteil der gesamten Immunozyten am Gesamtbild (siehe Reihe „Entzündliches Infiltrat) berechnen. Anschließend können die Anteile der lymphozytären Subtypen am gesamten entzündlichen Infiltrat $\left(\mathrm{CD} 45^{+}\right)$bestimmt werden. Die Reihe $\mathrm{CD} 4^{+} / \mathrm{CD}^{+}{ }^{-}$ Ratio gibt das Verhältnis der T-Helferzellen zu zytotoxischen T-Zellen an.

Tabelle 11: Spezielle Immunhistochemie der Seminome

\begin{tabular}{|c|c|c|c|c|}
\hline & $\begin{array}{c}\text { Total } \\
\mathrm{n}=92\end{array}$ & $\begin{array}{c}\text { kein Rezidiv } \\
n=75\end{array}$ & $\begin{array}{c}\text { Rezidiv } \\
\mathrm{n}=17\end{array}$ & p-Wert \\
\hline \multicolumn{4}{|c|}{ Entzündliches Infiltrat (CD45/Gesamtpixelzahl) } & 0,17 \\
\hline Mean (SD) & $0,25( \pm 0,12)$ & $0,24( \pm 0,13)$ & $0,29( \pm 0,11)$ & \\
\hline Fehlend & $19(20,65 \%)$ & $16(21,33 \%)$ & $3(17,65 \%)$ & \\
\hline \multicolumn{4}{|c|}{ T-Zell-Infiltration (CD3/CD45) } & 0,57 \\
\hline Mean (SD) & $0,50( \pm 0,43)$ & $0,51( \pm 0,47)$ & $0,44( \pm 0,15)$ & \\
\hline Fehlend & $19(20,65 \%)$ & $16(21,33 \%)$ & $3(17,65 \%)$ & \\
\hline \multicolumn{4}{|c|}{ B-Zell-Infiltration (CD20/CD45) } & 0,65 \\
\hline Mean (SD) & $0,29( \pm 0,47)$ & $0,30( \pm 0,52)$ & $0,24( \pm 0,14)$ & \\
\hline Fehlend & $19(20,65 \%)$ & $16(21,33 \%)$ & $3(17,65 \%)$ & \\
\hline \multicolumn{4}{|c|}{ T-Zell-/B-Zell-Verhältnis $\left(\mathrm{CD}^{+} / \mathrm{CD}^{2} 0^{+}\right)$} & 0,21 \\
\hline Mean (SD) & $2,88( \pm 2,18)$ & $3,03( \pm 2,36)$ & $2,22( \pm 0,91)$ & \\
\hline Fehlend & $19(20,65 \%)$ & $16(21,33 \%)$ & $3(17,65 \%)$ & \\
\hline \multicolumn{4}{|c|}{$\mathrm{CD}^{+}-\mathrm{T}-$ Zell-Infiltration $\left(\mathrm{CD}^{+} / \mathrm{CD}^{+} 5^{+}\right)$} & 0,51 \\
\hline Mean (SD) & $0,68( \pm 0,53)$ & $0,70( \pm 0,57)$ & $0,59( \pm 0,30)$ & \\
\hline Fehlend & $19(20,65 \%)$ & $16(21,33 \%)$ & $3(17,65 \%)$ & \\
\hline \multicolumn{4}{|c|}{$\mathrm{CD}^{+}-\mathrm{T}-$ Zell-Infiltration $\left(\mathrm{CD}^{+} / \mathrm{CD}^{4} 5^{+}\right)$} & 0,61 \\
\hline Mean (SD) & $0,51( \pm 0,83)$ & $0,54( \pm 0,91)$ & $0,41( \pm 0,26)$ & \\
\hline
\end{tabular}




\begin{tabular}{|l|c|c|c|c|}
\hline & \multicolumn{1}{|c|}{$\begin{array}{c}\text { Total } \\
\mathbf{n}=\mathbf{9 2}\end{array}$} & $\begin{array}{c}\text { kein Rezidiv } \\
\mathbf{n}=\mathbf{7 5}\end{array}$ & $\begin{array}{c}\text { Rezidiv } \\
\mathbf{n}=\mathbf{1 7}\end{array}$ & p-Wert \\
\hline Fehlend & $19(20,65 \%)$ & $16(21,33 \%)$ & $3(17,65 \%)$ & \\
\hline $\mathbf{C D 4}^{+} / \mathbf{C D 8}^{+}$-Ratio & & 0,43 \\
\hline Mean (SD) & $1,84( \pm 1,00)$ & $1,89( \pm 1,05)$ & $1,65( \pm 0,75)$ & \\
\hline Fehlend & $19(20,65 \%)$ & $16(21,33 \%)$ & $3(17,65 \%)$ & \\
\hline
\end{tabular}

Das entzündliche Infiltrat im Verhältnis zum Resttumorgewebe macht bei dem gesamten Kollektiv $25 \%$ (SD \pm 0.12$)$, bei Patienten ohne Rezidiv $24 \%(\mathrm{SD} \pm 0,13)$ und bei Patienten mit rezidivierendem Krankheitsverlauf $29 \%$ (SD $\pm 0,11)$ aus. Dabei macht das T-Zell-Infiltrat im gesamten Kollektiv ca. 50 \% $(\mathrm{SD} \pm 0,43)$ des gesamten entzündlichen Infiltrats aus. Bei Patienten mit einem Rezidiv liegt dieses Verhältnis mit 44\% (SD $\pm 0,15)$ darunter. Das Verhältnis von T-zu B-Zellen liegt insgesamt bei 2,88 (SD $\pm 2,18)$. Insgesamt liegt der Anteil an T-Helferzellen $\left(\mathrm{CD}^{+}\right)$am gesamten entzündlichen Infiltrat über dem der zytotoxischen TZellen $\left(\mathrm{CD} 8^{+}\right)$.

\subsubsection{Gegenüberstellung beider Methoden zur Analyse des inflammatorischen Infiltrats}

In diesem Kapitel werden die Ergebnisse der Quantifizierung der Quantität des entzündlichen Infiltrats aus den beiden vorherigen Kapiteln einander gegenübergestellt. Dies dient zum einen der Validierung der Ergebnisse der Methode mit ImageJ und kann zusätzlich durch die Kombination beider Methoden genauere Ergebnisse liefern. Das lymphozytäre Infiltrat wird für beide Methoden den in Kapitel 2.4.1.1 beschriebenen Kategorien zugeordnet (siehe Tabelle 13). Tabelle 12 stellt die Ergebnisse prozentual dar.

Tabelle 12: Das entzündliche Infiltrat - Übersicht der Auswertungsmethoden

\begin{tabular}{|c|c|c|}
\hline \multicolumn{3}{|c|}{ Entzündliches Infiltrat (CD45 $\left.{ }^{+}\right)$} \\
$\mathbf{n}=73$ \\
\hline Mikroskopische Analyse & Analyse mit Image & Abweichung \\
\hline $23 \%$ & $25 \%$ & $2 \%$ \\
\hline Angegeben: Mittelwerte & \\
\hline
\end{tabular}

Dargestellt sind die Ergebnisse der Analyse des Anteils des entzündlichen Infiltrats am restlichen Tumorgewebe beider gewählten Methoden (Analyse mit ImageJ und mikroskopische Auswertung). Das Kollektiv zeigt bei der mikroskopischen Analyse einen Anteil des entzündlichen Infiltrats von $23 \%$ und bei der Auswertung mit ImageJ einen Anteil von $25 \%$. 
Tabelle 13: Das entzündliche Infiltrat - Gegenüberstellung beider Auswertungsmethoden

\begin{tabular}{|c|c|c|c|c|}
\hline \multicolumn{5}{|c|}{$\begin{array}{l}\text { Entzündliches Infiltrat }\left(\mathrm{CD} 45^{+}\right) \\
\qquad \mathrm{n}=73\end{array}$} \\
\hline & Kategorie & $\begin{array}{c}\text { Mikroskopische } \\
\text { Analyse }\end{array}$ & $\begin{array}{l}\text { Analyse mit } \\
\text { ImageJ }\end{array}$ & Abweichung \\
\hline \multirow[t]{5}{*}{$\begin{array}{l}\text { Kategorie des } \\
\text { entzündlichen } \\
\text { Infiltrats }\end{array}$} & $\begin{array}{l}\text { 1. kein Infilt- } \\
\text { rat } \\
(0 \%)\end{array}$ & 0 & 0 & 0 \\
\hline & $\begin{array}{l}\text { 2. mildes In- } \\
\text { filtrat } \\
(1 \%-19 \%)\end{array}$ & 28 & 25 & 3 \\
\hline & $\begin{array}{l}\text { 3. mäßiges In- } \\
\text { filtrat } \\
(20 \%-39 \%)\end{array}$ & 37 & 38 & 1 \\
\hline & $\begin{array}{l}\text { 4. reichlich In- } \\
\text { filtrat } \\
(40 \%-74 \%)\end{array}$ & 8 & 10 & 2 \\
\hline & $\begin{array}{l}\text { 5. massives } \\
\text { Infiltrat } \\
(75 \%-100 \%)\end{array}$ & 0 & 0 & 0 \\
\hline \multicolumn{2}{|l|}{ Gesamt } & 73 & 73 & 6 \\
\hline
\end{tabular}

Insgesamt stellt sich das entzündliche Infiltrat der Seminome sehr heterogen dar. So wurden sowohl Tumoren mit minimaler Immunozyten-Infiltration wie auch Tumoren mit einer sehr ausgeprägten Infiltration beobachtet. $86 \%$ der untersuchten Seminome zeigten in der Analyse mit ImageJ ein inflammatorisches Infiltrat zwischen $1 \%$ und $39 \%$ im Verhältnis zum restlichen Gewebe. Bei 64 \% der Seminome wurde der Anteil der entzündlichen Zellen mit $>20 \%$ bestimmt.

Die Heterogenität des entzündlichen Infiltrats ist in den folgenden Abbildungen exemplarisch veranschaulicht. Dargestellt sind mit anti-CD45-AK immunhistochemisch gefärbte Seminome mit mildem entzündlichem Infiltrat (siehe Abbildung 14), mit reichlich Infiltrat (siehe Abbildung 15) und mit massiver entzündlicher Infiltration (siehe Abbildung 16). Die 
darauffolgenden Abbildungen 17 und 18 zeigen Aufnahmen von einerseits einem mit anti$\mathrm{CD}^{+}$(T-Zell-Marker) und andererseits einem anti-CD20 (B-Zell-Marker) immunhistochemisch gefärbten Seminom. Alle erwähnten Abbildungen zeigen eine Übersichtsaufnahme (rund dargestellt) in 100-facher Vergrößerung und eine Aufnahme mit deutlicher Vergrößerung (250-fach Vergrößerung). So soll sowohl ein repräsentativer Eindruck der Verteilung der Zellen über das gesamte Präparat, als auch auch von den einzelnen Zellen geschaffen werden.

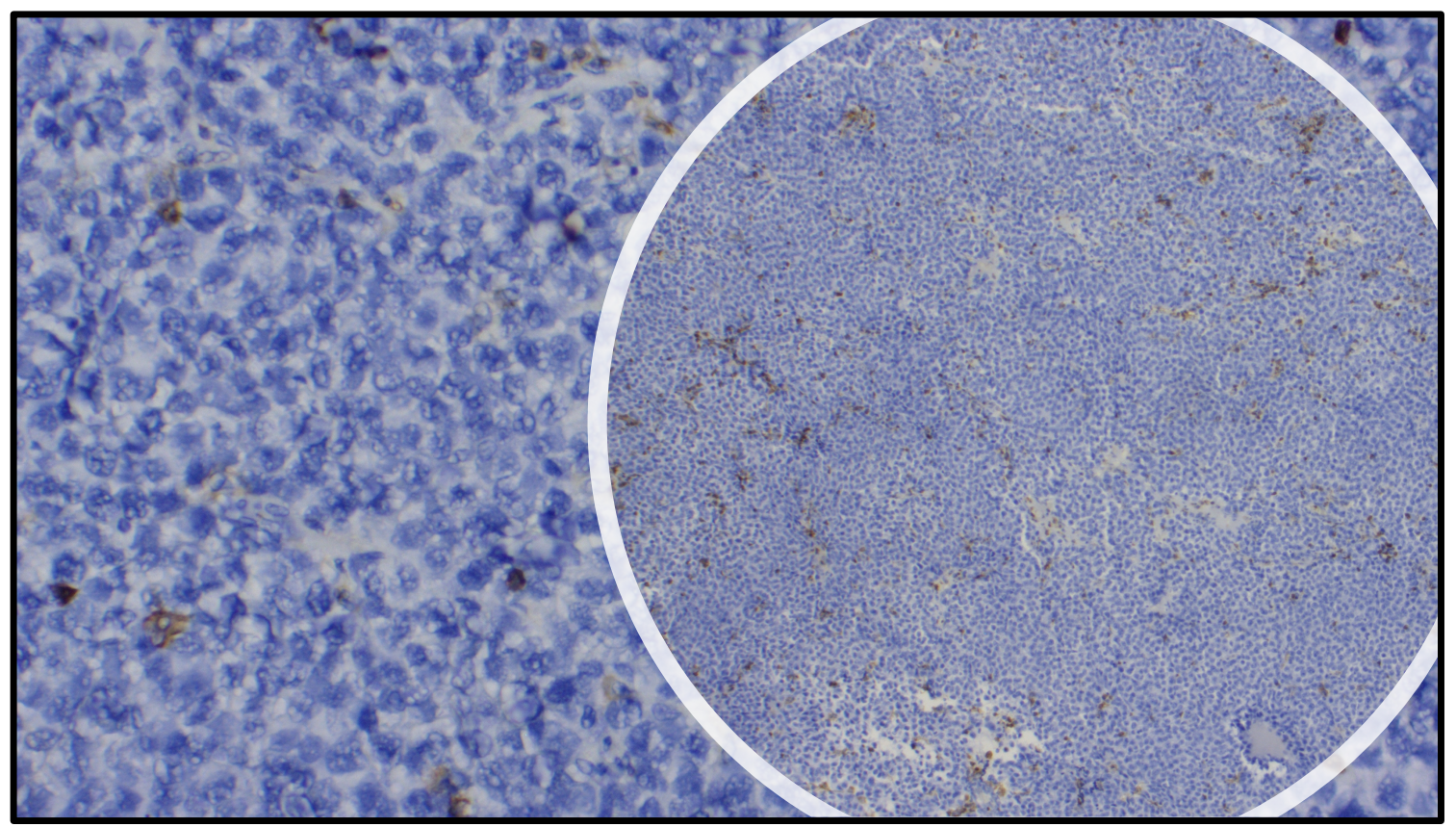

Abbildung 14: Seminom mit milder entzündlicher Infiltration

Die bräunlich-schwarz imponierenden Zellen stellen Immunozyten dar (CD45 $5^{+}$Zellen). Im Vergleich zu den folgenden Abbildungen (Abbildung 15 und 16) zeigen sich deutlich weniger Zellen mit diesem positiven Färbungsverhalten. In der Übersicht (rundlicher Teil der Abbildung) wird deutlich, dass nur wenig entzündliches Infiltrat im Verhältnis zur Gesamtzellzahl vorliegt. 


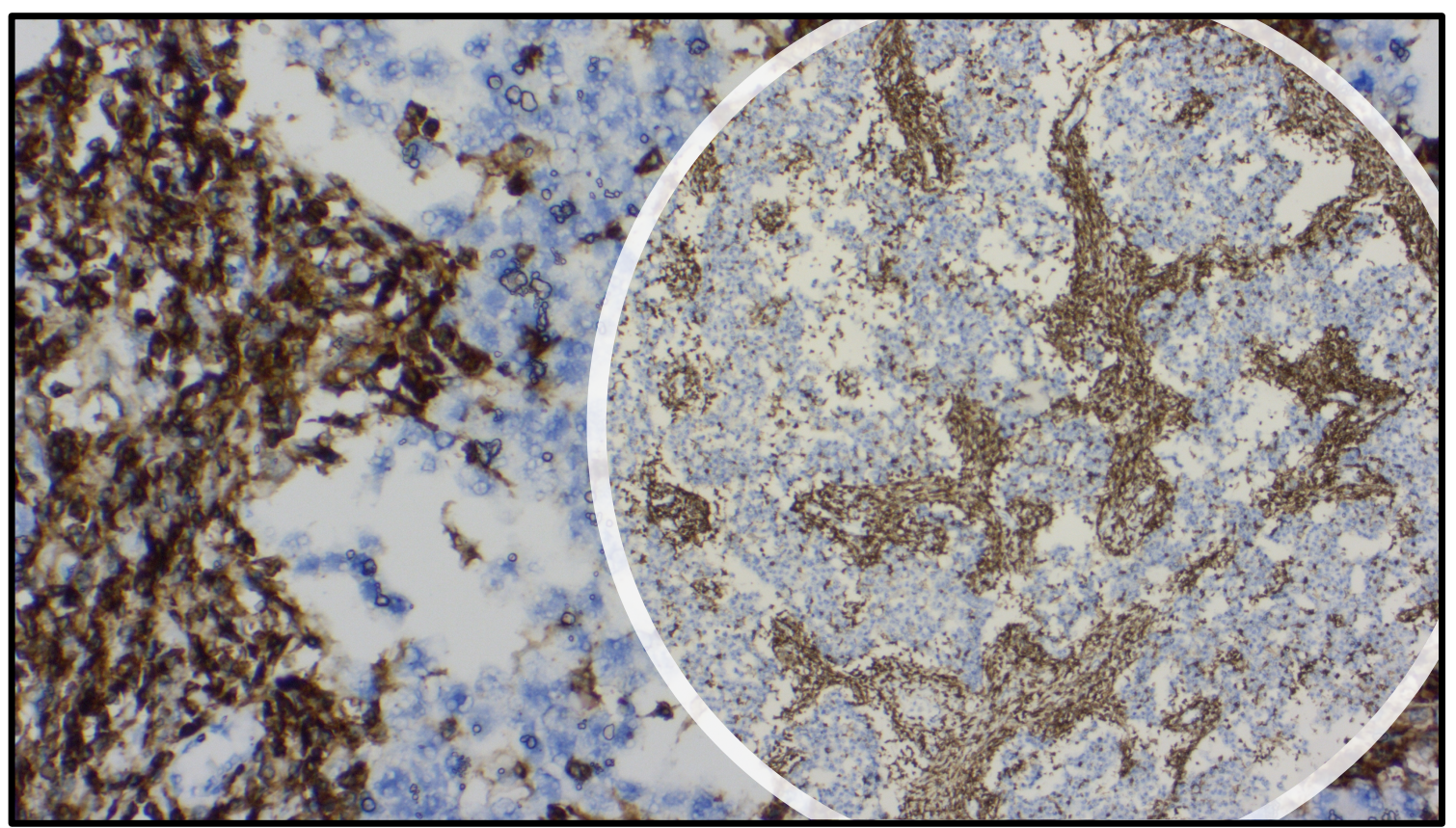

Abbildung 15: Seminom mit reichlich entzündlicher Infiltration

Die bräunlich-schwarz imponierenden Zellen stellen Immunozyten dar (CD45 ${ }^{+}$-Zellen). In der Übersichtsaufnahme wird deutlich, dass die CD $45^{+}$-positiven Zellen maßgeblichen Anteil an der Gesamtzellzahl haben (40-74\%).

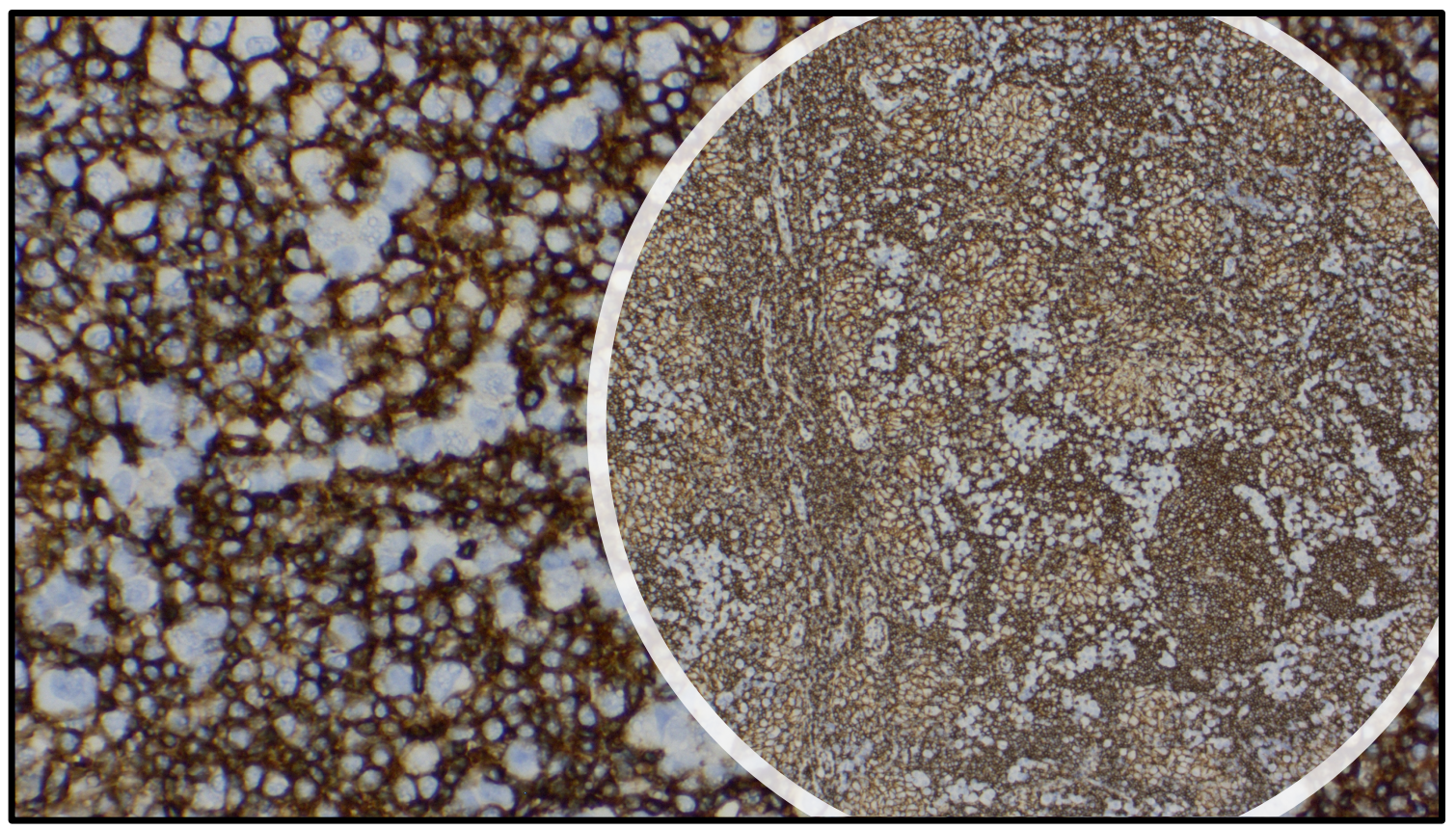

Abbildung 16: Seminom mit massiver entzündlicher Infiltration

Die bräunlich-schwarz imponierenden Zellen stellen Immunozyten dar (CD45 ${ }^{+}$-Zellen). Fast die gesamte Fläche beider Vergrößerungen zeigt ein positives Färbungsverhalten. Das entzündliche Infiltrat in diesem Hodentumorpräparat macht mehr als $75 \%$ aus (massives entzündlichen Infiltrat). 
Während sich das T-Zell-Infiltrat über den gesamten Tumor als sehr homogen verteilt präsentiert (siehe Abbildung 17), zeichnet sich die Infiltration der B-Lymphozyten durch formierte Hotspots und damit deutlich weniger homogen aus (siehe Abbildung 18). Häufig konnten Lymphfollikel identifiziert werden.

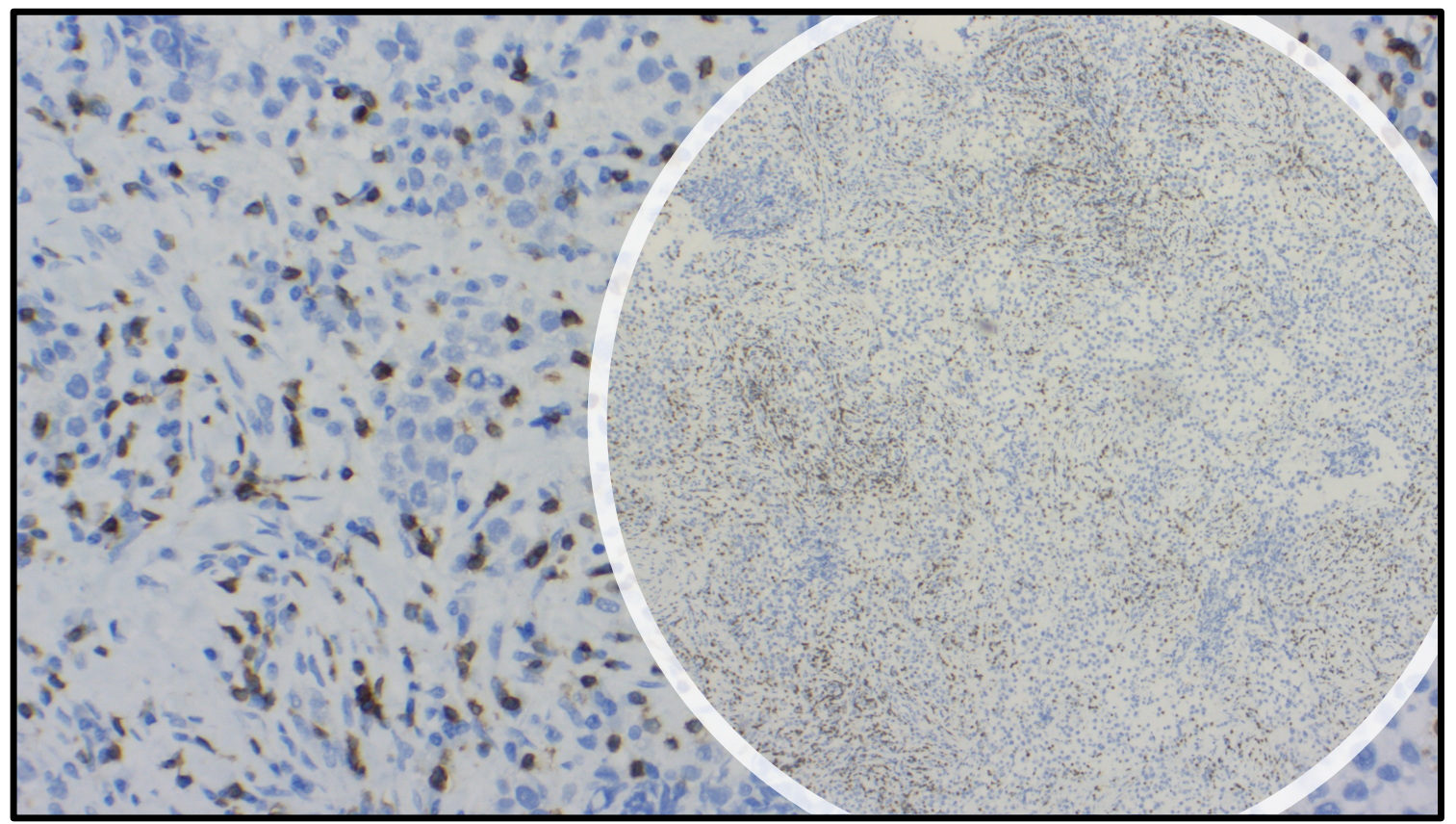

Abbildung 17: Homogenes T-Zell-Infiltrat im Seminom

Die bräunlich-schwarz imponierenden Zellen stellen T-Lymphozyten dar (CD3 ${ }^{+}$-Zellen). Sowohl in der Übersichtsaufnahme (rundlicher Teil), wie auch in der Vergrößerung stellt sich das T-Zell-Infiltrat sehr homogen verteilt dar.

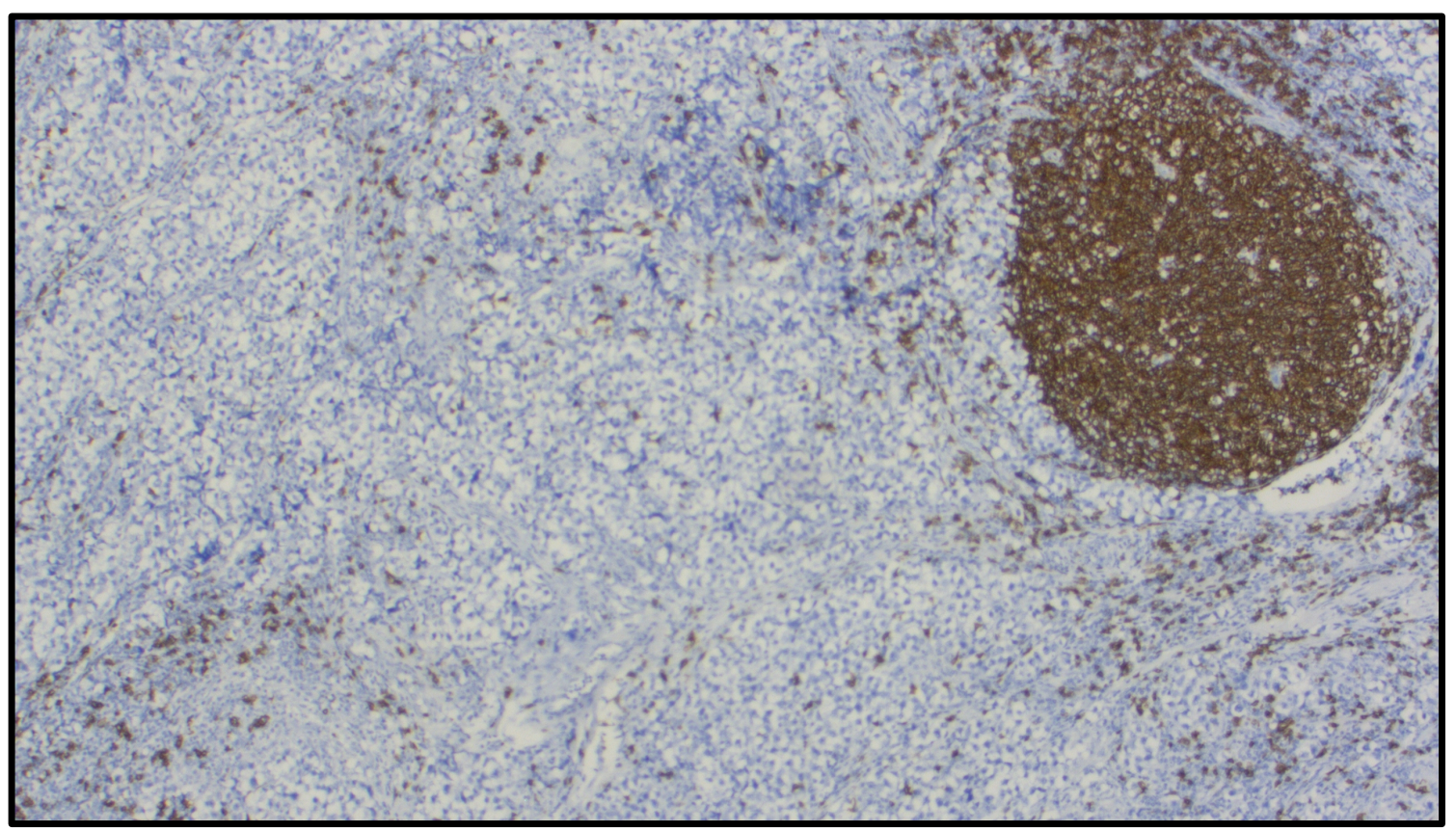

Abbildung 18: B-lymphozytäres Infiltrat mit Lymphfollikel im Seminom 
Die bräunlich-schwarz imponierenden Zellen stellen B-Lymphozyten dar (CD20-Zellen). Oben rechts in der Abbildung ist ein von B-Zellen dominierter Lymphfollikel zu sehen. Im restlichen Bereich der Aufnahme erscheint die Verteilung der B-Lymphozyten ebenfalls eher diffus und deutlich weniger homogen im Vergleich zu den T-Lymphozyten (siehe Abbildung 17)

\subsection{Ergebnisse der analytischen Statistik}

In diesem Kapitel werden sowohl die Ergebnisse der Analyse der klinischen Daten als auch die der immunhistochemischen Auswertung für relevanten Einflussfaktoren auf den klinischen Verlauf und die Rezidivwahrscheinlichkeit der Patienten und der Tumoren dargestellt (siehe Kapitel 3.3.1). Zusätzlich werden diverse Faktoren (unabhängige Variablen) bzgl ihres Einflusses auf andere abhängige Variablen untersucht (siehe Kapitel 3.3.2).

\subsubsection{Einflussfaktoren des klinischen Verlaufs}

In diesem Kapitel werden die statistisch relevanten Einflussfaktoren auf den klinischen Verlauf bzw. auf das Auftreten eines Rezidivs vorgestellt (siehe Tabelle 14). Die damit implizierte Time-To-Event-Analyse legt als Endpunkte entweder das Eintreten eines Rezidivs oder den letzten bekannten rezidivfreien Zeitpunkt der urologischen Nachsorge fest. Neben den erwähnten aufgeführten signifikanten Einflussfaktoren sind auf die Tabelle und Abbildungen folgend weitere untersuchte, statistisch aber nicht signifikante, Variablen erwähnt. Die statistisch relevanten Einflussfaktoren werden im Anschluss an die Tabelle in Abbildungen isoliert behandelt.

Tabelle 14: Statistisch signifikante Einflussfaktoren

\begin{tabular}{|c|c|c|c|c|}
\hline \multicolumn{5}{|c|}{ Statistisch signifikante Einflussfaktoren } \\
\hline Variable & $\begin{array}{c}\text { Punktschätzer } \\
\text { (HR) }\end{array}$ & $\begin{array}{c}\text { unteres 95 \% } \\
\text { KI }\end{array}$ & $\begin{array}{c}\text { oberes 95 \% } \\
\text { KI }\end{array}$ & p-Wert \\
\hline B-hCG erhöht & 3,342 & 1,145 & 9,757 & 0,0273 \\
\hline Chemotherapie & 0,1158 & 0,026 & 0,513 & 0,0045 \\
\hline Alter bei Diagnose & 0,9568 & 0,916 & 0,999 & 0,0455 \\
\hline Konfidenzintervall (KI) \\
Hazard Ratio (HR)
\end{tabular}

Die Faktoren „ß-hCG erhöht“, „Chemotherapie“ und „Alter bei Diagnose“ zeigten einen statistisch signifikanten Einfluss auf das Auftreten eines Rezidivs. Bei der dichotomisierten 
Analyse (B-hCG erhöht ja/nein) konnte den Patienten mit Markerwerten über dem Cut-Off eine erhöhte Wahrscheinlichkeit für das Auftreten eines Rezidivs nachgewiesen werden. Der Faktor „Chemotherapie“ reduziert das Risiko für ein Rezidiv im Vergleich zu Patienten ohne Chemotherapie um ca. 90 \%. Der Prädiktor „Alter bei Diagnose“ zeigt ebenfalls einen statistisch signifikanten Einfluss auf den klinischen Verlauf. Bei dem untersuchten Kollektiv zeigt der vorliegende Punktschätzer $(0,9568)$ eine Reduktion der Wahrscheinlichkeit für ein Rezidiv pro zunehmendem Alterungsjahr bei Diagnose um ca. $4 \%$.

\subsubsection{Beta-humanes Choriongonadotropin}

Tabelle 14 stellt die Time-To-Event-Analyse mittels Cox-proportional-Hazards-Modell (Punktschätzer $=$ Hazard Ratio) dar. Abbildung 19 stellt diesen Zusammenhang unter Verwendung des Log-Rank-Tests (p-Wert) und eines Kaplan-Meier-Plots dar.

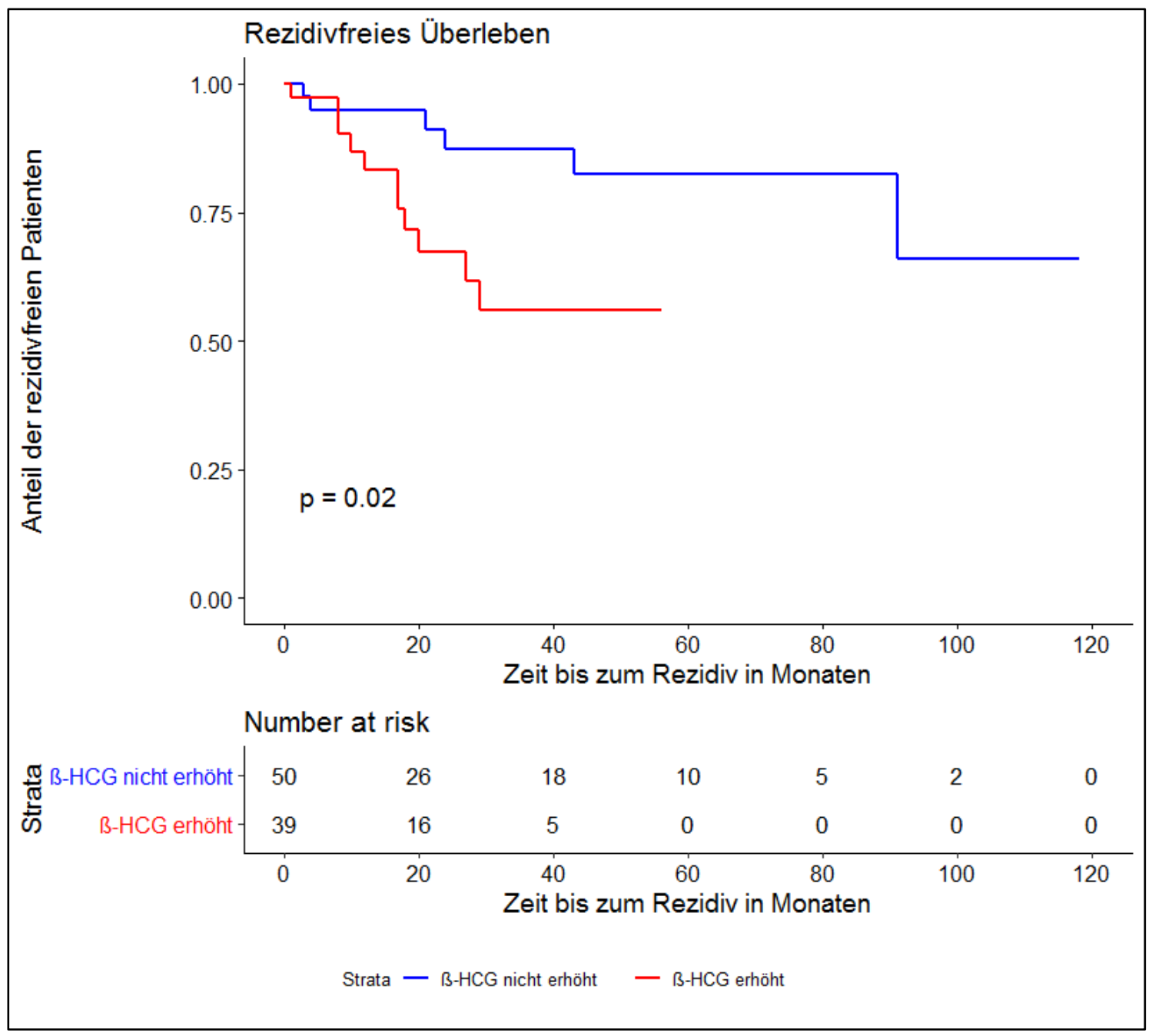

Abbildung 19: B-hCG Time-To-Event-Analyse

Patienten mit erhöhtem B-hCG haben ein statistisch signifikantes 3,34-mal so hohes Rezidivrisiko (95 \% KI 1,1145 - 9,757; p = 0,00273) im Vergleich zu Patienten ohne erhöhtes B- 
hCG. Dies bedeutet auch, dass die Zeit bis zum Auftreten eines Rezidivs im Vergleich zu Patienten mit normalen $\mathrm{B}-\mathrm{hCG}-$ Werten reduziert ist.

\subsubsection{Chemotherapie}

Abbildung 20 stellt die Time-to-Event-Analyse von Patienten in Abhängigkeit der Therapieoption ,adjuvante Chemotherapie“ dar. Die darauffolgende Abbildung 21 differenziert zwischen Patienten, die adjuvant Monochemotherapie (Cisplatin) und Polychemotherapie (PEB) erhalten haben.

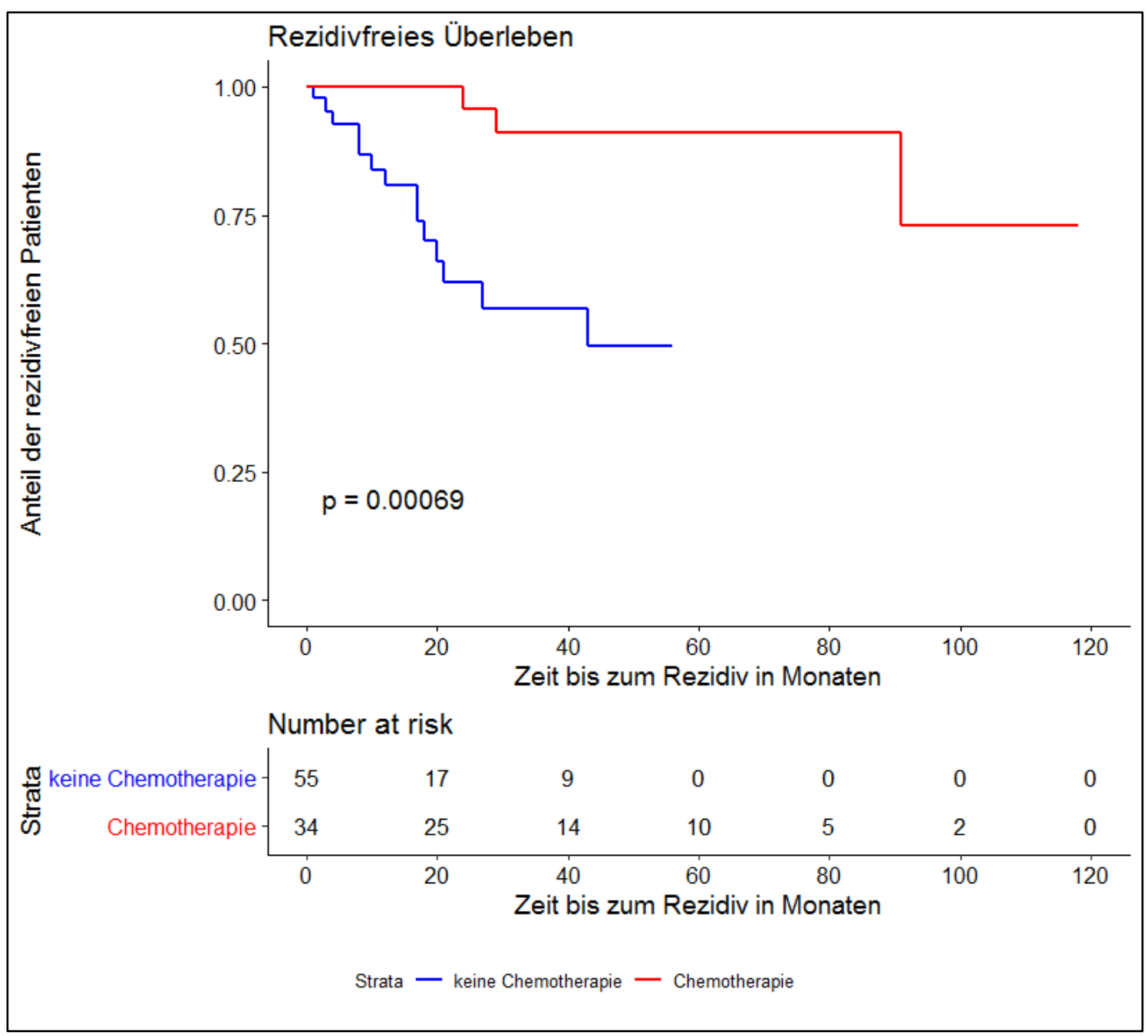

Abbildung 20: Chemotherapie Time-To-Event-Analyse

Patienten, die mit Chemotherapie behandelt wurden, haben ein statistisch signifikantes, um den Faktor 0,12 verändertes (=reduziertes Risiko), Rezidivrisiko (95 \% KI 0,026 - 0,513; p $=0,0045)$ im Vergleich zu Patienten ohne Chemotherapie. Nach Chemotherapie zeigen Patienten ein um ca. 90 \% reduziertes Risiko für ein Rezidiv verglichen mit Patienten ohne Chemotherapie. 


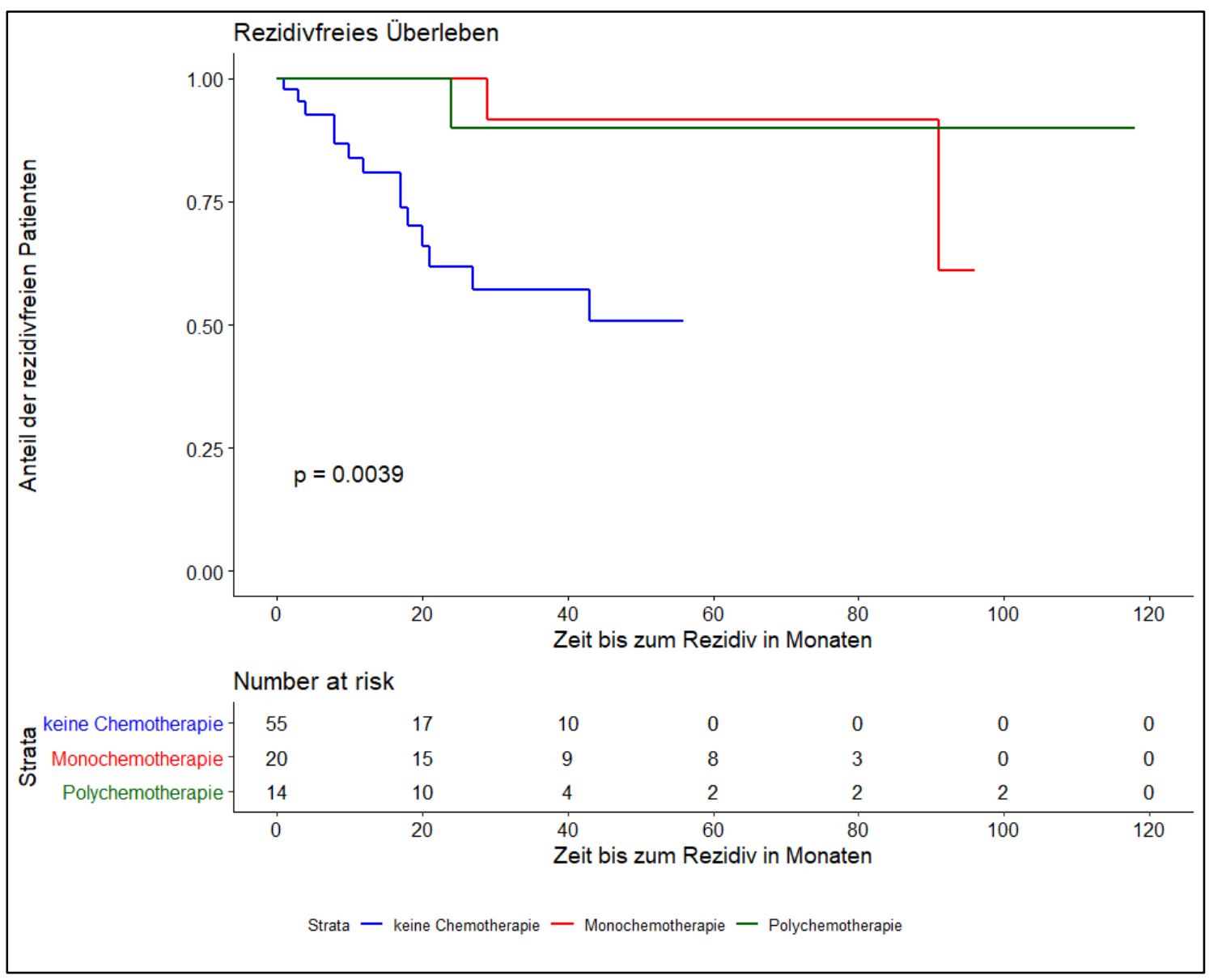

Abbildung 21: Monochemo- und Polychemotherapie Time-To-Event-Analyse

Sowohl Mono- als auch Polychemotherapie verringern im Vergleich zu keiner Chemotherapie statistisch signifikant das Rezidivrisiko um $86.5 \%$ (95\% KI 26,7 - 97,6; p = 0,0204) bzw. 90,1\% (95\% KI 12,9-98,9; p = 0,0371).

\subsubsection{Alter bei Diagnosestellung}

Das Alter bei Diagnosestellung zeigt ein statistisch signifikantes, um 0,956-mal reduziertes, Rezidivrisiko (KI 0,916 - 0,999; p = 0,0455). Mit jedem Lebensjahr, um das die Diagnose bei einem Patienten später gestellt wird, sinkt das Rezidivrisiko um ca. 4 \%.

\subsubsection{Untersuchte Variablen ohne statistische Signifikanz}

Für folgende Variablen ergab sich kein statistisch signifikanter Unterschied ( $\mathrm{p}$-Werte $>0,05$ ) bezüglich der Zeit bis zum Auftreten eines Rezidivs: Lymphgefäßinvasion, Samenstranginfiltration, Gefäßinvasion, Rete testis-Infiltration, Tumorgröße, AFP, LDH, entzündliches Infiltrat $\left(\mathrm{CD} 45^{+}\right)$, T-Zell-Infiltrat $\left(\mathrm{CD}^{+}\right)$, T-Helferzell-Infiltrat $\left(\mathrm{CD} 4^{+}\right)$, Infiltration durch zytotoxische T-Zellen $\left(\mathrm{CD}^{+}\right), \mathrm{CD}^{+} / \mathrm{CD}^{+}$-Ratio, B-Zell-Infiltrat $\left(\mathrm{CD} 20^{+}\right)$, T-Stadium, UICC-Stadium. 
Die Erstellung eines multivariablen Modells war nicht möglich. Ursächlich ist möglicherweise das vergleichsweise kleine Kollektiv und die damit verbundene geringe Power für statistische Tests. Aus der geringen Größe des Kollektivs resultiert eine niedrige Rezidivinzidenz.

\subsubsection{Korrelation kontinuierlicher Variablen}

In diesem Kapitel werden Korrelationen zwischen verschiedenen kontinuierlichen Variablen untersucht. Die gewählten Variablen setzen sich einerseits aus in der Literatur bereits beschriebenen Einflussfaktoren für den klinischen Verlauf (Tumorgröße und Tumormarker) und andererseits aus den durch die spezielle Immunhistochemie gewonnen Daten zusammen. Abbildung 22 veranschaulicht die Zusammenhänge.

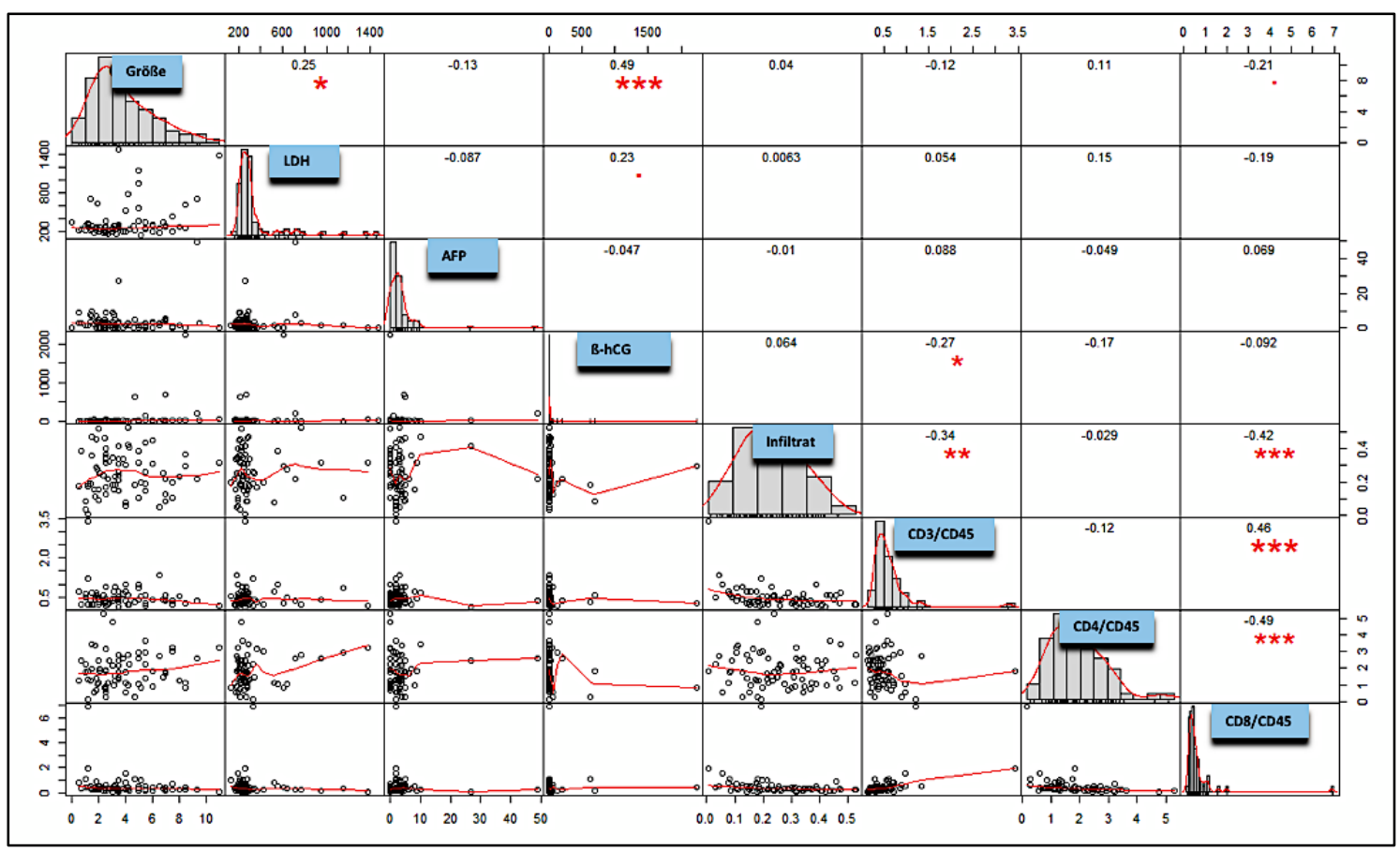

Abbildung 22: Verteilung und Korrelation kontinuierlicher Variablen

$* \mathrm{p}=0,05-0,01 ;{ }^{* *} \mathrm{p}=0,001-0,01 ;{ }^{* * *} \mathrm{p}<0,001$; Skalen: Größe (=Tumorgröße) [cm]; LDH $[\mathrm{U} / \mathrm{I}]$; B-hCG [IU/I]; AFP $[\mu / \mathrm{I}]$; Die in jedem Kästchen dargestellten Zahlen rechts der blau hervor gehobenen Variablen stellen den jeweiligen Korrelationskoeffizienten [KK] dar. Innerhalb der blau beschrifteten Kästchen ist das Verteilungsmuster im Diagramm dargestellt. Für jede geführte kontinuierliche Variable ist ihre Korrelation mit den anderen getestet. Die Ergebnisse dieser Analyse sind mit dem KK und im Falle einer statistischen Signifikanz durch „*“ in den sich treffenden Kästchen geführt. Links der blau hervorgehobenen Variablen sind visuell ihre korrelierenden Verteilungsmuster dargestellt.

Die Größe des Tumors und die Höhe des erhobenen Tumormarkers B-hCG korrelieren stark positiv $(\mathrm{KK}=0,49 ; \mathrm{p}<0.001)$ miteinander. Auch der Tumormarker LDH korreliert 
positiv mit einer Zunahme der Tumorgröße $(K K=0,25 ; \mathrm{p}=0,01-0,05)$. Die Quantität des T-Zell Infiltrats korreliert negativ mit der Höhe des Tumormarkers $\beta$-hCG (KK = -0,27; p $=0,01-0,05)$. Je höher sich das $\mathrm{CD}^{+}$-positive immunozytäre Infiltrat im Tumor darstellt, desto niedriger sind die B-hCG-Werte.

\subsubsection{Prädiktoren anderer Endpunkte}

In diesem Kapitel werden mittels binärer logistischer Regression verschiedene kategoriale Variablen (Prädiktoren) bzgl. ihres Einflusses auf eine abhängige Variable (neu definierter Endpunkt bzw. Zielvariable) untersucht. Die Auswahl der untersuchten Zielvariablen ergibt sich unter anderem aus in der Literatur diskutierten Rezidiv-Risikofaktoren. Tabelle 15 stellt die dabei signifikanten Zusammenhänge zwischen Zielvariable und unabhängiger Variable vor. Der Punktschätzer ist hier eine Odds Ratio (OR).

Tabelle 15: Statistisch signifikante Prädiktoren neuer Ziel-Variablen

\begin{tabular}{|c|c|c|c|c|c|}
\hline \multirow{2}{*}{ Ziel-Variable } & Prädiktor & $\begin{array}{c}\text { Punkt- } \\
\text { schätzer } \\
\text { (OR) }\end{array}$ & $\begin{array}{c}\text { unteres 95 } \\
\text { \% KI }\end{array}$ & $\begin{array}{c}\text { oberes } \\
\mathbf{9 5} \% \\
\text { KI }\end{array}$ & p-Wert \\
\hline $\begin{array}{c}\text { Lymphgefäß } \\
\text { Invasion }\end{array}$ & LDH & 1,004 & 1,001 & 1,006 & 0,0029 \\
\hline $\begin{array}{c}\text { Lymphgefäß } \\
\text { Invasion }\end{array}$ & Alter bei Diagnose & 1,084 & 1,023 & 1,160 & 0,010 \\
\hline Gefäß Invasion & Samenstrang & 29,583 & 4,298 & 593,985 & 0,0029 \\
\hline Gefäß Invasion & T-Zell Infiltrat & 0,0035 & 0,00001 & 0,251 & 0,0263 \\
\hline Gefäß Invasion & Tumorgröße & 1,51 & 1,2 & 1,96 & 0,0008 \\
\hline Odds Ratio (OR) & & & & & \\
\hline
\end{tabular}

\subsubsection{Rete testis-Infiltration}

Für keine der untersuchten Prädiktoren konnte ein signifikanter Einfluss $(p<0,05)$ auf die Zielvariable Rete testis-Infiltration beobachtet werden. Folgende Variablen wurden dabei untersucht: Gefäßinvasion, Lymphinvasion, Samenstranginfiltration, entzündliches Infiltrat, T-Zell-Infiltration, $\mathrm{CD}^{+} / \mathrm{CD}^{+}$-Ratio, zytotoxische T-Zell-Infiltration $\left(\mathrm{CD} 8^{+}\right)$, Tumorgröße, AFP, LDH, B-hCG, Alter bei Diagnose. 


\subsubsection{Tumorstadium nach UICC}

Für keine der untersuchten Prädiktoren konnte ein signifikanter Einfluss $(p<0,05)$ auf die Zielvariable Tumorstadium nach UICC beobachtet werden. Folgende Variablen wurden dabei untersucht: entzündliches Infiltrat, T-Zell Infiltration $\left(\mathrm{CD}^{+}\right)$, zytotoxische T-Zell-Infiltration $\left(\mathrm{CD}^{+}\right)$, T-Helferzell-Infiltration $\left(\mathrm{CD} 4^{+}\right), \mathrm{CD} 4^{+} / \mathrm{CD}^{+}-\mathrm{Ratio}$.

\subsubsection{Lymphgefäßinvasion}

Für die Zielvariable Lymphgefäßinvasion konnten Signifikanzen für die Prädiktoren LDH $(\mathrm{OR}=1,004 ; \mathrm{KI} 1,001-1,006 ; \mathrm{p}=0,0029)$ und Alter bei Diagnose $(\mathrm{OR}=1,084 ; \mathrm{KI} 1,023$ $-1,160 ; p=0,01)$ nachgewiesen werden. Für die weiteren bereits oben erwähnten möglichen Einflussfaktoren konnte kein signifikanter Zusammenhang $(p>0,05)$ gezeigt werden.

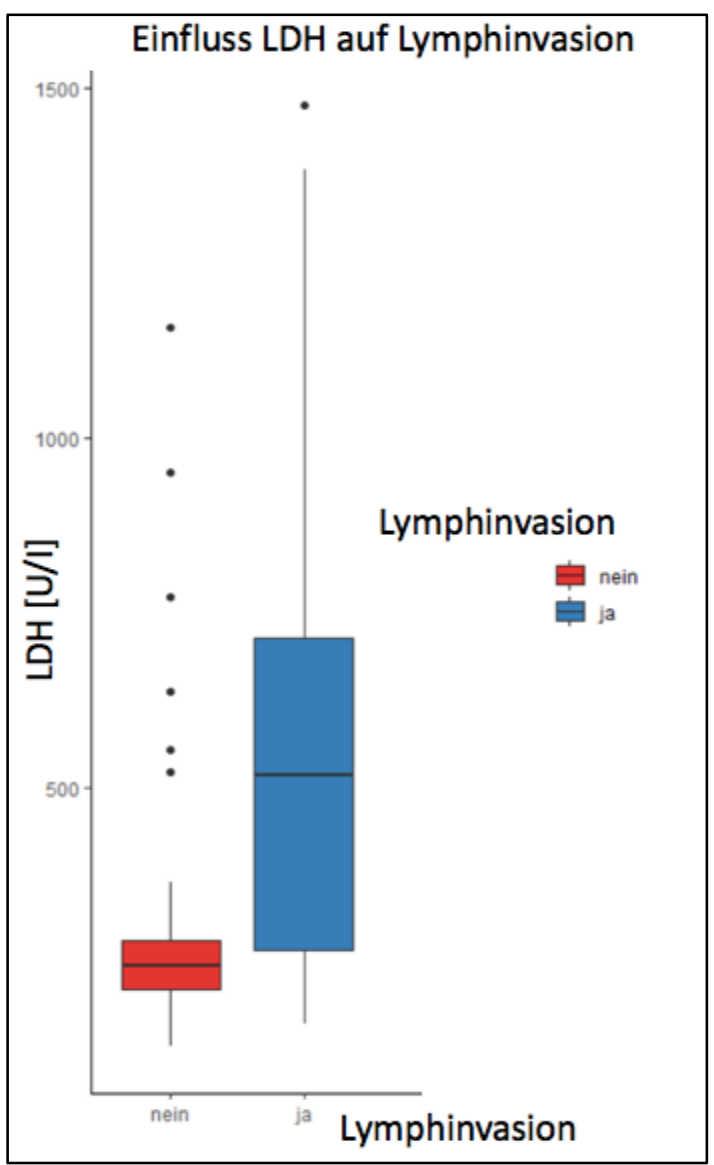

Abbildung 23: Einfluss von LDH auf die Lymphinvasion

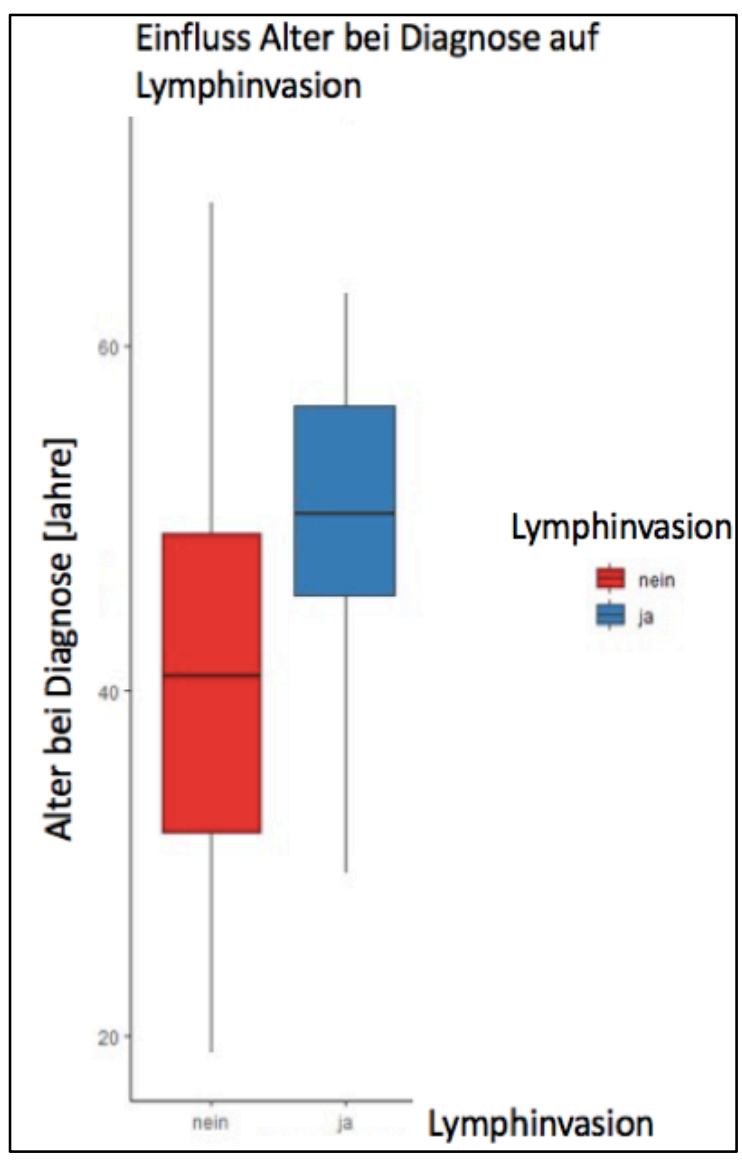

Abbildung 24: Einfluss des Alters bei Diagnose auf die Lymphinvasion

Mit zunehmender Konzentration des bei Diagnosestellung laborchemisch ermittelten Tumormarkers $L D H$ steigt pro Einheit die Wahrscheinlichkeit für eine Invasion der Tumorzellen des Seminoms in lokale Lymphgefäße um 0,1 \% (siehe Abbildung 23). 
Je jünger die Patienten bei Diagnosestellung eines Seminoms waren, desto seltener konnten im histopathologischen Hauptpräparat Invasionen von Tumorzellen in Lymphgefäße verzeichnet werden (siehe Abbildung 24). Pro Zunahme des Alters um ein Jahr konnte eine Erhöhung des Risikos für eine Lymphgefäßinvasion um 8,4 \% beobachtet werden.

\subsubsection{Gefäßinvasion}

Für die Zielvariable Gefäßinvasion konnten Signifikanzen für die Prädiktoren Samenstranginfiltration $(\mathrm{OR}=3,387$; KI 4,298 - 593,985; $\mathrm{p}=$ 0,0029), T-Zell-Infiltration $(\mathrm{OR}=0,0035$; KI 0,00001 - 0,251; $\mathrm{p}=0,0263)$ und Tumorgröße $(\mathrm{OR}=1,51 ; \mathrm{KI} 1,2-1,96 ; \mathrm{p}=0,0008)$ nachgewiesen werden. Für die restlichen bereits oben erwähnten möglichen Einflussfaktoren konnte kein signifikanter Zusammenhang ( $>>0,05)$ gezeigt werden. Die nachgewiesenen Signifikanzen sind für den Prädiktor T-Zell-Infiltration in Abbildung 25 und für den Faktor Tumorgröße in Abbildung 26 durch Boxplots visuell veranschaulicht.

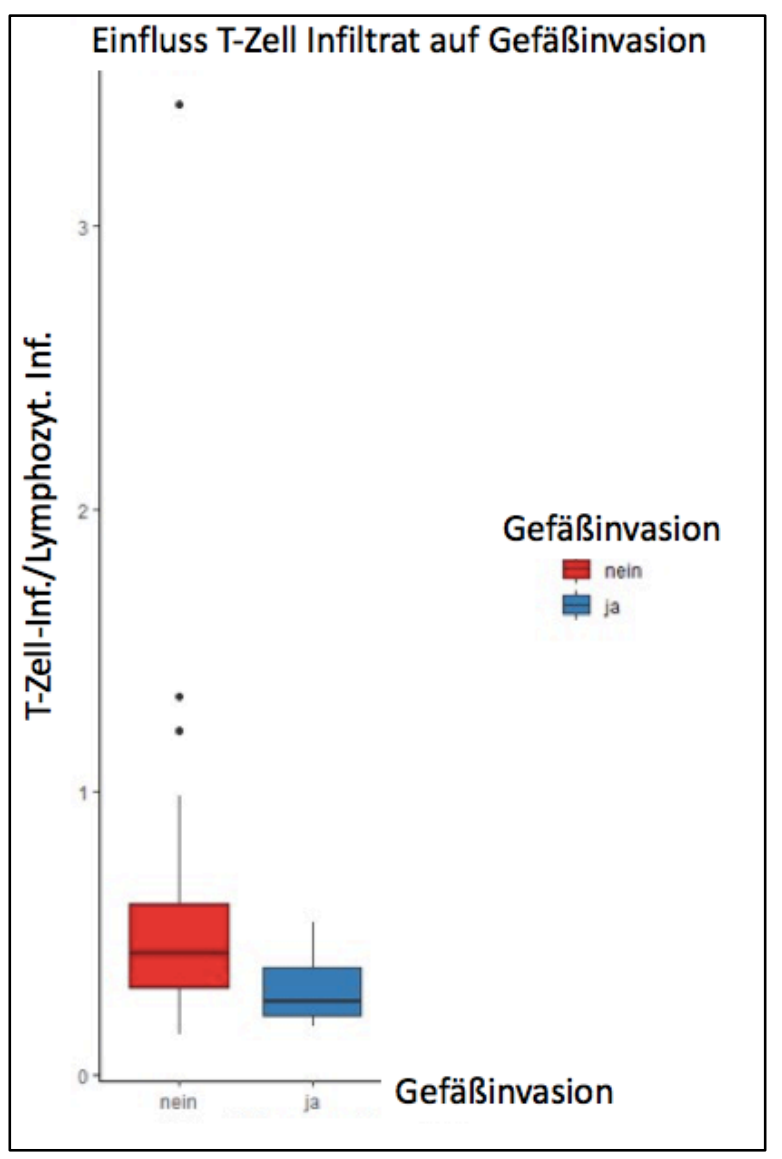

Abbildung 25: Einfluss des T-Zell Infiltrats auf die Gefäßinvasion

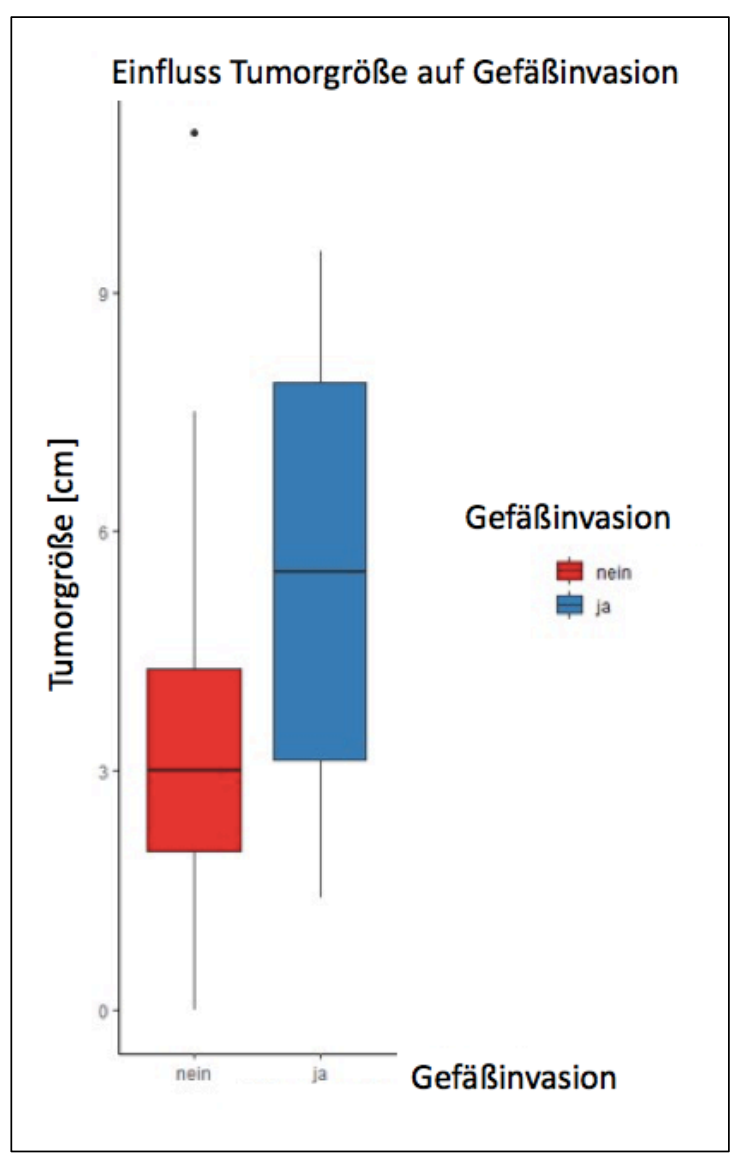

Abbildung 26: Einfluss der Tumorgröße auf die Gefäßinvasion 
Mit zunehmendem T-Zell-Infiltrat lässt sich seltener eine Gefäßinvasion der Tumorzellen des Primarius nachweisen.

Große Seminome zeigen häufiger eine Gefäßinvasion der Tumorzellen im Hodentumor. Pro Zunahme der Tumorgröße um einen $\mathrm{cm}$ steigt das Risiko für eine Gefäßinvasion der Tumorzellen um $50 \%$. 


\section{Diskussion}

Das entzündliche Infiltrat seminomatöser Tumoren und seine Bedeutung für die Kontrolle des Tumors und den klinischen Verlauf der betroffenen Patienten stellt eine nach wie vor unbeantwortete Frage der immunologischen Forschungen zu Hodentumoren dar. Auf die dargestellten Fragestellungen sollten im Rahmen dieser Arbeit durch die Erfassung und Analyse der Charakteristika eines 92 Patienten großen Kollektivs kombiniert mit der Auswertung von 73 immunhistochemischen Seminomschnitte und dem Zusammenschluss dieser Daten Antworten gefunden werden. Besonderes Augenmerk galt dabei der Suche nach möglichen Prädiktoren für das Auftreten eines Rezidivs und dem Einfluss der entzündlichen Komponenten des Tumors auf die lokale Kontrolle desselbigen und den klinischen Verlauf der Patienten. Am relevantesten ist dabei das Seminom im klinischen Stadium I.

\subsection{Das Patientenkollektiv und seine prognostischen Faktoren}

In diesem Kapitel werden die wesentlichen Ergebnisse bzgl. der Charakteristika des Patientenkollektivs (Kapitel 3.1.1), ihrer Primärtherapie (Kapitel 3.1.3) und der Tumormarker (Kapitel 3.1.5) mit den wesentlichen daraus resultierenden Ergebnissen der analytischen Statistik aus den Kapiteln 3.3.1, 3.3.2 und 3.3.3 diskutiert.

\subsubsection{Charakteristika des Patientenkollektivs}

Das mittlere Alter der Patienten bei Diagnosestellung lag bei 42,01 (SD $\pm 12,01$ ) Jahren. Damit liegt das Erkrankungsalter dieses Kollektivs über dem in der Literatur beschrieben Häufigkeitsgipfel (15. - 35. LJ)(Boujelbene et al. 2011)(Manecksha und Fitzpatrick 2009). Bei 79 Patienten $(85,87 \%$ ) wurde die Diagnose im klinischen Stadium I (nach UICC und Lugano) gestellt. Dies entspricht den Erwartungen (Sokoloff et al. 2007; Alexander et al. 2010; Heinzelbecker et al. 2011).

Die Rezidivrate liegt bei 18 \% (17 von 92 Patienten) bei einem Nachsorgezeitraum von 28.74 Monaten. 16 dieser Patienten wurden primär mit dem CSI diagnostiziert. In Abhängigkeit der Risikokonstellation werden in diesem Stadium rezidivierende Krankheitsverläufe mit einer Häufigkeit von 12,2 \% bis zu 20,3 \% beobachtet (Leung et al. 2013; Daugaard et al. 2014; Nayan et al. 2017). Alle Rezidive wurden dabei innerhalb von 29 Monaten (MW 16,38 \pm 11,09) nach Diagnosestellung festgestellt. Lediglich ein Rezidiv trat später als 24 Monate nach Diagnose auf. Große Studien beschreiben einen 24-monatigen Hauptrisikozeitraum für rezidivierende Krankheitsverläufe bei CSI Hodentumoren (Nayan et al. 2017). Betrachtet man alle Rezidive, werden Spät-Rezidive nur in bis zu $6 \%$ beobachtet (Lipphardt und Albers 2004). Daher ist zu vermuten, dass sich besonders unter den Patienten, deren Diagnose 
weniger als 2 Jahre (16 Patienten) zurück liegt, mindestens ein weiterer rezidivierender Krankheitsverlauf befindet.

Das Alter von rezidivfreien Patienten lag bei 43,12 ( \pm 12,03) Jahren und Das der Patienten mit einem rezidivierenden Krankheitsverlauf bei 37,06 ( $\pm 10,92)$ Jahren. Die Ergebnisse der analytischen Statistik lassen vermuten, dass der Faktor Alter bei Diagnosestellung (KI 0,916 0,999; $p=0,0455)$ einen Einfluss auf den klinischen Verlauf bzw. auf die Rezidivwahrscheinlichkeit und damit den Zeitpunkt eines Rezidivs hat. Der vorliegende Punktschätzer $(0,9568)$ implizierte eine Reduktion der Wahrscheinlichkeit für ein Rezidiv pro zunehmendem Jahr bei Diagnose um ca. 4\%. Verschieden Studien stützen diese Beobachtung (Warde et al. 2002; Aparicio et al. 2014). Andere Analysen von entsprechenden Kollektiven konnten das Alter bei Diagnose nicht als Prädiktor für das Auftreten eines Rezidivs bestätigen (Chung et al. 2015; Dieckmann et al. 2016). Dabei darf nicht außer Acht gelassen werden, dass der Faktor Alter bei Diagnose im Zusammenhang mit dem in der Literatur diskutieren Prädiktor „Lymphgefäßinvasion" steht. Die vorliegende Arbeit konnte zeigen, dass ein hohes Alter bei der Diagnosestellung mit einer Zunahme der Lymphinvasion von Tumorzellen im Primarius assoziiert ist $(\mathrm{OR}=1,084 ; \mathrm{KI} 1,023-1,160 ; \mathrm{p}=0,01)$. Teilweise widerspricht dieses Ergebnis anderen Studien, die von einer negativen Korrelation von Lymphgefäßinvasion und dem Alter berichten (Yossepowitch et al. 2013). Im vorliegenden Patientenkollektiv konnte kein signifikanter Einfluss der Lymphgefäßinvasion auf den klinischen Verlauf der Patienten festgestellt werden $(p>0,05)$. Sicherlich ist die Aussagekraft dieser Tatsache zurückhaltend zu bewerten. Das liegt vor allem an der geringen Inzidenz der Rezidive des vorliegenden Kollektivs. Verschiedene Studien klassifizieren die Lymphinvasion im primären Hodentumor als Risikofaktor (Parker et al. 2002)(Fosså et al. 1994)(Dunphy et al. 1988)(Colls et al. 1999). Andere sprechen diesem Faktor einen entscheidenden Einfluss ab (Johnson et al. 1976)(Zengerling et al. 2018). Die Lymphinvasion als histopathologisches Charakteristikum bleibt ein diskutierter Risikofaktor für die Entstehung von Rezidiven und lymphogener Metastasierung.

\subsubsection{Die Primärtherapie}

Alle Patienten erhielten im Rahmen ihrer Primärtherapie eine operative Entfernung des betroffenen Hodens. Die möglichen adjuvanten Therapieoptionen sind wie in Kapitel 3.2 beschrieben vielfältig und stellen in der klinischen Applikation ein uneinheitlich diskutiertes Thema dar. Dabei geht es vor allem um Patienten, die initial im CS1 diagnostiziert werden. Es gilt die Patienten zu identifizieren, deren Rezidivrisiko relativ erhöht ist. In Abhängigkeit dieser Risikokonstellation kann eine „passive“ adjuvante Therapie in Form von „Active Surveillance", oder die aktiven adjuvanten Therapievarianten wie Chemotherapie (Monochemotherapie mit Cisplatin) oder Radiatio gewählt werden. „Active Surveillance“ kann dabei in ca. 85 \% der Fälle eine Übertherapie verhindern (Chung und Warde 2006). Deshalb und wegen 
der exzellenten Aussichten auf Kuration im Falle eines Rezidivs mittels PEB-Chemotherapie ist diese Form der Therapie im CSI die aktuell präferierte Option (Nichols et al. 2013). Wichtige Bedingung für eine erfolgreiche Nachsorge ist jedoch eine hohe Compliance der Patienten. Um dem Konzept der „Active Surveillance "gerecht zu werden, muss erwähnt werden, dass die regelmäßigen abdominellen CT-Untersuchungen, die die Nachsorgeprotokoll vorsehen, ebenfalls mit einem erhöhten Risiko für Zweitmalignome assoziiert sind (Tarin et al. 2009). Das hier vorliegende CSI-Kollektiv wurde in 14 Fällen adjuvant mittels Monochemotherapie behandelt. Bei den meisten Patienten (60 von 79) entschied man sich für die passive Therapieform „Active Surveillance“. Unter dieser Strategie erlitten 14 Patienten (82.35\% der Rezidive; 23,3 \% der CSI Patienten) ein Rezidiv. Damit zeigt dieses Kollektiv im Vergleich zu anderen Studien eine erhöhte Inzidenz an CSI-Rezidiven unter "Active Surveillance" (Ondrusova et al. 2016). Zwei (11.76 \%) mit Monochemotherapie behandelte Patienten erlitten ein Rezidiv.

Die Therapieoptionen adjuvante Monochemotherapie (AMCT) und adjuvante Radiatio (AR) zeigen ähnliche Wirkungen bzgl. der Reduktion des Rezidivrisikos (Petrelli et al. 2015). Dazu untersuchten Oliver et al. randomisiert bei CSI Patienten das Outcome von adjuvant bestrahlten $(\mathrm{n}=904)$ und mit Carboplatin therapierten $(\mathrm{n}=573)$ Patienten (Oliver et al. 2005). Im Vergleich zur Chemotherapie hat die Bestrahlung jedoch in den vergangenen Jahren an Stellenwert verloren und wird in den aktuellen Leitlinien nicht mehr aufgenommen (Albers et al. 2015). Das liegt vor allem an dem ausgeprägten Kurzzeit-Nebenwirkungsspektrum und dem erhöhten Risiko für Zweitmalignome und kardiovaskuläre Erkrankungen (Tüzel 2016). Die Auswertung dieses Kollektivs lässt im Hinblick auf den Vergleich der beiden aktiven Therapieoptionen ACT und AR keine Schlussfolgerungen zu, da kein Stadium-I-Patient bestrahlt wurde.

Im Gegensatz dazu zeigen die Ergebnisse, dass AMCT zu einer Reduktion des Risikos für Rezidive um 86,5 \% führt (95 \% KI 26,7 - 97,6; p = 0,0204) (siehe Kapitel 3.3.1 Abbildung 21). Petrelli et al. konnten in einer Studie mit 12075 CSI Seminom Patienten eine vergleichbare Reduktion um $80 \%$ nachweisen (Petrelli et al. 2015). Fest steht, dass sich das Für und Wider einer aktiven adjuvante Therapie nach dem Risikoprofil des einzelnen Patienten richten sollte.

\subsubsection{Tumormarker}

In diesem Kapitel werden die in Kapitel 3.1.5 dargestellten wesentlichen Resultate der Datenerhebung der Tumormarker B-hCG und Lactatdehydrogenase vorgestellt und mit Bezug auf die relevanten Ergebnisse der analytischen Statistik aus den Kapiteln 3.3.1, 3.3.2 und 3.3.3 diskutiert. Da AFP von reinen Seminomen nicht produziert wird, wird auf die Ergebnisse dieses Hodentumormarkers nicht weiter eingegangen. 


\subsubsection{B-hCG}

Der Mittelwert der präoperativen B-hCG-Werte des gesamten Kollektivs lag bei 55,20 ( \pm 275,86) IU/I, bei rezidivfreien Patienten bei 67,86 ( \pm 307,07) IU/I und bei Patienten mit einem Rezidiv lediglich bei 3,69 ( \pm 4,63) IU/I. Dieses Ergebnis widerstrebt den eigentlichen Erwartungen. Es muss jedoch berücksichtigt werden, dass sich die Standardabweichung der Serumhöhen des Tumormarkers B-hCG in dem Kollektiv ohne Rezidive ( \pm 307,07) im Vergleich zu den Patienten mit einem Rezidiv ( \pm 4.63) deutlich erhöht präsentiert. Dafür verantwortlich sind primär Tumoren, die initial in einem hohen Tumorstadium diagnostiziert wurden und in Relation erheblich erhöhte B-hCG-Werte gezeigt haben. So wurden beispielsweise bei einem initial lymphogen metastasierten Patienten vor der Primärtherapie Werte von 2237 [IU/I] ermittelt. Dem gegenüber steht die Tatsache, dass 16 der 17 Patienten mit einem Rezidiv im CSI diagnostiziert wurden und deshalb eher moderate B-hCG-Werte zeigten. 3 -hCG zeigt sich in $8 \%-40 \%$ abhängig vom Tumorstadium im Serum erhöht (Swartz et al. 1984) Bei dem vorliegenden Kollektiv konnte kein statistisch signifikanter Zusammenhang zwischen der Höhe des Tumormarkers und der Wahrscheinlichkeit für einen Tumorrückfall beobachtet werden $(\mathrm{p}>0,05)$. Interessanterweise konnte jedoch eine statistische Signifikanz bei der dichotomisierten Analyse zwischen dem Parameter „,-hCG erhöht“ bzw. „B-hCG nicht erhöht“ und dem Auftreten von Rezidiven gefunden werden ( $p=0.00273$ ) (siehe Kapitel 3.3.1 Abbildung 19). Bei 11 der 17 Patienten (64,71 \%) mit einem erneuten Behandlungsbedarf nach abgeschlossener Primärtherapie wurden B-hCG-Werte oberhalb des beschriebenen Cut-Off-Wertes festgestellt. Das führt zu einem relativ erhöhten Risiko um den Faktor 3,34, ein Rezidiv zu erleiden. In der Vergangenheit wurde der mögliche Prädiktor B-hCG bereits auf seinen Einfluss auf den klinischen Verlauf der Patienten mit diagnostiziertem Seminom untersucht. Nur selten wird ihm dabei ein Einfluss auf das Auftreten eines Rezidivs attestiert (Fosså und Fosså 1989). In aller Regel wird diesem prätherapeutisch gewonnenen Tumormarker ein Einfluss auf die Rezidiv Wahrscheinlichkeit bzw. das klinische Outcome abgesprochen (Hori et al. 1997; Suzuki et al. 1998; Weissbach et al. 1999). Zusätzlich scheint er kein besonders sensitiver Marker zur Diagnosestellung zu sein (Paus et al. 1987; Trigo et al. 2000). Auf der anderen Seite werden persistierend erhöhte Serum Werte nach Orchiektomie, Bestrahlung oder Chemotherapie als Indikator für ein einen Verbleib von Tumorzellen im Körper gewertet (Leman und Gonzalgo 2010).

Bei einer Fehlerwahrscheinlichkeit von 5\% lässt sich nicht mit abschließender Sicherheit festlegen, ob initiale $\beta$-hCG-Werte über dem Cut-Offein Prädiktor für Verläufe mit Rezidiv sind. Mit Blick auf diverse Publikationen zu diesem Thema mit größerer Fallzahl muss sogar eher davon ausgegangen werden, dass die gefundene Signifikanz in diesem Kollektiv einem Zufall unterlegen ist.

Die Ergebnisse aus Kapitel 3.3.2 zeigen eine stark positive Korrelation zwischen der Größe des Tumors und der Höhe der Konzentration des laborchemisch ermittelten Tumormarkers ß-hCG $(\mathrm{KK}=0,49 ; \mathrm{p}<0$,001) (siehe Abbildung 22). Der Risikofaktor „Tumorgröße“ wird 
in Zusammenschau der Ergebnisse dieser Arbeit ausführlich in Kapitel 4.2 diskutiert. In anderen beschriebenen Kollektiven konnte der hier vorliegende Zusammenhang dieser beiden Faktoren nicht bestätigt werden (Bruns et al. 2005).

\subsubsection{Lactatdehydrogenase}

Der sehr unspezifische Tumormarker LDH spielt besonders in der Prognoseklassifizierung nach Orchiektomie eine entscheidende Rolle. Im fortgeschrittenen Tumorstadium konnten bei Seminomen in ca. 80 \% der Fälle erhöhte LDH-Werte registriert werden. Die LDH als diagnostisches Kriterium scheint dennoch nur selten zur früheren Erkennung von Rezidiven beitragen zu können (Venkitaraman et al. 2007; Vesprini et al. 2012). Häufig werden bei CTUntersuchungen im Rahmen der Nachsorgeprotokolle bildmorphologische Korrelate eines Tumorrezidivs vor einer Erhöhung der Serum-LDH entdeckt (Ackers und Rustin 2006).

Es wird davon ausgegangen, dass sich über die Höhe dieses Markers im Serum Rückschlüsse auf die Wachstumsrate und die Tumorlast ziehen lassen (Gori et al. 2005). Passend dazu zeigen die Ergebnisse aus Kapitel 3.3.2 eine positive Korrelation von Tumorgröße und LDH Werten (siehe Abbildung 22) ( $\mathrm{p}<0$,05). Dieser Zusammenhang - mit Blick auf den in Kapitel 4.2 diskutierten Prädiktor „Tumorgröße“ - lässt die Vermutung zu, dass die Lactatdehydrogenase zumindest als Indikator einer Zunahme der Größe des Primärtumors fungieren kann und so doch mit der Rezidivrate in Zusammenhang stehen könnte.

Isoliert betrachtet lassen die Serum-LDH-Werte bei dem untersuchten Kollektiv keine Rückschlüsse auf den Einfluss in Bezug auf die Rezidivwahrscheinlichkeit zu. Vielmehr konnten bei Patienten mit einem Rückfall $(294,94$ U/I $\pm 166,08)$ im Vergleich zum restlichen Kollektiv $(335,40 \mathrm{U} / \mathrm{I} \pm 265,46)$ niedrigere Werte festgestellt werden. Auch in der dichotomisierten Analyse dieses Markers konnte kein statistisch signifikanter Einfluss ermittelt werden ( $p>$ 0,05). Diese Ergebnisse decken sich mit den in der Literatur beschrieben Untersuchungen zu diesem Thema (Kobayashi et al. 2013).

Die Ergebnisse aus Kapitel 3.3.3 zeigen eine Assoziation zwischen der Höhe des LDH-Spiegels im Serum und dem Auftreten einer Lymphgefäßinvasion im histopathologischen Präparat $(\mathrm{p}<0,05)$ (siehe Abbildung 23). Die Bedeutung der Lymphgefäßinvasion wurde in dieser Arbeit bereits diskutiert. Analysen größerer Kollektive konnten den Zusammenhang dieser beiden Faktoren bestätigen (Yossepowitch et al. 2013).

\subsection{Histopathologische Risikofaktoren}

In diesem Kapitel werden die wesentlichen Daten der histopathologischen Tumorcharakteristika aus Kapitel 3.1.2 vorgestellt und mit Bezug auf die Literatur und die relevanten Ergebnisse der analytischen Statistik der Kapitel 3.3.1, 3.3.2 und 3.3.3 diskutiert. 
Entscheidend für das adjuvante Therapieregime der CSI Patienten ist die Konstellation der histopathologischen Risikofaktoren. Die diskutierten Prädiktoren wie Tumorgröße und Rete-testis-Infiltration sprechen dabei eher für eine ACMT, auch wenn ihre Sensitivität umstritten ist. Es wird davon ausgegangen, dass eine Zunahme der Tumorgröße mit häufigeren Rezidiven korreliert, auch wenn einige Studien dies nicht bestätigen konnten (Tandstad et al. 2011; Kohut et al. 2014). Dabei kann besonders der Unterschied zwischen Tumoren $<4 \mathrm{~cm}$ bzw. >4cm von Relevanz sein (von der Maase et al. 1993; Warde et al. 2002; Nichols et al. 2013; Aparicio et al. 2014; Mortensen et al. 2014; Chung et al. 2015; Boormans et al. 2017). Bei dem vorliegenden Kollektiv konnte diesem möglichen Risikofaktor kein signifikanter Einfluss auf die Rezidivwahrscheinlichkeit nachgewiesen werden ( $p>0,05)$. Dies gelang auch durch Dichotomisierung in Tumoren $<4 \mathrm{~cm}$ bzw. $>4 \mathrm{~cm}$ nicht. Bei einer mittleren Größe der Tumoren von $3,80 \mathrm{~cm}( \pm 2,25)$ fällt auf, dass die untersuchten Tumoren der rezidivierenden Krankheitsverläufe $(\mathrm{n}=16)$ im Mittel $(3,80 \mathrm{~cm} \pm 1,62)$ genau so groß sind wie die der rezidivfreien Patienten $(3,80 \mathrm{~cm} \pm 2,37)$. Limitiert ist die Aussagekraft dieser Ergebnisse durch die geringe Fallzahl. Nichtsdestotrotz verstärkt sich besonders durch die Vielzahl an veröffentlichten Arbeiten zu diesem Thema der Eindruck, dass die Tumorgröße der verlässlichste Risikofaktor zu sein scheint. Die oben genannten Studien umfassen in aller Regel Kollektive von ca. 700 bis hin zu ca. 2000 Patienten. Die Studie von Kohut et al. hat 29000 Patienten eingeschlossen. Die vorliegende Kollektivgröße liegt deutlich darunter.

Auch die Rete testis-Infiltration als histopathologisches Charakteristikum konnte im Rahmen dieser Arbeit nicht als Rezidiv-Prädiktor bestätigt werden ( $p>0,05)$. Bei sieben der 17 (41,18 \%) rezidivierenden Tumoren konnte eine Rete-testis-Infiltration nachgewiesen werden, während sie ebenfalls bei $26(34,67 \%$ ) Patienten ohne bisher bekanntes Rezidiv festgestellt wurde. Im Vergleich zur Tumorgröße scheint die Rete testis-Infiltration als klinischer Prädiktor deutlich umstrittener zu sein. So kamen diverse Studien zu ähnlichen Ergebnissen und konnten keinen signifikanten Einfluss feststellen (Tandstad et al. 2011; Ruf et al. 2013; Kohut et al. 2014; Mortensen et al. 2014; Soper et al. 2014; Chung et al. 2015). Dem gegenüber stehen Forschungsergebnisse anderer Arbeitsgruppen, die diesen Faktor als prädiktiv einstufen (von der Maase et al. 1993; Parker et al. 2002; Warde et al. 2002; Choo et al. 2005; Tandstad et al. 2016; Boormans et al. 2017). Die Analyse des vorliegenden Kollektivs lässt keine finale Schlussfolgerung zu.

Anderen vermeintlich weniger wahrscheinlichen histopathologischen Risikofaktoren wie der Invasion der Seminomzellen in Blut- oder Lymphgefäße oder der Samenstranginfiltration konnte ebenfalls kein statistisch signifikanter Einfluss auf den klinischen Verlauf der Patienten nachgewiesen werden $(p>0,05)$. Die Invasion der kleinen Blutgefäße $\left(V_{1}\right)$ und der Lymphgefäße $\left(\mathrm{L}_{1}\right)$ wurden zwar bereits als Risikofaktoren beschrieben, konnten aber nur in selten Fällen bestätigt werden (Parker et al. 2002; Trevino et al. 2018). Besonders die Invasion von Blutgefäßen im Tumor scheint zwar mit dem Metastasierungspotential zusammen zu hängen, wohl aber nicht mit dem Risiko eines Rezidivs (Valdevenito et al. 2007). 
Die in Kapitel 3.3.3 vorgestellten Ergebnisse der Analyse von Prädiktoren neuer Zielvariablen konnten sowohl einen signifikanten Zusammenhang zwischen der Gefäßinvasion von Tumorzellen im Primarius und der Infiltration des Samenstrangs (Punktschätzer 29,583; 95 \% KI 4,298 - 593,985; $\mathrm{p}=$ 0,0029), als auch zwischen der Gefäßinvasion und der Tumorgröße aufzeigen (Punktschätzer 1,51; 95 \% KI 1,2 - 1,96; p = 0,0008). Besonders der dargestellte statistisch signifikante Zusammenhang zwischen der Gefäßinvasion und dem Vorkommen einer Samenstranginfiltration mit dem angegebenen sehr großen Konfidenzintervall ist kritisch zu betrachten. Es ist davon auszugehen, dass dieses Ergebnis vor allem aufgrund einer sehr niedrigen Eventrate zustande kommt. Lediglich viermal traten beide Faktoren gemeinsam auf, weshalb die Aussagekraft stark limitiert ist und vernachlässigt werden sollte. Im Gegensatz dazu ist bezogen auf dieses Kollektiv das Ergebnis der Analyse von Gefäßinvasion und Tumorgröße zu beachten. Es erscheint plausibel, dass ein Progress im lokalen Wachstum des Tumors mit einer vermehrten Invasion der benachbarten Blutgefäße einher geht. Da im Rahmen der Literaturrecherche keine wesentlichen Erkenntnisse über den Zusammenhang dieser beiden Faktoren gefunden werden konnte, muss davon ausgegangen werde, dass der hier nachgewiesene statistische Zusammenhang eine zufällige Erscheinung ist.

\subsection{Das entzündliche Infiltrat der Seminome}

In diesem Kapitel werden die wesentlichen Charakteristika der speziellen Immunhistochemie der Seminom-Präparate aus Kapiteln 3.2 und die daraus resultierenden Ergebnisse (Kapitel 3.3) diskutiert. Ebenso werden die beiden Methoden zur Beurteilung des entzündlichen Infiltrats (beschrieben in den Kapiteln 2.4.1.1 und 2.4.1.2) und ihre Ergebnisse (Kapitel 3.2.1, 3.2.2) mit Betrachtung des Vergleichs beider Methoden (Kapitel 3.2.3) kritisch beurteilt.

\subsubsection{Heterogenität des entzündlichen Infiltrats im Seminom}

Das entzündliche Infiltrat der untersuchten seminomatösen Tumoren stellt sich sehr heterogen dar. Dies bezieht sich zum einen auf die Quantität des gesamten entzündlichen Infiltrats, auf die Menge der verschiedenen den Tumor infiltrierenden Lymphozyten ( $\mathrm{T}$ - und BZellen) und auf ihr Verteilungsmuster. Während einige Tumore durch vergleichsweise regelmäßig verteiltes Infiltrat gekennzeichnet waren, ließen sich bei anderen Seminomen Hotspots der entzündlichen Infiltration ausmachen, die nicht selten von entzündungsarmen Tumorbereichen begleitet wurden. Bezogen auf die Quantität der Immunozyten über den gesamten Tumor konnte einerseits ein Tumor mit massivem Aufkommen lokaler Entzündungszelle, aber auch Tumoren mit Anteilen unter $10 \%$ beobachtet werde. 


\subsubsection{Das gesamte Infiltrat (CD45 ${ }^{+}$-Zellen)}

Forschungsergebnisse der Vergangenheit legen nahe, dass das Immunsystem und damit die infiltrierenden Lymphozyten an der Kontrolle des Tumors beteiligt sind (Hadrup et al. 2006). Passend zu dieser Hypothese ist die Tatsache, dass AIDS-Infektionen mit einem erhöhten Risiko für Seminome assoziiert sind (Frisch et al. 2001; Rakoff-Nahoum et al. 2006). Zusätzlich konnte im Rahmen einer vergleichbaren Follow-up-Studie von CSI Seminom-Patienten ein signifikanter Zusammenhang zwischen einer in Relation niedrigen lymphozytären Infiltration und dem Auftreten von Rezidiven festgestellt werden (Parker et al. 2002). Bei Untersuchungen fortgeschrittener Tumorstadien zeigten Patienten mit hoher lymphozytärer Tumorinfiltration einen Überlebensvorteil (Evensen et al. 1987). Diese Beobachtung konnte im Rahmen dieser Arbeit nicht bestätigt werden. Das liegt an der geringen Anzahl an Patienten mit einem klinischen Stadium II und/oder III (13 Patienten). Seminome weisen im Vergleich zu Nicht-Seminomen ein deutlich ausgeprägteres Infiltrat auf und haben gleichzeitig eine bessere Prognose (Yakirevich et al. 2002). Das lässt die Schlussfolgerung zu, dass ein ausgeprägtes entzündliches Infiltrat positiven Einfluss auf den klinischen Verlauf hat und eine anti-Tumoraktivität vorliegt.

Die Tumoren dieses Kollektivs zeigten in allen Fällen sowohl die Anwesenheit von B- als auch von T-Lymphozyten. Die Dichte der T-Lymphozyten $(50 \% \pm 0,43)$ stellte sich in aller Regel ausgeprägter als die der B-Lymphozyten $(29 \% \pm 0,47)$ dar. Das ermittelte Verhältnis zwischen Ihnen lag bei 2,88 $( \pm 2,18)$ zu Gunsten der T-Zellen. Andere Untersuchungen stützen diese Beobachtung (Bell et al. 1987; Nakanoma et al. 1992). B-Lymphozyten ordneten sich häufig in Follikel an oder präsentierten sich mit Blick auf das gesamte Präparat eher gruppiert. Dem gegenüber stehen die T-Lymphozyten, deren Verteilung regelmäßiger erschien.

Im vorliegenden Kollektiv konnte kein signifikanter Zusammenhang zwischen der quantitativen Ausprägung des gesamten entzündlichen Infiltrats und der Rezidivwahrscheinlichkeit bzw. dem klinischen Verlauf und dem Tumorstadium (UICC) gefunden werden ( $p>0,05)$. Auch bei der Analyse in Kombination mit anderen kategorialen Zielvariablen konnten keine statistisch signifikanten Ergebnisse erzielt werden. Bemerkenswert ist die negative Korrelation zwischen der Quantität des CD45 ${ }^{+}$-Infiltrats und der T-Zell- $(\mathrm{p}=0,01-0,001) \mathrm{bzw}$. $\mathrm{CD} 8^{+}$-Infiltration $(\mathrm{p}<0,001)$. Bei einer erwarteten positiven Korrelation zwischen einem Subtyp der T-Zellen (CD8 ${ }^{+}$-Zelle) und dem gesamten T-Zell-Infiltrat $(\mathrm{p}<0,001)$ überrascht die Tatsache, dass eine Zunahme der Lymphozyten zu einer Reduktion des Anteils an TLymphozyten führt. Da parallel keine Zunahme der B-Lymphozyten zu verzeichnen ist, muss davon ausgegangen werden, dass der hier suggerierte Zusammenhang aus qualitativen Unterschieden der Immunhistochemie der verschiedenen Färbungen und Auswertungsdefiziten resultiert. Exemplarisch dafür stehen ermittelte Quotienten $>1$ bspw. bei der Bestimmung des T-Zell-Anteils am gesamten Infiltrat $\left(\mathrm{CD}^{+} / \mathrm{CD}^{4} 5^{+}\right)$. Dieser Umstand verdeutlicht 
die Limitation der Aussagekraft in Einzelfällen, nicht jedoch beim Blick auf das gesamte Kollektiv.

\subsubsection{T-Zellen (CD3 ${ }^{+}$-Zellen) und ihre Subtypen (CD4 ${ }^{+}$- und $\mathrm{CD}^{+}$-Zellen)}

Jedes untersuchte Seminom zeigte eine T-Zell-Infiltration (50\% \pm SD 0,43). Vergleicht man die Ergebnisse der rezidivfreien Tumoren mit denen mit rezidivierendem Verlauf, fällt auf, dass sich in allen T-Zell-Differenzierungen $\left(\mathrm{CD}^{+}, \mathrm{CD}^{+}\right.$und $\left.\mathrm{CD}^{+}\right)$im Kollektiv mit Rezidiv eine reduzierte Infiltration zeigt (siehe Kapitel 3.2.2 Tabelle 11). Eine statistische Signifikanz konnte hier jedoch nicht gefunden werden $(p>0,05)$. Dennoch kann man diskutieren, ob die T-Zell-Infiltration im Seminom als prognostischer Parameter etabliert werden kann und ob damit ein niedriges entzündliches Infiltrat zu erhöhten Rezidivraten führt. Bei anderen Tumoren wie bspw. dem kolorektalen Karzinom, dem ösophagealen Karzinom oder dem Mamma-Karzinom wurde die lymphozytäre Infiltration bereits als prognostisches Kriterium anerkannt (Marrogi et al. 1997). Dabei spielt die zytotoxische T-Zell-Aktivität (CD8 ${ }^{+}$) eine zentrale Rolle (Ropponen et al. 1997; Schumacher et al. 2001). Seminome zeichnen sich im Vergleich zu Nicht-Seminomen durch eine höhere T-Zell-Infiltration aus und zeigen bessere Prognosen (Torres et al. 1997). Tatsächlich konnten Korrelationen zwischen T-Zellen und dem rezidivfreien Überleben festgestellt werden (Siska et al. 2017). Dem gegenüber stehen die Untersuchung der Arbeitsgruppe um Hvarness et al., die das charakteristische Immuninfiltrat im Hodentumor auch in vergleichbarer Weise im gesunden Gewebe bzw. bei der Abwesenheit von Tumorzellen nachweisen konnten und daraus schlussfolgerten, dass es keine aktive immunologische Kontrolle von Hodentumoren geben könne (Hvarness et al. 2013). Die Analyse der vorliegenden Seminome lässt diesbezüglich keine abschließende Beurteilung zu.

Bei der Analyse kontinuierlicher Variablen zeigte sich ein statistisch signifikanter Zusammenhang zwischen dem T-Zell-Infiltrat und der Höhe des Tumormarkers B-hCG im Serum (p $=0,01-0,05)$. Hierbei handelt es sich um eine negative Korrelation $(\mathrm{KK}=-0,27)$. Das bedeutet, dass die Zunahme der T-Zell Infiltration im Tumor zu einer Reduktion der gemessenen B-hCG-Werte im Serum führt. Die Zusammenschau der bereits diskutierten Ergebnisse der $\mathrm{CD}^{+}{ }^{+}$-Präsenz im Primarius und der ebenso thematisierten Bedeutung des Tumormarkers B-hCG lässt erneut die Hypothese zu, dass eine hohe T-Zell Infiltration den klinischen Verlauf begünstigt und so von prognostischer Relevanz sein kann. Zusätzlich besteht - wie bereits erwähnt - eine stark positive Korrelation zwischen den Faktoren „Tumorgröße“ und „ß-hCG“. Es konnte zwar keine signifikante Korrelation zwischen der T-Zell Infiltration und der Tumorgröße nachgewiesen werden, dennoch ist es durchaus möglich, dass über die lokale Tumorkontrolle der T-Zellen und dem skizzierten Zusammenhang der T-Zellen und dem Serum Marker B-hCG Einfluss auf den sichersten aller Seminom Rezidivrisiko Faktoren „Tumorgröße“ genommen wird. 
Die Tumoren dieses Kollektivs zeigten in aller Regel eine Dominanz der CD4 ${ }^{+}$-Zellen und damit einen positiven $\mathrm{CD}^{+} / \mathrm{CD}^{+}$-Quotienten. Andere Untersuchungen konnte dieses Verteilungsmuster nicht bestätigen (Nakanoma et al. 1992; Nouri et al. 1993; Bols et al. 2000). Im Vergleich zeigten die Patienten mit einem Rezidiv einen niedrigeren Quotienten und damit einen relativ erhöhten Anteil an zytotoxischen T-Zellen $\left(\mathrm{CD} 8^{+}\right)$. Da besonders bei diesem Zelltyp ein positiver Einfluss auf den Krankheitsverlauf vermutet wird, überraschen die Ergebnisse (Pagès et al. 2010). Nichtsdestotrotz sollte die Validität der vorliegenden Daten zum $\mathrm{CD}^{+}$- und $\mathrm{CD}^{+}$-Infiltrat nicht in Frage gestellt werden. Bei 14 immunhistochemisch ausgewerteten Gewebeproben können Abweichungen zu Analysen größerer Kollektive entstehen.

\subsubsection{B-Zellen (CD20 ${ }^{+}$-Zellen)}

Die häufig in Follikeln und gruppiert erscheinenden B-Lymphozyten waren in jedem Tumor präsent, stellten aber den kleinsten Anteil (29\% \pm SD 0,47) am entzündlichen Infiltrat dar. Dies deckt sich mit den Untersuchungen anderer Arbeitsgruppen (Nakanoma et al. 1992). Die Rolle der B-Zellen und die von ihnen produzierten Antikörper wird in Bezug auf die immunologische Tumorkontrolle sehr kontrovers diskutiert. Für diverse Tumoren gibt es beschriebene Antigene, die als Target einer AK Reaktion dienen könnten (Reuschenbach et al. 2009). Zusätzlich kommt der B-Zelle über ihren regulatorischen Einfluss auf T-Zellen und ihre Subtypen eine entscheidende Rolle zu (Yuen et al. 2016). Die Ergebnisse dieser Arbeit konnten keinen signifikanten Einfluss auf den klinischen Verlauf der Patienten detektieren. In Relation zum gesamten entzündlichen Infiltrat konnte bei den Rezidivpatienten $(24 \% \pm$ SD 0,14) im Vergleich zu Patienten ohne Rezidiv (30\% \pm SD 0,52) eine reduzierte B-Zell Infiltration beobachtet werden. Diese Tendenz stützt die Vermutung, dass B-Zellen und ihre AK-Produktion positiven klinischen Einfluss nehmen und deshalb auch in der Therapie eine wichtig Rolle spielen können (Kim et al. 2007; Grivennikov et al. 2010; Gunderson und Coussens 2013).

\subsection{Vergleich der Methoden zur Analyse der speziellen Immunhistochemie der Seminome}

Zur Analyse des entzündlichen Infiltrats $\left(\mathrm{CD} 45^{+}\right)$wurden die beiden in Kapitel 2.4 beschrieben Methoden verwendet. In Kapitel 3.2.3 wurden die Ergebnisse dieser beiden Methoden gegenübergestellt. In diesem Kapitel soll besonders die Validität der Analyse mithilfe des Bildbearbeitungs- und Auswertungsprogramms ImageJ im Vergleich zur klassischen mikroskopischen Analyse diskutiert werden.

Die Ergebnisse aus Kapitel 3.2.3 zeigen, dass bei der Einteilung der Quantität des entzündlichen Infiltrats in die beschriebenen Kategorien (siehe Kapitel 2.4.1.1, Tabelle 13) lediglich bei 6 Tumoren unterschiedliche Kategorien gewählt wurden. Dabei liegt in keinem Fall eine 
Abweichung $>1$ Kategorie vor. Insgesamt stellt sich über alle Tumoren der prozentuale Anteil des Infiltrats bei der mikroskopischen Analyse mit $23 \%$ dar, während die Ergebnisse mit ImageJ ein mittleres entzündliches Infiltrat von $25 \%$ gezeigt haben. Damit weichen die beiden Methoden bei Betrachtung des gesamten Kollektivs lediglich um $2 \%$ voneinander ab. Die maximale Abweichung beider Methoden in der Beurteilung des entzündlichen Infiltrats lag bei $23 \%$. Die skizzierten Ergebnisse lassen wenig Zweifel an ihrer Verlässlichkeit zu.

Es handelt sich bei beiden Auswertungsvarianten um untersucherabhängige Methoden und daher um nicht standardisierte Verfahren. Mit den ersten Auswertungen der immunhistochemischen Hodentumorpräparate mittels ImageJ sind einzelne Färbungen mehrfach zeitlich versetzt analysiert worden. Die so ermittelten Anteile des entzündlichen Infiltrats an der Gesamtfläche des Tumors wichen nie in der Einteilung in die dargestellten Kategorien, und in unter $10 \%$ um mehr als $5 \%$ von vorherigen Untersuchungen ab. Daraus lässt sich schlussfolgern, dass die vorliegenden Ergebnisse sehr verlässlich sind.

Bei der Beurteilung der Verlässlichkeit der Ergebnisse darf nicht vergessen werden, dass gerade bei der Auswertungsmethode mit ImageJ durch den Untersucher ein repräsentativer Ausschnitt des immunhistochemisch gefärbten Seminoms gewählt wurde. Damit einher geht die Tatsache, dass andere Bildbereiche des Tumors in dieser Auswertung keine Berücksichtigung finden. Relativierend wirken die sehr vergleichbaren Resultate der mikroskopischen Auswertung, die zehn FOV berücksichtigt und damit nahezu das vollständige Präparat abdecken.

Insgesamt zeigen beide Methoden sehr ähnliche Ergebnisse und weichen nur in Einzelfällen wirklich relevant voneinander ab. Die Auswertung mittels ImageJ kann daher auch für künftigen Projekten als objektivierbare Methode angewendet werden.

\subsection{Ausblick}

Die Ergebnisse dieser Arbeit konnten Hinweise auf relevante klinische Parameter und die Bedeutung des entzündlichen Infiltrats im Hodentumor geben. Neben den bereits in vielen Studien untersuchten Zusammenhängen zwischen klinischen Einflussfaktoren und der Rezidivwahrscheinlichkeit von Seminompatienten stellt der zweite Schwerpunkt dieser Arbeit - das entzündliche Infiltrat im Tumor - ein interessantes und facettenreiches Forschungsthema dar.

Sicher ist, dass sich Hodentumoren und besonders Seminome durch eine exzellente Prognose auszeichnen und parallel durch ein ausgeprägtes entzündliches Infiltrat gekennzeichnet sind. Die Kombination dieser Beobachtungen lässt die starke Vermutung zu, dass eine körpereigene inflammatorische Reaktion bedeutsam für den klinischen Verlauf der Patienten ist. Das Verständnis der Bedeutung des entzündlichen Infiltrats im Tumor kann sowohl bei Prognoseklassifizierungen und damit bei der Entscheidung des sinnvollsten Therapieregimes 
als auch für die Entwicklung neuer immunologischer Therapieansätze bedeutsam werden. Daher scheinen weitere Analysen größerer Kollektive mit im Ppeziellen einer höheren Anzahl an Rezidivpatienten sinnvoll.

Sehr relevant ist dabei die Bedeutung der T-Zellen. Im Rahmen des Bestrebens, alternative Therapieformen zur Chemo- und Strahlentherapie zu finden, repräsentiert die Immuntherapie basierend auf Eigenschaften von T-Zellen ein an Wichtigkeit immer mehr zunehmendes Kapitel der immunologischen antineoplastischen Forschung und zukünftiger Therapieansätze. Im Speziellen versucht man, sich die Eigenschaften dieser den Tumor infiltrierenden Immunzellen durch Isolation, Sequenzierung und Klonierung zu Nutze zu machen. Damit einher geht die Suche nach Antigenen der Seminome, die als Target einer möglichen Immuntherapie fungieren können.

Im Rahmen dieser Arbeit wurde in Versuchen auch das Protein ZAP70 (Zeta-Ketten-assoziiertes Protein mit einem Gewicht von $70 \mathrm{kDa}$ ) und dessen Präsenz im Seminom immunhistochemisch untersucht. ZAP70 als integraler Bestandteil des TCRs ist eine essentielle Komponente der T-Zell-Signalkaskade und spielt als prognostischer Marker bei anderen Tumorerkrankungen eine Rolle und kann als wichtiges Target des T-Cell Controllings und so der T-Zell-vermittelten Immunantwort fungieren (Chan et al. 1992; Arpaia et al. 1994; Chan et al. 1994; Elder et al. 1994; Au-Yeung et al. 2009; Wang et al. 2010; Yan et al. 2013; Courtney et al. 2018). Die Auswertung dieser Färbungen der Seminomschnitte gestaltete sich jedoch als schwierig und wenig aussagekräftig, weshalb sie nicht als Teil dieser Arbeit geführt werden. Ein Grund dafür ist, dass die Anti-ZAP70(P)-AK methodisch neu etabliert werden mussten, welches trotz mehrfacher Versuche nicht gelang. Daraus resultierend konnten bei vielen immunhistochemischen Präparaten keine eindeutig ZAP70-positiven Zellen identifiziert und nachfolgend ausgewertet werden. Wie bereits in dem Kapitel „Zielsetzung und Fragestellung“ erwähnt, könnte ein Schlüssel der adäquaten Risikostratifizierung jedes Patienten in der Analyse molekularer Marker liegen. In Voruntersuchungen wurde ZAP 70 bereits bei cisplatinresistenten Hodentumoren untersucht und es konnte eine signifikante Überexpression dieses Proteins und seiner phosphorylierten Form im Vergleich zu sensibleren Tumoren nachgewiesen werden. Es erscheint daher lohnenswert, auch in künftigen Arbeiten nach potentiellen Risikomarkern in Hodentumoren zu suchen und die Rolle der T-Zell-Signalkaskade und ihrer Komponenten für die Klinik der Patienten zu begreifen.

Abschließend bleibt zu sagen, dass die Zukunft der modernen antineoplastischen Medizin wahrscheinlich auf molekularer Ebene liegt. Die so mögliche individuelle Therapie des einzelnen Patienten adaptiert an sein molekulares Risikoprofil ist bereits wesentlicher Bestandteil vieler verschiedener Tumorerkrankungen und wird künftig an Relevanz gewinnen.

Die Immuntherapie mit all ihren Facetten (Checkpoint-Inhibitoren, CAR-T-Zell-Therapie, Immunmodulatoren etc.) ist ein aktuell intensiv beforschtes Thema. In den Therapiealgorithmen bei Hodentumoren und Seminomen spielt sie bis heute keine Rolle. Dabei könnte 
der wissenschaftliche Fortschritt mit Blick auf die Bedeutung des entzündlichen Infiltrats neue Möglichkeiten in der Tumortherapie bei Hodentumoren schaffen. 


\section{$5 \quad$ Zusammenfassung}

Mit dieser retrospektiven Studie und der Analyse der speziellen Immunhistochemie wurde die Bedeutung des entzündlichen Infiltrats im Seminom und klinischer Charakteristika auf den Krankheitsverlauf der Patienten untersucht. Dabei lag besonderes Augenmerk auf der Evaluation potentieller Rezidiv-Prädiktoren.

Bei einer Rezidivrate von 18 \% (17 von 92 Patienten) konnten die Faktoren „ß-hCG erhöht“, „Alter bei Diagnose“ und „Chemotherapie“ als statistisch signifikante Prädiktoren für bzw. wider das Auftreten eines Rezidivs ermittelt werden. Patienten mit ß-hCG-Werten über dem Cut-off-Wert für erhöhte Markerkonzentrationen zeigten im Vergleich zu Patienten ohne erhöhte B-hCG-Werte ein um den Faktor 3,34 erhöhtes Risiko ein Rezidiv zu erleiden. Pro Zunahme des Alters um ein Jahr bei Diagnosestellung reduziert sich das Risiko, ein Rezidiv zu erleiden, um 4\%. Ein adjuvanter Zyklus Carboplatin reduziert statistisch signifikant das Risiko eines Rezidivs um 86,5 \% im Vergleich zu Patienten, die keine AMCT erhielten. Nach Polychemotherapie sinkt das Risiko für ein Rezidiv betroffener Patienten um 90,1 \% im Vergleich zu Patienten, die keine APCT erhielten.

Die Analyse von Abhängigkeiten kontinuierlicher Variablen ergab relevante Zusammenhänge zwischen dem Faktor „Tumorgröße“ und den beiden Tumormarkern „LDH“ und „ßhCG“ ( $\mathrm{p}<0,05)$. Die Zunahme der präoperativ laborchemisch ermittelten Tumormarker LDH oder B-hCG korreliert positiv mit der Größe des Tumors. Zusätzlich zeigte sich eine statistisch signifikante Abhängigkeit zwischen der T-Zell-Infiltration und B-hCG. Die Quantität des T-Zell-Infiltrats korreliert negativ mit der Höhe des Tumormarkers B-hCG. Je höher sich das $\mathrm{CD}^{+}{ }^{+}$-positive immunozytäre Infiltrat im Tumor darstellt, desto niedriger fallen die ermittelten B-hCG-Werte aus.

Bei der statistischen Auswertung des entzündlichen Infiltrats wurde eine positive Korrelation zwischen dem T-Zell-Infiltrat und der Quantität der CD8 ${ }^{+}$-Zellen (zytotoxischen T-Zellen) gefunden. Im Gegensatz dazu zeigte sich eine statistisch relevante negative Korrelation zwischen der Infiltration von T-Helferzellen $\left(\mathrm{CD}^{+}\right)$und zytotoxischen T-Zellen $\left(\mathrm{CD} 8^{+}\right)$. Zusätzlich korreliert das gesamte immunozytäre Infiltrat $\left(\mathrm{CD} 45^{+}\right)$negativ mit dem Ausmaß der Infiltration des Seminoms durch zytotoxische T-Zellen $\left(\mathrm{CD} 8^{+}\right)$.

Im Rahmen der Analyse neuer Zielvariablen und möglicher Prädiktoren zeigten sich diverse statistisch signifikante Zusammenhänge. Für die Zielvariable „Lymphgefäßinvasion“ konnten die Prädiktoren „LDH“ und „Alter bei Diagnose“ bestimmt werden. Bei der Analyse der Zusammenhänge mit der Zielvariable „Gefäßinvasion“ konnten drei Prädiktoren ermittelt werden. Dabei zeigten die Faktoren (unabhängigen Variablen) „Samenstranginfiltration“, „T-Zell-Infiltration“, und „Tumorgröße“ einen signifikanten Einfluss auf die Häufigkeit des Auftretens einer Gefäßinvasion von Tumorzellen im Primärtumor.

In Anbetracht der Ergebnisse der beiden Methoden zur quantitativen Bestimmung des inflammatorischen Infiltrats im Seminom konnten kaum bemerkenswerte Abweichungen 
festgestellt werden. Die Analyse mit ImageJ gleichen in vielen Fällen den durch professionelle Mikroskopie ermittelten Anteilen des entzündlichen Infiltrats am Tumor und können daher auch für Folgeprojekte als Methode Anwendung finden. 


\section{$6 \quad$ Literaturverzeichnis}

Ackers C, Rustin GJS (2006): Lactate dehydrogenase is not a useful marker for relapse in patients on surveillance for stage I germ cell tumours. Br J Cancer 244, 1231-1232

Albers P, Albrecht W, Algaba F, Bokemeyer C, Cohn-Cedermark G, Fizazi K, Horwich A, Laguna MP (2011): EAU Guidelines on Testicular Cancer: 2011 Update. Eur Urol 60, 304 319

Albers P, Albrecht W, Algaba F, Bokemeyer C, Cohn-Cedermark G, Fizazi K, Horwich A, Laguna MP, Nicolai N, Oldenburg J, European Association of Urology (2015): Guidelines on Testicular Cancer: 2015 Update. Eur Urol 68, 1054-1068

Alexander EJ, White IM, Horwich A (2010): Update on management of seminoma. Indian J Urol 26, 82-91

Aparicio J, Maroto P, García del Muro X, Sánchez-Muñoz A, Gumà J, Margelí M, Sáenz A, Sagastibelza N, Castellano D, Arranz JA, et al. (2014): Prognostic factors for relapse in stage I seminoma: a new nomogram derived from three consecutive, risk-adapted studies from the Spanish Germ Cell Cancer Group (SGCCG). Ann Oncol 25, 2173-2178

Arpaia E, Shahar M, Dadi H, Cohen A, Roifman CM (1994): Defective T cell receptor signaling and $\mathrm{CD} 8+$ thymic selection in humans lacking zap-70 kinase. Cell $\underline{76}$, 947-958

Au-Yeung BB, Deindl S, Hsu L-Y, Palacios EH, Levin SE, Kuriyan J, Weiss A (2009): The structure, regulation, and function of ZAP-70. Immunol Rev 228, 41-57

Bahrami A, Ro JY, Ayala AG (2007): An overview of testicular germ cell tumors. Arch Pathol Lab Med 131, 1267-1280

Bell DA, Flotte TJ, Bhan AK (1987): Immunohistochemical characterization of seminoma and its inflammatory cell infiltrate. Hum Pathol 18, 511-520

Beyer J, Albers P, Altena R, Aparicio J, Bokemeyer C, Busch J, Cathomas R, Cavallin-Stahl E, Clarke NW, Claßen J, et al. (2013): Maintaining success, reducing treatment burden, focusing on survivorship: highlights from the third European consensus conference on diagnosis and treatment of germ-cell cancer. Ann Oncol 24, 878-888

Boccellino M, Vanacore D, Zappavigna S, Cavaliere C, Rossetti S, D’Aniello C, Chieffi P, Amler E, Buonerba C, Di Lorenzo G, et al. (2017): Testicular cancer from diagnosis to epigenetic factors. Oncotarget $\underline{8}, 104654-104663$

Bols B, Jensen L, Jensen A, Braendstrup O (2000): Immunopathology of in situ seminoma. Int J Exp Pathol 1ㅗ, 211-217

Boormans JL, Mayor de Castro J, Marconi L, Yuan Y, Laguna Pes MP, Bokemeyer C, Nicolai N, Algaba F, Oldenburg J, Albers P (2017): Testicular Tumour Size and Rete Testis Invasion as Prognostic Factors for the Risk of Relapse of Clinical Stage I Seminoma Testis Patients Under Surveillance: a Systematic Review by the Testicular Cancer Guidelines Panel. Eur Urol 
73, 394-405

Borski AA (1973): Diagnosis, staging, and natural history of testicular tumors. Cancer $\underline{32}$, 1202-1205

Bosl GJ, Lange PH, Nochomovitz LE, Goldmann A, Fraley EE, Rosai J, Johnson K, Kennedy BJ (1981): Tumor markers in advanced nonseminomatous testicular cancer. Cancer $\underline{47}$, $572-576$

Boujelbene N, Cosinschi A, Boujelbene N, Khanfir K, Bhagwati S, Herrmann E, Mirimanoff R-O, Ozsahin M, Zouhair A (2011): Pure seminoma: A review and update. Radiat Oncol $\underline{6}$, 90

Bruns F, Raub M, Schaefer U, Micke O (2005): No predictive value of beta-hCG in patients with stage I seminoma--results of a long-term follow-up study after adjuvant radiotherapy. Anticancer Res 25, 1543-1546

Chan AC, Iwashima M, Turck CW, Weiss A (1992): ZAP-70: a $70 \mathrm{kd}$ protein-tyrosine kinase that associates with the TCR zeta chain. Cell $\underline{71}, 649-662$

Chan AC, Kadlecek TA, Elder ME, Filipovich AH, Kuo WL, Iwashima M, Parslow TG, Weiss A (1994): ZAP-70 deficiency in an autosomal recessive form of severe combined immunodeficiency. Science 264, 1599-1601

Choo R, Thomas G, Woo T, Lee D, Kong B, Iscoe N, Danjoux C, Klotz L, Morton G, Chander S (2005): Long-term outcome of postorchiectomy surveillance for Stage I testicular seminoma. Int J Radiat Oncol Biol Phys $\underline{61}, 736-740$

Chung P, Warde P (2006): Surveillance in stage I testicular seminoma. Urol Oncol 24 , 75-79

Chung P, Daugaard G, Tyldesley S, Atenafu EG, Panzarella T, Kollmannsberger C, Warde P (2015): Evaluation of a prognostic model for risk of relapse in stage I seminoma surveillance. Cancer Med $\underline{4}, 155-160$

Clark WH (1991): Tumour progression and the nature of cancer. Br J Cancer $\underline{64}$, 631-644

Classen J, Schmidberger H, Meisner C, Souchon R, Sautter-Bihl M-L, Sauer R, Weinknecht S, Köhrmann K-U, Bamberg M (2003): Radiotherapy for stages IIA/B testicular seminoma: final report of a prospective multicenter clinical trial. J Clin Oncol 21, 1101-1106

Colls BM, Harvey VJ, Skelton L, Frampton CM, Thompson PI, Bennett M, Perez DJ, Dady PJ, Forgeson GV, Kennedy IC (1999): Late results of surveillance of clinical stage I nonseminoma germ cell testicular tumours: 17 years' experience in a national study in New Zealand. BJU Int $\underline{83}, 76-82$

Courtney AH, Lo W-L, Weiss A (2018): TCR Signaling: Mechanisms of Initiation and Propagation. Trends Biochem Sci $\underline{43}, 108-123$

Dalal PU, Sohaib SA, Huddart R (2006): Imaging of testicular germ cell tumours. Cancer Imaging $\underline{6}, 124-134$ 
Daugaard G, Gundgaard MG, Mortensen MS, Agerbæk M, Holm NV, Rørth M, von der Maase H, Christensen IJ, Lauritsen J (2014): Surveillance for stage I nonseminoma testicular cancer: outcomes and long-term follow-up in a population-based cohort. J Clin Oncol $\underline{32}$, $3817-3823$

Dieckmann K-P, Dralle-Filiz I, Matthies C, Heinzelbecker J, Bedke J, Ellinger J, Anheuser P, Souchon R, Pichlmeier U, German Testicular Cancer Study Group (2016): Testicular seminoma clinical stage 1: treatment outcome on a routine care level. J Cancer Res Clin Oncol 142, 1599-1607

Dunphy CH, Ayala AG, Swanson DA, Ro JY, Logothetis C (1988): Clinical stage I nonseminomatous and mixed germ cell tumors of the testis. A clinicopathologic study of 93 patients on a surveillance protocol after orchiectomy alone. Cancer 62, 1202-1206

Elder ME, Lin D, Clever J, Chan AC, Hope TJ, Weiss A, Parslow TG (1994): Human severe combined immunodeficiency due to a defect in ZAP-70, a T cell tyrosine kinase. Science 264, 1596-1599

Evensen JF, Fosså SD, Kjellevold K, Lien HH (1987): Testicular seminoma: histological findings and their prognostic significance for stage II disease. J Surg Oncol 36, 166-169

Ferlay J, Soerjomataram I, Dikshit R, Eser S, Mathers C, Rebelo M, Parkin DM, Forman D, Bray F (2015): Cancer incidence and mortality worldwide: sources, methods and major patterns in GLOBOCAN 2012. Int J Cancer 136, E359-386

Fosså A, Fosså SD (1989): Serum lactate dehydrogenase and human choriogonadotrophin in seminoma. Br J Urol 63, 408-415

Fosså SD, Jacobsen AB, Aass N, Heilo A, Stenwig AE, Kummen O, Johannessen NB, Waaler G, Ogreid P, Borge L (1994): How safe is surveillance in patients with histologically low-risk non-seminomatous testicular cancer in a geographically extended country with limited computerised tomographic resources? Br J Cancer $\underline{70}$, 1156-1160

Fosså SD, Aass N, Heilo A, Daugaard G, E Skakkebaek N, Stenwig AE, Nesland JM, Looijenga LHJ, Oosterhuis JW (2003): Testicular carcinoma in situ in patients with extragonadal germ-cell tumours: the clinical role of pretreatment biopsy. Ann Oncol 14, 1412-1418

Frisch M, Biggar RJ, Engels EA, Goedert JJ, AIDS-Cancer Match Registry Study Group (2001): Association of cancer with AIDS-related immunosuppression in adults. JAMA $\underline{285}$, $1736-1745$

Fukawa T, Kanayama H (2018): Current knowledge of risk factors for testicular germ cell tumors. Int J Urol 25, 337-344

Gorbonos A (2015): Stage 1 Testicular Seminoma: Observation. J Urol 193, 1886-1887

Gori S, Porrozzi S, Roila F, Gatta G, De Giorgi U, Marangolo M (2005): Germ cell tumours of the testis. Crit Rev Oncol Hematol $\underline{53}, 141-164$ 
Grivennikov SI, Greten FR, Karin M (2010): Immunity, inflammation, and cancer. Cell 140 , 883-899

Guan X-F, Deng Y-L, Liu Q-M, Zhou D-X, Yang Y-K, Lu K, Li F (2013): [Changes of AFP and beta-hCG in testicular tumors analyzed by a function method]. Zhonghua Nan Ke Xue $\underline{19}, 59-62$

Gunderson AJ, Coussens LM (2013): B cells and their mediators as targets for therapy in solid tumors. Exp Cell Res 319, 1644-1649

Hadrup SR, Brændstrup O, Jacobsen GK, Mortensen S, Pedersen LØ, Seremet T, Andersen MH, Becker JC, Straten P thor (2006): Tumor infiltrating lymphocytes in seminoma lesions comprise clonally expanded cytotoxic T cells. Int J Canc 119, 831-838

Hadziselimović F, Kruslin E (1979): The role of the epididymis in descensus testis and the topographical relationship between the testis and epididymis from the sixth month of pregnancy until immediately after birth. Anat Embryol 155, 191-196

Heinzelbecker J, Katzmarzik M, Weiss C, Trojan L, Michel MS, Haecker A (2011): Changes of stage, predictive factors and adjuvant treatment modalities in seminomatous testicular cancer from 1987 to 2007 and their impact on the status of metastasis, recurrence-free and overall survival: a single-center analysis. Urol Int $\underline{87}, 282-287$

Hemminki K, Chen B (2006): Familial risks in testicular cancer as aetiological clues. Int J Androl 29, 205-210

Hori K, Uematsu K, Yasoshima H, Yamada A, Sakurai K, Ohya M (1997): Testicular seminoma with human chorionic gonadotropin production. Pathol Int 47, 592-599

Hvarness T, Nielsen JE, Almstrup K, Skakkebaek NE, Rajpert-De Meyts E, Claesson MH (2013): Phenotypic characterisation of immune cell infiltrates in testicular germ cell neoplasia. J Reprod Immunol 100, 135-145

Johnson DE, Gomez JJ, Ayala AG (1976): Histologic factors affecting prognosis of pure seminoma of the testis. South Med J 69, 1173-1174

Jones G, Arthurs B, Kaya H, MacDonald K, Qin R, Fairbanks RK, Lamoreaux W'T, Jawed I, Tward JD, Martincic D, et al. (2013): Overall Survival Analysis of Adjuvant Radiation Versus Observation in Stage I Testicular Seminoma: A Surveillance, Epidemiology, and End Results (SEER) Analysis. Am J Clin Oncol $\underline{36}$, 500-504

Kamba T, Kamoto T, Okubo K, Teramukai S, Kakehi Y, Matsuda T, Ogawa O (2010): Outcome of different post-orchiectomy management for stage I seminoma: Japanese multiinstitutional study including 425 patients. Int J Urol $\underline{17}$, 980-987

Khan O, Protheroe A (2007): Testis cancer. Postgrad Med J 83, 624-632

Kim R, Emi M, Tanabe K (2007): Cancer immunoediting from immune surveillance to immune escape. Immunology 121, 1-14 
Kobayashi K, Saito T, Kitamura Y, Nobushita T, Kawasaki T, Hara N, Takahashi K (2013): Oncological outcomes in patients with stage I testicular seminoma and nonseminoma: pathological risk factors for relapse and feasibility of surveillance after orchiectomy. Diagn Pathol $\underline{8}, 57$

Kohut RM, Minnillo BJ, Kypriotakis G, Abouassaly R, Zhu H (2014): Changes in adjuvant therapy utilization in stage I seminoma: are they enough to prevent overtreatment? Urology 84, 1319-1324

Krege S, Beyer J, Souchon R, Albers P, Albrecht W, Algaba F, Bamberg M, Bodrogi I, Bokemeyer C, Cavallin-Ståhl E, et al. (2008): European Consensus Conference on Diagnosis and Treatment of Germ Cell Cancer: A Report of the Second Meeting of the European Germ Cell Cancer Consensus group (EGCCCG): Part I. Eur Urol 53, 478-496

Larosa DF, Orange JS (2008): 1. Lymphocytes. J Allergy Clin Immunol 121, 364-369

LeBien TW, Tedder TF (2008): B lymphocytes: how they develop and function. Blood 112 , $1570-1580$

Leman ES, Gonzalgo ML (2010): Prognostic features and markers for testicular cancer management. Indian J Urol 26, 76-81

Leung E, Warde P, Jewett M, Panzarella T, O’Malley M, Sweet J, Moore M, Sturgeon J, Gospodarowicz M, Chung P (2013): Treatment burden in stage I seminoma: a comparison of surveillance and adjuvant radiation therapy. BJU Int 112, 1088-1095

Lipphardt ME, Albers P (2004): Late relapse of testicular cancer. World J Urol 22, 47-54

Luckheeram RV, Zhou R, Verma AD, Xia B (2012): CD4+T Cells: Differentiation and Functions. Clin Dev Immunol 2012, 12

von der Maase H, Specht L, Jacobsen GK, Jakobsen A, Madsen EL, Pedersen M, Rørth M, Schultz H (1993): Surveillance following orchidectomy for stage I seminoma of the testis. Eur J Cancer 29A, 1931-1934

Manecksha RP, Fitzpatrick JM (2009): Epidemiology of testicular cancer. BJU International $\underline{104}, 1329-1333$

Marrogi AJ, Munshi A, Merogi AJ, Ohadike Y, El-Habashi A, Marrogi OL, Freeman SM (1997): Study of tumor infiltrating lymphocytes and transforming growth factor-beta as prognostic factors in breast carcinoma. Int J Cancer 74, 492-501

McGlynn KA, Cook MB (2009): Etiologic factors in testicular germ cell tumors. Future On$\operatorname{col} \underline{5}, 1389-1402$

Mikuz G (2014): Hodenkrebs - eine Frage der Geographie? Pathologe 35, 211-217

Moch H, Cubilla AL, Humphrey PA, Reuter VE, Ulbright TM (2016): The 2016 WHO Classification of Tumours of the Urinary System and Male Genital Organs-Part A: Renal, Penile, and Testicular Tumours. Eur Urol 70, 93-105 
Mortensen MS, Lauritsen J, Gundgaard MG, Agerbæk M, Holm NV, Christensen IJ, von der Maase H, Daugaard G (2014): A nationwide cohort study of stage I seminoma patients followed on a surveillance program. Eur Urol 66, 1172-1178

Mosillo C, Scagnoli S, Pomati G, Caponnetto S, Mancini ML, Bezzi M, Cortesi E, Gelibter A (2017): Burned-Out Testicular Cancer: Really a Different History? Case Rep Oncol 10 , 846-850

Mostafa T, Labib I, El-Khayat Y, El-Rahman El-Shahat A, Gadallah A (2008): Human testicular arterial supply: gross anatomy, corrosion cast, and radiologic study. Fertil Steril $\underline{90}$, $2226-2230$

Müller J, Schrader AJ, Jentzmik F, Schrader M (2011): [Assessment of residual tumours after systemic treatment of metastatic seminoma: ${ }^{18} \mathrm{~F}$-2-fluoro-2-deoxy-D-glucose positron emission tomography - meta-analysis of diagnostic value]. Urologe A $\underline{50}, 322-327$

Nakanoma T, Nakamura K, Deguchi N, Fujimoto J, Tazaki H, Hata J (1992): Immunohistological analysis of tumour infiltrating lymphocytes in seminoma using monoclonal antibodies. Virchows Arch A Pathol Anat Histopathol 421, 409-413

Nayan M, Jewett MAS, Hosni A, Anson-Cartwright L, Bedard PL, Moore M, Hansen AR, Chung P, Warde P, Sweet J, et al. (2017): Conditional Risk of Relapse in Surveillance for Clinical Stage I Testicular Cancer. Eur Urol 71, 120-127

Nichols CR, Roth B, Albers P, Einhorn LH, Foster R, Daneshmand S, Jewett M, Warde P, Sweeney CJ, Beard C, et al. (2013): Active surveillance is the preferred approach to clinical stage I testicular cancer. J Clin Oncol 31, 3490-3493

Nouri AM, Hussain RF, Oliver RT, Handy AM, Bartkova I, Bodmer JG (1993): Immunological paradox in testicular tumours: the presence of a large number of activated T-cells despite the complete absence of MHC antigens. Eur J Cancer 29A, 1895-1899

Oliver RTD, Mason MD, Mead GM, von der Maase H, Rustin GJS, Joffe JK, de Wit R, Aass N, Graham JD, Coleman R, et al. (2005): Radiotherapy versus single-dose carboplatin in adjuvant treatment of stage I seminoma: a randomised trial. Lancet 366 , 293-300

Ondrusova M, Ondrus D, Miskovska V, Kajo K, Szoldova K, Usakova V, Stastna V (2015): Management of clinical stage I testicular seminoma: active surveillance versus adjuvant chemotherapy. Int Urol Nephrol 47, 1143-1147

Ondrusova M, Balogova S, Lehotska V, Kajo K, Mrinakova B, Ondrus D (2016): Controversies in the management of clinical stage I testicular seminoma. Cent Eur J Urol 69, 35-39 Pagès F, Galon J, Dieu-Nosjean M-C, Tartour E, Sautès-Fridman C, Fridman W-H (2010): Immune infiltration in human tumors: a prognostic factor that should not be ignored. Oncogene 29, 1093-1102

Parker C, Milosevic M, Panzarella T, Banerjee D, Jewett M, Catton C, Tew-George B, 
Gospodarowicz M, Warde P (2002): The prognostic significance of the tumour infiltrating lymphocyte count in stage I testicular seminoma managed by surveillance. Eur J Cancer $\underline{38}$, 2014-2019

Paus E, Fosså SD, Risberg T, Nustad K (1987): The diagnostic value of human chorionic gonadotrophin in patients with testicular seminoma. Br J Urol 59, 572-577

Pearce H, Hutton P, Chaudhri S, Porfiri E, Patel P, Viney R, Moss P (2017): Spontaneous $\mathrm{CD} 4{ }^{+}$and $\mathrm{CD} 8{ }^{+} \mathrm{T}$-cell responses directed against cancer testis antigens are present in the peripheral blood of testicular cancer patients. Eur J Immunol 47, 1232-1242

Petrelli F, Coinu A, Cabiddu M, Ghilardi M, Borgonovo K, Lonati V, Barni S (2015): Surveillance or Adjuvant Treatment With Chemotherapy or Radiotherapy in Stage I Seminoma: A Systematic Review and Meta-Analysis of 13 Studies. Clin Genitourin Cancer 13, 428-434

Rajpert-De Meyts E, Skakkebaek NE, Toppari J: Testicular Cancer Pathogenesis, Diagnosis and Endocrine Aspects; Endotext.org 2000; URL:

https://www.ncbi.nlm.nih.gov/books/NBK278992/

Rakoff-Nahoum S, Kuebler PJ, Heymann JJ, E Sheehy M, Ortiz GM, S Ogg G, Barbour JD, Lenz J, Steinfeld AD, Nixon DF (2006): Detection of T lymphocytes specific for human endogenous retrovirus $\mathrm{K}(\mathrm{HERV}-\mathrm{K})$ in patients with seminoma. AIDS Res Hum Retroviruses $22,52-56$

Reuschenbach M, von Knebel Doeberitz M, Wentzensen N (2009): A systematic review of humoral immune responses against tumor antigens. Cancer Immunol Immunother $\underline{58}, 1535-$ 1544

Ropponen KM, Eskelinen MJ, Lipponen PK, Alhava E, Kosma VM (1997): Prognostic value of tumour-infiltrating lymphocytes (TILs) in colorectal cancer. J Pathol 182, 318-324

Ruf CG, Khalili-Harbi N, Sachs S, Isbarn H, Wagner W, Matthies C, Meineke V, Fisch M, Chun FK, Abend M (2013): The search for biomarkers of metastatic seminoma. J Urol 190 , 1046-1051

Schmoll H-J, Jordan K, Huddart R, Pes MPL, Horwich A, Fizazi K, Kataja V, ESMO Guidelines Working Group (2010): Testicular seminoma: ESMO Clinical Practice Guidelines for diagnosis, treatment and follow-up. Ann Oncol 21 Suppl 5, 140-146

Schumacher K, Haensch W, Röefzaad C, Schlag PM (2001): Prognostic significance of activated CD8(+) T cell infiltrations within esophageal carcinomas. Cancer Res 61, 3932-3936

Siska PJ, Johnpulle RAN, Zhou A, Bordeaux J, Kim JY, Dabbas B, Dakappagari N, Rathmell JC, Rathmell WK, Morgans AK, et al. (2017): Deep exploration of the immune infiltrate and outcome prediction in testicular cancer by quantitative multiplexed immunohistochemistry and gene expression profiling. Oncoimmunology $\underline{6}, 4$

SkakkebæK NE, Berthelsen JG, Giwercman A, MüLler J (1987): Carcinoma-in-situ of the 
testis: possible origin from gonocytes and precursor of all types of germ cell tumours except spermatocytoma. Int J Androl 10, 19-28

Sokoloff MH, Joyce GF, Wise M, Urologic Diseases in America Project (2007): Testis cancer. J Urol 177, 2030-2041

Soper MS, Hastings JR, Cosmatos HA, Slezak JM, Wang R, Lodin K (2014): Observation versus adjuvant radiation or chemotherapy in the management of stage I seminoma: clinical outcomes and prognostic factors for relapse in a large US cohort. Am J Clin Oncol 37, 356359

Stang A, Jansen L, Trabert B, Rusner C, Eberle A, Katalinic A, Emrich K, Holleczek B, Brenner H, GEKID Cancer Survival Working Group (2013): Survival after a diagnosis of testicular germ cell cancers in Germany and the United States, 2002-2006: a high resolution study by histology and age. Cancer Epidemiol 37, 492-497

Suzuki K, Nakazato H, Kurokawa K, Suzuki T, Suzuki K, Yamanaka H (1998): Treatment of stage I seminoma: should beta-HCG positive seminoma be treated aggressively? Int Urol Nephrol 30, 593-598

Swartz DA, Johnson DE, Hussey DH (1984): Should an elevated human chorionic gonadotropin titer alter therapy for seminoma? J Urol 131, 63-65

Tandstad T, Smaaland R, Solberg A, Bremnes RM, Langberg CW, Laurell A, Stierner UK, Ståhl O, Cavallin-Ståhl EK, Klepp OH, et al. (2011): Management of seminomatous testicular cancer: a binational prospective population-based study from the Swedish norwegian testicular cancer study group. J Clin Oncol 29, 719-725

Tandstad T, Ståhl O, Dahl O, Haugnes HS, Håkansson U, Karlsdottir Å, Kjellman A, Langberg CW, Laurell A, Oldenburg J, et al. (2016): Treatment of stage I seminoma, with one course of adjuvant carboplatin or surveillance, risk-adapted recommendations implementing patient autonomy: a report from the Swedish and Norwegian Testicular Cancer Group (SWENOTECA). Ann Oncol 27, 1299-1304

Tarin TV, Sonn G, Shinghal R (2009): Estimating the risk of cancer associated with imaging related radiation during surveillance for stage I testicular cancer using computerized tomography. J Urol 181, 627-632

Torres A, Casanova JF, Nistal M, Regadera J (1997): Quantification of immunocompetent cells in testicular germ cell tumours. Histopathology $\underline{30}$, 23-30

Trabert B, Chen J, Devesa SS, Bray F, McGlynn KA (2015): International patterns and trends in testicular cancer incidence, overall and by histologic subtype, 1973-2007. Andrology $\underline{3}, 4$ 12

Trevino KE, Esmaeili-Shandiz A, Saeed O, Xu H, Ulbright TM, Idrees MT (2018): Pathological risk factors for higher clinical stage in testicular seminomas. Histopathology $\underline{73}, 741-$ 747 
Trigo JM, Tabernero JM, Paz-Ares L, García-Llano JL, Mora J, Lianes P, Esteban E, Salazar R, López-López JJ, Cortés-Funes H (2000): Tumor markers at the time of recurrence in patients with germ cell tumors. Cancer $\underline{88}, 162-168$

Tüzel E (2016): Best treatment option for clinical stage I seminoma patients. Cent European J Urol $\underline{69}, 40-41$

Valdevenito JP, Gallegos I, Fernández C, Acevedo C, Palma R (2007): Correlation between primary tumor pathologic features and presence of clinical metastasis at diagnosis of testicular seminoma. Urology $\underline{70}, 777-780$

van As NJ, Gilbert DC, Money-Kyrle J, Bloomfield D, Beesley S, Dearnaley DP, Horwich A, Huddart RA (2008): Evidence-based pragmatic guidelines for the follow-up of testicular cancer: optimising the detection of relapse. Br J Canc $\underline{98}$, 1894-1902

van Echten J, Timmer A, van der Veen AY, Molenaar WM, de Jong B (2002): Infantile and adult testicular germ cell tumors. a different pathogenesis? Cancer Genet Cytogenet 135, 5762

Venkitaraman R, Johnson B, Huddart RA, Parker CC, Horwich A, Dearnaley DP (2007): The utility of lactate dehydrogenase in the follow-up of testicular germ cell tumours. BJU Int $\underline{100}, 30-32$

Vesprini D, Chung P, Tolan S, Gospodarowicz M, Jewett M, O’Malley M, Sweet J, Moore M, Panzarella T, Sturgeon J, et al. (2012): Utility of serum tumor markers during surveillance for stage I seminoma. Cancer $\underline{118}, 5245-5250$

Virtanen HE, Toppari J (2014): Embryology and physiology of testicular development and descent. Pediatr Endocrinol Rev 11 Suppl 2, 206-213

Wang H, Kadlecek TA, Au-Yeung BB, Goodfellow HES, Hsu L-Y, Freedman TS, Weiss A (2010): ZAP-70: An Essential Kinase in T-cell Signaling. Cold Spring Harb Perspect Biol 2 , 5

Warde P, Gospodarowicz MK, Panzarella T, Catton CN, Sturgeon JF, Moore M, Goodman P, Jewett MA (1995): Stage I testicular seminoma: results of adjuvant irradiation and surveillance. J Clin Oncol 13, 2255-2262

Warde P, Specht L, Horwich A, Oliver T, Panzarella T, Gospodarowicz M, von der Maase H (2002): Prognostic Factors for Relapse in Stage I Seminoma Managed by Surveillance: A Pooled Analysis. J Clin Oncol 20, 4448-4452

Weissbach L, Bussar-Maatz R, Löhrs U, Schubert GE, Mann K, Hartmann M, Dieckmann KP, Fassbinder J (1999): Prognostic factors in seminomas with special respect to HCG: results of a prospective multicenter study. Seminoma Study Group. Eur Urol $\underline{36}$, 601-608

Williamson SR, Delahunt B, Magi-Galluzzi C, Algaba F, Egevad L, Ulbright TM, Tickoo SK, Srigley JR, Epstein JI, Berney DM (2017): The World Health Organization 2016 classification 
of testicular germ cell tumours: a review and update from the International Society of Urological Pathology Testis Consultation Panel. Histopathology 70, 335-346

Yakirevich E, Lefel O, Sova Y, Stein A, Cohen O, Izhak OB, Resnick MB (2002): Activated status of tumour-infiltrating lymphocytes and apoptosis in testicular seminoma. J Pathol 196 , 67-75

Yan Q, Barros T, Visperas PR, Deindl S, Kadlecek TA, Weiss A, Kuriyan J (2013): Structural Basis for Activation of ZAP-70 by Phosphorylation of the SH2-Kinase Linker. Mol Cell Biol $\underline{33}, 2188-2201$

Yeh SD, Morse MJ, Grando R, Kleinert EL, Whitmore WF (1986): Lymphoscintigraphic studies of lymphatic drainage from the testes. Clin Nucl Med 11, 823-827

Yossepowitch O, Ehrlich Y, Lubin M, Tal R, Konichezsky M, Baniel J (2013): Lymphovascular invasion in testicular germ cell tumors: clinicopathological correlates. Cent European J Urol 66, 266-270

Yuen GJ, Demissie E, Pillai S (2016): B lymphocytes and cancer: a love-hate relationship. Trends Cancer 2, 747-757

Zengerling F, Kunath F, Jensen K, Ruf C, Schmidt S, Spek A (2018): Prognostic factors for tumor recurrence in patients with clinical stage I seminoma undergoing surveillance-A systematic review. Urol Oncol $\underline{36}, 448-458$

Zhang L, Conejo-Garcia JR, Katsaros D, Gimotty PA, Massobrio M, Regnani G, Makrigiannakis A, Gray H, Schlienger K, Liebman MN, et al. (2003): Intratumoral T cells, recurrence, and survival in epithelial ovarian cancer. N Engl J Med $\underline{348}, 203-213$

Zhao X, Wei Y-Q, Kariya Y, Teshigawara K, Uchida A (1995): Accumulation of $\gamma / \delta$ T Cells in Human Dysgerminoma and Seminoma: Roles in Autologous Tumor Killing and Granuloma Formation. Immunol Investig 24, 607-618 


\section{Danksagung}

Mein Dank gilt den folgenden Personen, die mich nicht nur während der Fertigstellung dieser Dissertation, sondern auch in den vergangenen Jahren meines Studiums immer tatkräftig unterstützt haben.

Ich möchte mich bei Prof. Dr. med. L. Trojan, meinem Doktorvater, für die Betreuung dieser Arbeit bedanken. Den regelmäßigen Austausch habe ich stets als ganz besonders bereichernd und motivierend empfunden. Diese Promotion stellt den Ausgangspunkt einer hoffentlich langjährigen Zusammenarbeit dar.

Ebenfalls danken möchte ich PD Dr. med. F. Bremmer. Als Zweitbetreuer und zentraler Ansprechpartner des praktischen Aspekts dieser Arbeit ist er ganz entscheidend an der erfolgreichen Fertigstellung dieser Dissertation beteiligt.

Für die kompetente Unterstützung als hilfsbereite Ansprechpartner in jeglicher Hinsicht danke ich Herrn Dr. med. O. Hahn und Frau Dr. med. A. Uhlig. 